\title{
Tanks Focus Area Midyear Review Report FY00
}

April 2000

Prepared for

the U.S. Department of Energy

under Contract DE-AC06-76RLO 1830

Pacific Northwest National Laboratory

Richland, Washington 99352 


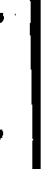

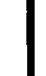




\section{DISCLAIMER}

This report was prepared as an account of work sponsored by an agency of the United States Government. Neither the United States Government nor any agency thereof, nor any of their employees, make any warranty, express or implied, or assumes any legal liability or responsibility for the accuracy, completeness, or usefulness of any information, apparatus, product, or process disclosed, or represents that its use would not infringe privately owned rights. Reference herein to any specific commercial product, process, or service by trade name, trademark, manufacturer, or otherwise does not necessarily constitute or imply its endorsement, recommendation, or favoring by the United States Government or any agency thereof. The views and opinions of authors expressed herein do not necessarily state or reflect those of the United States Government or any agency thereof. 


\section{DISCLAIMER}

Portions of this document may be illegible in electronic image products. Images are produced from the best available original document. 


\section{Executive Summary}

The U.S. Department of Energy (DOE) continues to face a major radioactive waste tank remediation problem with hundreds of waste tanks containing hundreds of thousands of cubic meters of high-level waste (HLW) and transuranic (TRU) waste across the DOE complex. These tanks must be maintained in a safe condition and eventually remediated to minimize the risk of waste migration and/or exposure to workers, the public, and the environment. However, programmatic drivers are more ambitious than baseline technologies and budgets will support. Science and technology development investments are required to reduce the technical and programmatic risks associated with tank remediation baselines.

The Tanks Focus Area (TFA) was initiated in 1994 to serve as the DOE Office of Environmental Management's (EM's) national technology development program for radioactive waste tank remediation. The national program was formed to increase integration and realize greater benefits from DOE's technology development budget. The TFA is responsible for managing, coordinating, and leveraging technology development to support the needs of DOE's five major tank sites: Hanford Site (Washington), Idaho National Engineering and Environmental Laboratory (INEEL) (Idaho), Oak Ridge Reservation (ORR) (Tennessee), Savannah River Site (SRS) (South Carolina), and West Valley Demonstration Project (WVDP) (New York). In addition, the Fernald Environmental Management Project (Ohio), requested technical assistance from the TFA and has been added as an adjunct member of the program

In accordance with EM guidance, the TFA conducted a Midyear Review to validate and document the maturity and progress of the projects in its portfolio. The initial phase of the review took place February 2-4, 2000, in Las Vegas, Nevada. This technical review focused on assessing the completeness and adequacy of the TFA's technical strategy in response to user science and technology needs. The second phase of the review was held on March 7-8, 1999, also in Las Vegas, Nevada. This review included the participation of key program, technical, and advisory personnel, focusing on reaffirming project relevance and providing a status on the progress of each technology toward meeting end user requirements, including readiness to advance to the next stage of development. The third phase of the review took place in Atlanta, Georgia, on April 25-27, 2000, at the Environmental Management Science Program National Workshop. This workshop provided an opportunity for the TFA to review completed and ongoing basic science research and evaluate its potential applicability to TFA's customers.

This report provides an explanation of the TFA review process, an overview of the TFA program, and highlights the results of the Fiscal Year 2000 (FY00) Midyear Review. A brief overview of each project reviewed is provided, including key issues and recommendations. 
' 


\section{Acronyms and Abbreviations}

\begin{tabular}{ll} 
ADMP & Advanced Design Mixer Pump \\
AEAT & AEA Technology \\
Al & aluminum \\
AMP-PAN & ammonium molybdophosphate-polyacrylonitrile \\
ASME & American Society of Mechanical Engineers \\
ASTD & Accelerated Site Technology Deployment \\
ASTM & American Society for Testing and Materials \\
AWRS & Advanced Waste Retrieval System \\
BH & Bechtel Hanford \\
BJC & Bechtel Jacobs Corporation \\
BNFL & British Nuclear Fuels, Ltd. \\
BVEST & Bethel Valley Evaporator Service Tank \\
Ca & calcium \\
CHG & CH2M Hill Hanford Group \\
CIF & Consolidated Incineration Facility \\
CMST & Characterization, Monitoring, and Sensor Technology Program \\
Cs & cesium \\
CsR & Cesium Removal System \\
CST & crystalline silicotitanate \\
CTS & Concentrate Transfer System \\
Cu & copper \\
D\&D & decontamination and decommissioning \\
DDFA & Deactivation and Decommissioning Focus Area \\
DF & decontamination factor \\
DOE & U.S. Department of Energy \\
DOE-ID & DOE Idaho Operations Office \\
DOE-OH & DOE Ohio Field Office \\
DOE-OR & DOE Oak Ridge Operations Office \\
DOE-SR & DOE Richland Operations Office \\
\hline
\end{tabular}




\begin{tabular}{|c|c|}
\hline DNFSB & Defense Nuclear Facility Safety Board \\
\hline DST & double-shell tank \\
\hline DWPF & Defense Waste Processing Facility \\
\hline EIS & Environmental Impact Statement \\
\hline EM & Office of Environmental Management (DOE) \\
\hline EMSP & Environmental Management Science Program \\
\hline EN & electrochemical noise \\
\hline $\mathrm{ESH}$ & Environmental Safety \& Health \\
\hline ESP & Efficient Separations and Processing Program \\
\hline F & fluorine \\
\hline FETC & Federal Energy Technology Center \\
\hline FFA & Federal Facility Agreement \\
\hline FIU & Florida International University \\
\hline F\&R & functions and requirements \\
\hline FY & fiscal year \\
\hline GAAT & Gunite and Associated Tanks \\
\hline HAW & high-activity waste \\
\hline HCET & Hemispheric Center for Environmental Technology \\
\hline HEPA & high-efficiency particulate air (filter) \\
\hline HIFR & High Flux Isotope Reactor \\
\hline HLW & high-level waste \\
\hline HQ & headquarters \\
\hline HWVP & Hanford Waste Vitrification Plant \\
\hline ID & identification, or inside diameter \\
\hline ILAW & immobilized low-activity waste \\
\hline INEEL & National Engineering and Environmental Laboratory \\
\hline KfK & Kernforschungszentrum Karlsruhe \\
\hline LAW & low-activity waste \\
\hline LMER & Lockheed Martin Energy Research \\
\hline LMES & Lockheed Martin Environmental Services \\
\hline LPR & linear polar resistance \\
\hline LVDG & low volume density gradient \\
\hline
\end{tabular}




\begin{tabular}{|c|c|}
\hline MACT & maximum achievable control technology \\
\hline MLDUA & Modified Light-Duty Utility Arm \\
\hline $\mathrm{MPI}^{\mathrm{TM}}$ & Multi-Point Injection $^{\mathrm{TM}}$ \\
\hline MST & monosodium titanate \\
\hline MVCIT & Melton Valley Capacity Increase Tank \\
\hline MVST & Melton Valley Storage Tank \\
\hline MYTR & Multiyear Technical Response \\
\hline $\mathrm{Na}$ & sodium \\
\hline NDE & nondestructive examination \\
\hline NETL & National Energy Technology Laboratory \\
\hline NGLW & newly generated liquid waste \\
\hline $\mathrm{Np}$ & neptunium \\
\hline NWTP & Nuclear Waste Treatment Program \\
\hline OD & outside diameter \\
\hline $\mathrm{OHF}$ & Old Hydrofracture Facility \\
\hline ORNL & Oak Ridge National Laboratory \\
\hline ORP & Office of River Protection \\
\hline ORR & Oak Ridge Reservation \\
\hline OST & Office of Science and Technology (EM) \\
\hline OTE & Out of Tank Evaporator \\
\hline $\mathrm{Pd}$ & palladium \\
\hline $\mathrm{PE}$ & professional engineer \\
\hline PEG & Program Execution Guidance \\
\hline PI & principal investigator \\
\hline PNNL & Pacific Northwest National Laboratory \\
\hline POC & point of contact \\
\hline $\mathrm{Pt}$ & platinum \\
\hline $\mathrm{Pu}$ & plutonium \\
\hline RAL & Research Analytical Laboratory \\
\hline RCRA & Resource Conservation and Recovery Act \\
\hline $\mathrm{R} \& \mathrm{D}$ & research and development \\
\hline REDOX & reduction oxidation \\
\hline
\end{tabular}


RFP request for proposal

RPP River Protection Project

SBW sodium-bearing waste

$\mathrm{Si}$

silicon

SLS

solid-liquid separation

SNL Sandia National Laboratories

$\mathrm{Sr}$

strontium

SRS

Savannah River Site

SRTC Savannah River Technology Center

TAG Technical Advisory Group .

TBD to be determined

TCLP toxicity characteristic leach procedure

TFA Tanks Focus Area

TIM Technology Integration Manager

TPB tetraphenylborate

TRIAD nickname for the integrated Solid-Liquid Separation System at Oak Ridge Reservation (Crossflow Filtration, Out of Tank Evaporator and Cesium Removal System)

TRU transuranic

TRUEX transuranic element extraction

TTP Technical Task Plan

TTR Technical Task Request

$\mathrm{U}$

uranium

UDS undissolved solids

UNEX Universal Solvent Extraction

VSL . Vitreous States Laboratory

WSRC Westinghouse Savannah River Company

WVDP West Valley Demonstration Project

WVNS West Valley Nuclear Services 


\section{Contents}

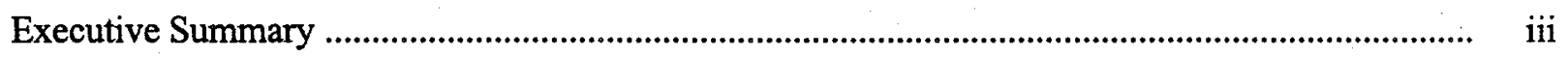

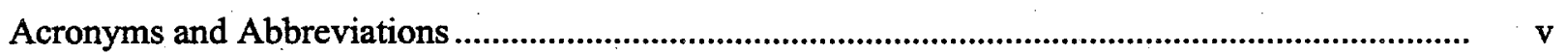

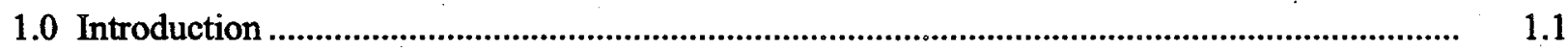

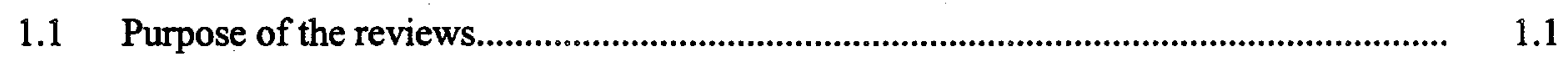

1.2 Multiyear Technical Response Review ............................................................. 1.1

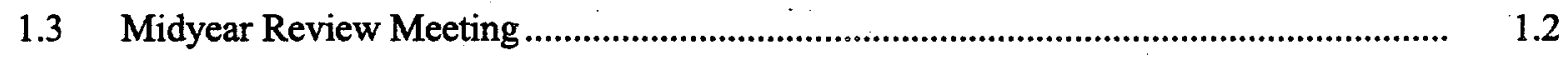

1.4 Environmental Management Science Program Workshop........................................ 1.3

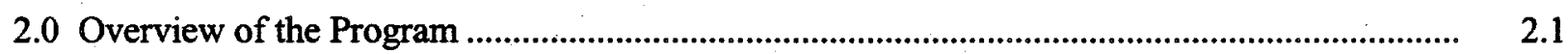

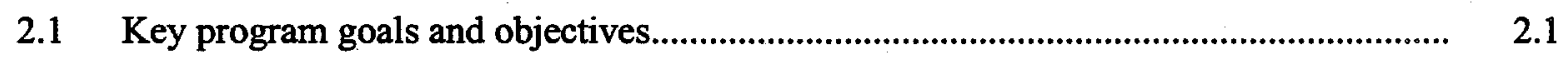

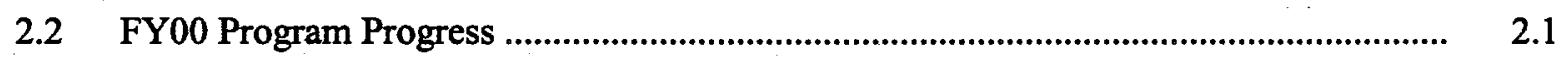

2.3 Environmental Management Science Program .................................................... 2.2

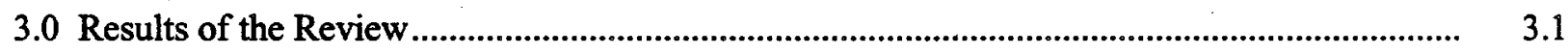

3.1 99043, High-Level Waste Tank Corrosion Control and Monitoring............................... 3.2

$3.2 \quad 99071$, Alternative Air Filtration Technology ...........................................................

$3.3 \quad 99046$, Waste Sampling and At-Tank Analysis..........................................................

3.499067 , Heel Retrieval from Obstructed and Unobstructed Tanks................................. 3.4

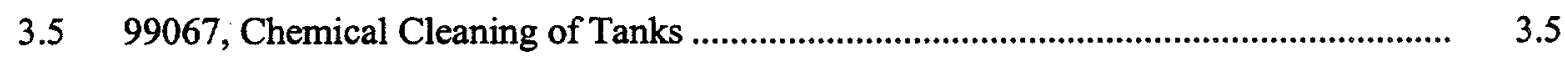

3.6 99076, Waste Transfer Line Unplugging Methods .................................................. $\quad 3.6$

$3.7 \quad 99001$, Integrated Radionuclide Separations Processes................................................ $\quad 3.6$

$3.8 \quad 99054$ A\&B, Prevention of Solids Formation and Saltcake Dissolution......................... 3.7

$3.9 \quad 99084$, Solid Liquid Separation (Crossflow Filtration) .............................................. 3.8 
$3.10 \quad 99086$, Consolidated Incineration Facility Evaporator .................................................... 3.8

3.1199019 , Conditioning and Immobilization of Low-Activity Waste.................................. 3.8

3.1299068 , Specify and Enhance Design of High-Level Waste Glass Melters ..................... 3.9

3.13 99073, Improve Waste Loading in High-Level Waste Glasses........................................ $\quad 3.10$

$3.14 \quad$ 99023, Enhanced Grout Formulations for Tank Closure............................................... $\quad 3.10$

3.1599085 , Demonstration of Grout Injection Technology for Tank Closure ......................

3.16 99070, Salt Processing Project: Cesium Separations Using Crystalline Silicotitanate, Tetraphenylborate Process for Cesium Separations; and Actinide Separations using Monosodium Titanate

4.0 References and Bibliography .............................................................................................

Appendix A - Review Panels.................................................................................................... A.1

Appendix B - Multiyear Technical Responses .............................................................................. B. B.1

Appendix C - Review Comments and Responses ...................................................................... C.1

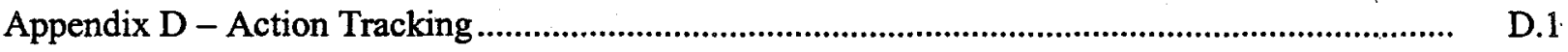

Appendix E - Project Checklists/Maturity Evidence....................................................................... E.1

Appendix F - Other FY00 Reviews ........................................................................................... F. F.1

Appendix G - Environmental Management Science Program Tasks .............................................. G. G.1 


\subsection{Introduction}

The Tanks Focus Area (TFA) was initiated in 1994 to serve as the U.S. Department of Energy (DOE) Office of Environmental Management's (EM's) national technology development program for radioactive tank waste remediation. This national program was formed to increase integration and realize greater benefits from DOE's science and technology budget.

\subsection{Purpose of the reviews}

In accordance with EM's Office of Science and Technology (OST), the TFA is committed to assessing the maturity of technology development projects and ensuring their readiness for implementation and subsequent deployment. The TFA conducts an annual Midyear Review to document the status of ongoing projects, reaffirm and document user commitment to selected projects, and to improve the effective deployment of technology by determining and documenting the readiness of selected projects to move ahead.

Since 1995, OST has used a linear technology maturation model that spans through seven defined stages of maturity, from basic research to implementation. Application of this "Stage/Gate" model to technology development resulted in prescriptive and somewhat cumbersome review procedures, resulting in limited and inconsistent use. Subsequently, in February 2000, OST issued revised guidance in an effort to streamline the technology tracking and review process (DOE, 2000).

While the new OST guidance reinforces peer review requirements and the use of the American Society of Mechanical Engineers (ASME) for independent reviews, it also implements a simplified Gate model. The TFA is now responsible for providing auditable documentation for passing only three stages of technology maturity:

- Ready for Research (Gate 0)

- Ready for Development (Gate 2)

- Ready for Demonstration (Gate 5)

The TFA Midyear Review is a key element in the overall review procedure, as the tracking evidence for all active projects is required to be available at this time. While the Midyear Report contains an overview of the status of all TFA reviews and projects, not all the reviews were conducted during the Midyear Review. The TFA used a phased approach to accomplish the Midyear Review requirements.

\subsection{Multiyear Technical Response Review}

The initial phase of the TFA Midyear Review focused on assessing the completeness and adequacy of the TFA's current and planned technical strategy in response to user needs. This technical review took place February 2-4, 2000, in Las Vegas, Nevada. The TFA FY01-03 Multiyear Technical Responses (MYTRs) include FY00 tasks with continuing applicability based on the most current set of site user 
needs. Out of the 68 TFA FY01-03 Technical Responses, 23 included FY00 tasks. Each TFA FY01-03 Technical Response which included current FY work scope was reviewed by the TFA Technical Advisory Group (TAG). Made up of technical experts from across the country familiar with high-level waste $(\mathrm{HLW})$ problems and solutions, the TAG provides high-quality technical reviews for the TFA. Members of the TAG participating in this review are included in Appendix A. A listing of the technical responses reviewed are contained in Appendix B.

The TAG review addressed the following questions:

1. Does the technical response address the critical issues of the need?

2. Does the technical response identify issues not addressed in the need?

3. Is the technical approach appropriate and based on sound scientific and engineering principles?

4. Are there additional technical issues related to the user need that should be addressed?

5. Is the need written clearly and completely enough to allow development of a quality technical response?

After the TAG review, the MYTRs were provided to the site users for additional review and comment. The MYTRs were revised as appropriate based on the TAG and user comments received. Appendix $\mathrm{C}$ contains the comments and issues generated by these reviews on FY00 work activities, including the TFA's disposition of the comment or issue:

\subsection{Midyear Review Meeting}

The second phase of the Midyear Review, held on March 7-8, 1999, also in Las Vegas, Nevada, covered a smaller set of ongoing FY00 projects, providing the users a status of nearer-term demonstrations, deployments and special projects. Key program, technical, and advisory personnel participated in this review, which focused on project relevance and providing a status of the progress of each technology toward meeting end user requirements, including readiness to advance to the next stage of development. The intent of this review was to determine the readiness of these projects to deliver as scheduled, including evaluating the commitment and readiness of the site user to accept the technical solutions. In support of this activity, the TFA Technical Team developed Project Maturity Status Determination checklists (see Appendix E) for all FY00 active projects. Sixteen projects were selected for a technical status presentation at the meeting, based on one or more of the following criteria:

- represented an FY00 key deployment, demonstration or data delivery

- benefited two or more sites

- involved each step in the tank waste remediation process and each TFA partner program: Accelerated Site Technology Deployment (ASTD), Characterization, Monitoring and Sensor Technology (CMST), Efficient Separations Program (ESP), Robotics, University and Industry

- a technical or programmatic concern was previously identified

- a major change to the project occurred since the last review.

The TFA's Technology Integration Managers (TIMs) presented the project review information which described project need, identified the site(s) it applies to, and the problem it address. A technical and 
programmatic status of each project was given, including the technical approach and activities, allowing for discussion of current or potential issues.

The review panel for this meeting (see Appendix A) consisted of members of the DOE Management Team, the TFA User Steering Group, and the TAG Chair. The panel was requested to engage in discussions, provide comments, and raise any programmatic or technical issues or recommendations. A summary of the TIM project reviews is provided in Section 3. Specific comments and issues raised are included in Appendix C.

\subsection{Environmental Management Science Program Workshop}

The third phase of the Midyear Review took place in Atlanta, Georgia, on April 25-27, 2000, at the Environmental Management Science Program (EMSP) National Workshop. This workshop provided an opportunity for the TFA to review completed and ongoing basic science research and evaluate its potential applicability to TFA's customers. Approximately 68 poster sessions were identified as providing information specific to HLW tanks.

Prior to the EMSP Workshop, EMSP tasks associated with HLW tank remediation were identified by the TFA (see Appendix G). The TFA provided these tasks to its site users for their consideration of relevancy during development and review of the MYTRs. Because of the timing of this report, it is not possible to include the results of the EMSP Workshop. However, the TFA considered the site input as it participated in the EMSP Workshop, and plans to incorporate the results of the Workshop, in combination with the user relevancy review, into its technical program. 


\subsection{Overview of the Program}

The TFA is responsible for managing, coordinating, and leveraging technology development to support the needs of DOE's five major tank sites: Hanford Site (Washington), Idaho National Engineering and Environmental Laboratory (INEEL) (Idaho), Oak Ridge Reservation (ORR) (Tennessee), Savannah River Site (SRS) (South Carolina), and West Valley Demonstration Project (WVDP) (New York). The Fernald Site in Ohio joined the TFA in FY00 as an adjunct member; it does not submit needs to or receive funding from the TFA, but participates in relevant program activities and receives technical assistance.

The TFA's technical scope covers the major functions that comprise a complete tank remediation system: waste retrieval, waste pretreatment, waste immobilization, tank closure, and characterization and monitoring of both the waste and tank, with safety integrated into all the functions. The TFA integrates program activities across organizations that fund tank technology development, including the DOE Offices of Site Closure, Project Completion, and Science and Technology.

\subsection{Key program goals and objectives}

The TFA mission is to deliver integrated technical solutions that enable tank waste remediation to be successful across the DOE complex. Inherent to this mission, the TFA seeks to:

- Respond to the unique technical challenges intrinsic to the program's mission

- Focus on filling technical gaps and making tangible process toward solving key tank problems

- Provide technical solutions to enable and enhance remediation

- Work with users and program partners through the entire process, from problem identification to implementation of technical solutions.

Needs submitted by user (site) organizations provide the foundation for the TFA's technical program. The TFA analyzes individual site needs and develops technical responses to address the needs. Users then review the technical responses for applicability and adequacy to the submitted site need. This focus on the user has increased the serviceability of the TFA to deliver and implement technical solutions across the sites. Renewed emphasis on the identification of strategic tasks will enhance the ability of TFA's investment portfolio to solve user needs.

\subsection{FY00 Program Progress}

Significant events and activities thus far in FY00 include:

- The TFA is providing valuable technical assistance to INEEL in the roadmapping efforts in support of the site's High Level Waste and Facilities Disposition Environmental Impact Statement. 
- The TFA continued their role as technical advisor to DOE's evaluation of the Radioactive Isolation Consortium's Advanced Vitrification System.

- The Fernald Environmental Management Project requested technical assistance from the TFA and has been added as an adjunct member (receives no funding and is not part of the Management Team, but participates in various forums)

- The TFA has been designated as the technical lead for managing the critical research and development evaluation within the Salt Processing Project at SRS. This high-priority activity will require the establishment of a new project office at SRS, and reflects admirably on the TFA's ability to manage highly technical and sensitive projects.

In addition, FY00 Key Deliverables achieved to date include:

- Mobile Retrieval System deployed in Federal Facility Agreement Tank 3003-A for ORR

- Resource Conservation and Recovery Act (RCRA) compliant fluidic sampler demonstrated for Hanford and INEEL

- Report on melter testing for direct vitrification glass runs for INEEL

- Low-level waste (LLW) disposal site recommendations and treatment requirements for INEEL

\subsection{EM Science Program}

The TFA takes the EM philosophy of Focus-Area-centered very seriously, especially with regard to the role and importance of science in HLW remediation. HLW tank remediation, a $\$ 47 \mathrm{~B}$ effort currently scheduled to be completed by 2046 (DOE, 1998), is the DOE's most costly and prolonged cleanup problem. Science has the potential to significantly benefit HLW remediation.

TFA believes EMSP research will primarily produce data that aids the HLW users in understanding problems and processes, reducing risk, and enabling better decisions. Although some EMSP research is likely to produce new technologies, the most valuable product is likely to be scientific data and knowledge. In addition, the involvement of a broader set of technical experts in addressing EM science needs will result in a greater resource and talent base to access for technical advice and assistance.

The TFA has engaged with EMSP in efforts to communicate with and integrate specific projects and principal investigators into the TFA network of users and technical experts. Through this integration, TFA is able to help EMSP guide projects to the most relevant end points useful to EM users. Once a project is initiated, TFA and its Crosscutting Programs must work with EMSP in the program execution phase to enhance the relevancy and benefit of the funded work to the EM program. In addition, TFA must be fully cognizant of the project progress to ensure that particularly relevant work is integrated with 
user requirements and multi-year program planning. This will enable EMSP and TFA to plan for, and make decisions on continuation and/or transition to other DOE programs for additional research and development. 


\subsection{Results of the Review}

The three-phased review process (MYTR Review, Midyear Review Meeting, and EMSP Workshop) allows the TFA to focus appropriate review resources on specific portions of the technical program to maximize the benefit from these review activities. Results of the first two activities are summarized below, however due to the late date of the EMSP workshop, results of that review meeting are not included in this report.

The MYTR review addressed key issues in TFA's current and outyear technical strategy. The following points summarize the outcome of this review:

- Technical approaches were generally sound

- TAG comments were provided to enhance the technical approach presented

- Additional effort by the sites to fully explain issues and potential benefits will lead to more robust technical responses.

The Midyear Review Meeting included strong participation of site user organizations who provided important information regarding programmatic and technical changes at their sites, and the current emphases in site baselines. The TFA Technical Team presented the status of current TFA projects and any changes in technical approach. Specific technical or other programmatic issues were addressed as part of a dialogue between the TFA and site user representatives. Specific comments on the presentations and discussions are provided in Appendix C.

While the timing of this report does not allow reporting on the third phase of the TFA Midyear Review - the EMSP National Workshop - it should be noted that the TFA has taken a proactive position with regard to the EMSP and the role of science in HLW cleanup. As the program was being formulated, TFA worked with the Hanford Site Technology Coordination Group as a pilot project to identify and document science needs for Hanford's HLW remediation. TFA also engaged other site users and technical experts to identify complex-wide, longer-term science issues requiring investment. This information helped shape EMSP solicitations in the HLW area. TFA also invested significant time and energy interacting with EMSP principal investigators to build the bridges between science projects and the end user programs. Although much has already been done, there remains significant room for improvement.

A final outcome of the Midyear Review relates to the project maturity determination and gate/peer review evidence required to comply with OSTs revised guidance. TFA was able to develop $90 \%$ (34 of 37 ) of the checklists for currently funded projects that have been active for at least 3 months, although the availability of some evidence documentation is still being investigated. The remaining projects are small in scope or will be completed in FY00. This level of effort represents substantial compliance with the intent of the OST Guidance requirements for FY00. TFA will acquire the necessary outstanding information and fully implement the revised OST Gate Model for FY01. Appendix E contains the evidentiary material prepared for the FY00 Midyear Review. 
The following subsections provide summaries of the projects presented and reviewed at the Midyear Review Meeting, listed in the order presented. Specific comments and issues raised during the meeting are contained in Appendix C, listed by FY00 Technical Response number. An Action Tracking List is provided in Appendix D.

\subsection{3, High-Level Waste Tank Corrosion Control and Monitoring}

Improved knowledge of tank chemistry and corrosion processes is needed throughout the DOE complex to maintain tank integrity and reduce downstream processing requirements. Early corrosion probe designs provided the building blocks for developing more sensitive instruments capable of detecting uniform and localized corrosion, while providing continuous data for detecting the onset of conditions leading to pitting or stress corrosion cracking.

At Hanford, the latest Multifunction Probe contains an instrument tree that incorporates traditional tank monitoring sensors (e.g., thermocouples, level detectors, etc.) onto the same deployment platform as the corrosion probe. This approach improves functionality, provides a better understanding of the relationship between corrosion and other tank operations parameters, and optimizes the use of limited tank riser space. The probe developers are also upgrading the data acquisition electronics package to eliminate interference picked up by the underground cable. This multifunction probe was deployed in FY00 into Hanford double-shell tank (DST) 241-AN-105, which has shown indications of tank wall thinning. Performance tests are now being conducted in order to upgrade the previously installed systems (AN-102 and AN-107). Once the feedback is obtained, the developer (HiLine Engineering and Fabrication, Inc.) will complete the final design for a future installation. The next step in transitioning to a fully operational system will be to route all data acquisition systems back to a centralized control location. TFA will then work with site staff to determine the engineering, operations, and site management steps needed to move from chemistry monitoring to corrosion monitoring (14 DST are . scheduled to be fitted with electrochemical [EN] probes). The estimated budget for FY00 work is $\$ 315 \mathrm{~K}$, including \$270K TFA funding with \$27K from carryover funds. Hanford River Protection Project (RPP) cofunding had not been authorized as of February 18, 2000, however some site resources were provided to support the probe deployment in $\mathrm{AN}-105$.

SRS has opted to include the EN capability into their Raman corrosion species probe for deployment in Tank 43H in FY01. EIC Laboratories and HiLine Engineering have completed fabricating the components for the combined Raman/EN probe, and designs for the deployment mechanism have also been completed. SRS is contracting with HiLine Engineering to provide technical support based on Hanford experience with the EN corrosion probe. Staff at Savannah River Technology Center have conducted hot tests of the Raman species probe in a hot cell at SRS on actual tank waste. The EN and Raman species probe technologies underwent ASME peer reviews in August 1998, and a CMST/TFA project review last year. The project is currently in Stage 5, Engineering Development. Combined TFA/CMST funding for the FY00 SRS work is $\$ 378 \mathrm{~K}$. Deployment is contingent on successful cold tests site scheduling considerations. Issues with site resource and funding support are being worked and will become less of an issue when the technology is delivered and the activity receives a specific site project designation. 
ORR is also pursuing a corrosion probe for their stainless-steel Melton Valley Storage Tanks (MVSTs). TFA is supporting evaluation of extending the EN probe technology to provide monitoring of these thanks. Functions and requirements (F\&Rs) developed by ORNL staff were issued in January. The site will now pursue negotiation of a contract for probe design in FY00 and fabrication in FY01. HiLine Engineering will be providing support $t$ his project to transfer experience from the Hanford $E N$ probe technology deployments. A Gate Review is anticipated for FY01. This is a new task and TFA funded the FY00 work at ORR at $\$ 95 \mathrm{~K}$.

User Acceptance: User expectations were consistent with project status. User representatives are actively engaged in addressing issues related to site funding and resource support to these tasks.

\subsection{1, Alternative Air Filtration Technology}

As detailed in a report issued by the Defense Nuclear Facilities Safety Board (DNFSB) in May 1999, high-efficiency particulate air (HEPA) filters used throughout the DOE complex are fraught with a number of problems, including: fires, elevated temperatures, wetting, filter strength, air leakage, and aging. Alternative HEPA filter technologies are being investigated to replace current fiberglass filters used at SRS and for the proposed calcine transfer system from Bin Set 1 at INEEL. The technology specification requires that the new filter will be able to be cleaned in place, which will lower exposure risks to workers and reduce or eliminate filter disposal costs, as well as address many of the issues described above.

In FY99, the Savannah River Technology Center (SRTC) tested multiple filter media with positive results, and awarded two industry contracts for Phase I conceptual design development. Full-scale conceptual design reviews for the competing SRS filter system technologies are complete, with a cold demonstration plan and a preliminary hot demonstration plan for Tank 7 in preparation. The filter system is currently in Stage 5, with an ASME review scheduled for September 2000. Combined TFA, National Energy Technology Laboratory (NETL), and site funding for the FY00 filter development work at SRS is \$926K.

INEEL is currently defining the F\&Rs for their filter system and participated in a filter technology exchange in January. The INEEL system is in Stage 5, however as calcine bin retrieval is not yet an active project, a specific user interface has not been identified. The TFA budget for INEEL's FY00 filter work is $\$ 60 \mathrm{~K}$.

User Acceptance: User expectations were consistent with project status.

\subsection{6, Waste Sampling and At-Tank Analysis}

Development of multiple depth remote sampling equipment is needed for large waste tanks and Hanford and INEEL tanks to: (1) obtain representative samples from several vertical locations in the tank; (2) obtain large sample volumes (up to 15 liters); (3) verify the inventory of constituents in feed staging tanks before batch transfer to the privatization contractor; (4) ensure sampling methods are compliant 
has reached steady state composition from mixing and representative samples can be taken. Work on attank analysis has been suspended due to FY00 budget cut and changes in user requirements. This work is of lower-priority and can be delayed without significant project impact at this point.

A single point fluidic sampler with an inverted bottle was deployed at SRS in 1998. The alternative method under development by AEA Technology (AEAT) uses an upright bottle with a valve to drain an in-line sample reservoir by gravity flow. This approach satisfies regulatory requirements that (1) the waste not be exposed to vacuum during sampling operations to prevent loss of volatiles, (2) the bottle is filled to zero head-space, and (3) the sample undergoes minimum agitation. AEAT successfully demonstrated this approach in March 2000, however some limitations in sample delivery for highly viscous materials was identified. This project is currently in the conceptual design stage; $30 \%$ designs are planned this year, and a Gate Review is planned in November 2000 for a decision on whether to proceed with detailed designs. Hanford RPP co-funding to restart design activities has not been released as of March, therefore authorization to proceed with the outline design is pending resolution of this issue. This may impact the ability to achieve the planned $30 \%$ design completion in FY00.

A TFA budget cut resulted in the elimination of funding to support the INEEL task this year and reduced the funding to support the detailed design of the sampler previously planned for FYO0. The funding reduction does not significantly impact the project schedule as delays had already been identified due to requirement changes resulting from revisions to Hanford's feed delivery strategy. FY00 TFA funding to support the Hanford work $(\sim 535 \mathrm{~K})$ is supporting the AEAT bottle filling tests, charge vessel degassing tests, and development of the Component Specification document, as. well as $30 \%$ design of the fluidic system, sample station and deployment platform. Recent changes to the riser size proposed by Hanford may require major redesign/retesting of components. TFA plans to conduct a technical review prior to restart of design activities to validate this basis for requirements changes and impact on the technical feasibility of the sampling process. Additionally, although a technology insertion point is embedded into the Hanford baseline, availability of site co-funding has been problematic and is critical for outyear activities. Cold tests are scheduled for FY03, with deployment in FY04.

User Acceptance: User expectations were consistent with project status. Site commitment of cofunding to support the project is a continuing issue and is being worked jointly by TFA and the site representatives.

\subsection{7, Heel Retrieval from Obstructed and Unobstructed Tanks}

The strategy to address the tank heel retrieval needs is logically centered around three basic areas. The first area is heel retrieval from unobstructed tanks using mechanical methods; the second is heel retrieval from obstructed tanks using mechanical methods; and the third is heel retrieval using chemical methods. Structuring along these lines will provide data and information to the sites in the most costeffective manner, while allowing the collection and documentation of data in all three regimes to find technology gaps that currently exist, especially for obstructed tank heel removal.

For SRS, TFA is evaluating the following technologies to address Tank 19 heel retrieval: Flygt Mixer, Disposable Crawler, Pitbull Pump. The site plans to use three Flygt Mixers to mobilize the tank 
solids. Mechanical deficiencies uncovered during FY00 testing of the Flygt Mixers are being reengineered and retested. TFA is workign with SRS to address cost and schedule issues related to these problems. The Pitbull Pump will retrieve the slurry (liquids and solids) from the tank and divert it to Tank 18, decant the waste, and transfer it back. This cycle will repeat until diminishing returns are reached. These two technologies underwent a Gate 5 review in November 1999, resulting in a recommend to proceed, and ready to proceed through Gate 5 to Stage 6, Demonstration. The low-cost disposable crawler outfitted with a sluicing nozzle will be deployed only if necessary to wash remaining sludge toward the Pitbull Pump. In a technical review conducted in November 1999, the crawler was judged to require more development prior to proceeding through Gate 5. FY00 TFA funding for the SRS retrieval tasks is $\$ 650 \mathrm{~K}$, plus an additional $\$ 100 \mathrm{~K}$ for re-engineering. Additional cost impacts to address Flygt mixer issues will be evaluatated and addresssed subsequent to this review. Demonstrating compliance with the current site Authorization Basis and applying lessons learned from Tank 8 retrieval activities may require additional site funds for readiness preparations.

For WVDP, TFA is teaming with Robotics to develop an Advanced Waste Retrieval System (AWRS) to augment existing waste retieval methods. The system has a $20-\mathrm{ft}$ reach and uses a steam jet eductor to vacuum residual waste from the tank floor. Robotics is also developing a sampling tool for deployment by a Mast Tool Delivery System (a site-developed subsystem of the AWRS) in the event samples are required for residuals analysis to support tank closure. The AWRS is in Stage 5, Engineering Development, and functional testing is underway. The FY00 objective for this work is to have the system declared ready to turn over to operations. TFA funding for the FY00 AWRS task is $\$ 1100 \mathrm{~K}$.

For ORR, AEAT developed a Mobile Retrieval System, based on their power fluidics technology, using suction and charge vessels to retrieve waste from the site's Federal Facility Agreement (FFA) tanks. The system is mounted on a skid to allow ease of transporting among tanks. It was installed on Tank 3003-A in January 2000, and has since completed retrieval in that tank, successfully reaching Stage 6, Demonstration. This project was funded through the ASTD program at $\$ 101 \mathrm{~K}$.

User Acceptance: User expectations were consistent with project status. SRS user is actively engaged in addressing issue resolution to support deployment of the Flygt Mixers in Tank 19. SRS HLW program is proposing to match increased TFA funds to address cost increases.

\subsection{7, Chemical Cleaning of Tanks}

The primary goal of chemical cleaning is to remove all the residual contaminants from a waste tank. The main concerns associated with chemical cleaning are maintaining criticality safety during waste dissolution or softening, prevention of tank walls and floor disintegration, and minimizing the impacts on downstream treatment processes. Chemical cleaning developments will consider residual heel removal, bulk sludge removal, and selective ${ }^{99} \mathrm{Tc}$ removal. Investigation of using chemical additions to enhance mechanical retrieval methods will also be evaluated, particularly as it relates to increased retrieval performance in obstructed tanks.

TFA is contracting with Russian scientists to develop improved chemical cleaning methods leading to recommendations in FY00 for hot chemical cleaning methods. The Russian work will be validated for 
compatibility by SRTC scientists during confirmatory testing. TFA FY00 funding for this task is $\$ 275$. The chemical cleaning method is at Stage 5, Engineering Development, and a gate review is planned in late FY00 todetermine readiness to proceed to a large-scale demosntation either in Russia or in an SRS tank. A preliminary technical review was conducted in November 1999. If SRTC validation testing is successful and a candidate formulation is selected for demonstration, more exhaustive testing will be performed in FY01 and Authorization Basis issues will be addressed.

User Acceptance: User expectations were consistent with project status. Based on the progress to date with this project, SRS user submitted a proposal to DOE-NN requesting support to conduct an intank chemical cleaning demonstration at the "Tank Retrieval and Closure Demonstration Center" in Zheleznogorsk.

\subsection{6, Waste Transfer Line Unplugging Methods}

To ensure safe and timely transfer of waste, methods are needed to unplug waste transfer lines that may plug due to particle settling, phase changes, or reactions accompanied by precipitation or gelation. TFA partners at Florida International University (FIU) have constructed three tests beds at the Hemispheric Center for Environmental Technology (HCET) for full-scale investigations on pipeline unplugging and blockage locating technologies. These pipelines simulate: (1) 3 -inch transfer lines at Hanford and SRS; (2) a 2-inch gravity drain line at SRS; and (3) a buried section of 3-inch doublecontained lines serving for remote plug detection system demonstrations. A statement of work was posted by NETL in March 2000 to determine the interest of vendors for testing available technologies on these lines. A request for proposal will be issued in May and vendors selected to demonstrate technologies at the FIU test site. NETL reported they were three moths behind schedule in placing the contract, which will impact completing the FY00 demonstrations on the planned schedule. An ASME technical peer review is currently scheduled for October 20000 , but is likely to be impacted by the procurement delay. A related student design competition will be conducted in April at the Waste Management Education and Research Consortium at new Mexico State University.

In addition, an instrumented flow-loop has been constructed in the HCET lab to monitor slurry flow properties, including critical velocity and pressure drop. Results of the flow loop experiments will be used to address operations methods to respond to pipeline plugs, and to develop gel-plugs for use in mechanical unplugging tests.

This project is in Stage 5, Engineering Development. Current activities are geared toward identifying systems and processes that can be used on nuclear waste pipelines. SRS and Hanford users will review the identified processes for applicability at their site. Combined TFA FY00 funding for the test bed and slurry monitoring activities is $\$ 1075$.

User Acceptance: User expectations were consistent with project status.

\subsection{1, Integrated Radionuclide Separations Processes}


Removal of radioactive actinides from liquid HAW at INEEL is required to develop a viable process flowsheet for treatment of waste stream feeds for vitrification and grouting programs. This task involves integrated testing of three separate unit operations: Transuranic element extraction (TRUEX), ion exchange using crystalline silicotitanate (CST) or ammonium molybdophosphate- polycrylonitrile (AMPPAN), and Universal Solvent Extraction (UNEX).

Data from the development and evaluation of these radionuclide separation processes is being used by INEEL to support the process downselect according to the site's Draft Environmental Impact Statement guidelines. TFA testing in FY00 and FY01 will provide detailed data to support selection of a preferred separations technology and conceptual design of the process options in late FY01 or in FY02. All process options have undergone integrated cold testing and selected hot tests. Further refinement of planned FY01 work is expected following the INEEL process decision point. This work is in Stage 4, Advanced Development, and TFA will evaluate conducting a technical peer or gate review in FY01 following the process downselect. An ASME Peer Review was conducted on the TRUEX/SREX technology in FY98. TFA FY00 funding of $\$ 1150$ is supplemented with significant user co-funding of $\$ 900 \mathrm{~K}$ for this activity.

User Acceptance: User expectations were consistent with project status. User is applying data from TFA work to support the process downselect decision and EIS decision process.

\subsection{A\&B, Prevention of Solids Formation and Saltcake Dissolution}

TFA, in conjunction with work to identify pipeline unplugging technologies, is performing work to better understand the chemical kinetic and thermodynamic processes that result in the formation of pipeline blockages. This work will support the development of recommendations on operations envelopes for pipeline waste transfers that should minimize the potential for solids formation and pipeline plugging. In FY00, TFA is focusing on Hanford waste transfer needs and is funding a collaborative effort involving experts from the Hanford RPP, ORNL, AEAT, FIU, and Mississippi State University's Diagnostic Instrumentation and Analysis Laboratory to address this challenging problem.

Solids formation laboratory experiments and modeling to simulate waste transfer conditions are being conducted in order to: predict the conditions leading to the onset of solid phase formation tank waste solutions; determine the nature of particle formation; and; refine waste dilution parameters for slurry transport. Additional development and validation of the Environmental Simulation Program (ESP) for saltcake dissolution and enhanced sludge washing is also underway. Hanford uses the ESP code in conjunction with the Hanford Tank Waste Operations Simulator program to analyze waste transfer scenarios in preparation for feed delivery. Improvements to the ESP program will enhance the results of this waste transfer analysis and planning.

Data on the above will be provided in FY00 to support related transport and pipeline plugging investigations for SRS and ORR. These studies are in Stage 4, Advanced Development. Combined TFA FY00 funding for this project is $\$ 1375 \mathrm{~K}$.

User Acceptance: User expectations were consistent with project status. 


\subsection{4, Solid Liquid Separation (Crossflow Filtration)}

ORR is consolidating all liquid waste from the Bethel Valley Evaporator Service Tanks (BVESTs) High Flux Isotopes Reactor tanks, and Gunite and Associated Tanks (GAATs) into the MVSTs and Melton Valley Capacity Increase Tanks (MVCITs). ORR desires to prevent the accumulation of difficult to retrieve solids in the new MVCITs and is deploying crossflow filtration technology to mitigate this problem. In FY99, the Solids Liquid Separation (SLS) System using crossflow filtration technology was deployed at ORR, in series with the Out of Tank Evaporator (OTE) and Cesium Removal System (CsR). The integrated SLS system, also known as the "TRIAD", will be used at ORR through 2000.

In FY00, this task will evaluate the performance and issue a report summarizing the SLS system operations. This analysis will be combined with an FY01 report on the CsR/OTE operations to benefit waste reduction activities at ORR, facilitate transfer of the technologies to ORR's site operations contractor, and provide valuable information to other sites interested in this technology. Deployment of the SLS technology represents successful transition from Gate 6, Demonstration, to the Deployment stage. TFA FY00 funding for this project is $\$ 910 \mathrm{~K}$.

User Acceptance: User expectations were consistent with project status.

\subsection{6, Consolidated Incineration Facility (CIF) Evaporator}

Improved evaporator operations are needed at SRS to reduce the generation of secondary waste volume from the site's CIF wet off-gas system, and reduce the frequency of HEPA filter replacement. Installation of the CIF evaporator will increase CIF waste treatment capacity and decrease downstream stabilization and disposal costs. Based on process flowsheet analysis, a technical specification for the evaporator was completed and bench-scale tests performed using actual CIF waste. Fabrication of the evaporator is in progress, although the authorization to proceed was delayed by a site assessment of a potential shutdown of the CIF plant. The current project milestones need to be revised in light of the delay to reflect the current schedule for delivery and installation of the evaporator. Current funding is adequate to complete installation design and delivery of the equipment to SRS in FY00. The CIF equipment will be delivered in FY00 and TFA is working with SRS to determine whether the equipment will be installed in FY01, which is contingent o the operation status of CIF. If the evaporator is not installed, TFA will investigate alternate deployment opportunities at SRS or other DOE sites.

User Acceptance: User expectations were consistent with project status.

\subsection{9, Conditioning and Immobilization of Low-Activity Waste}

Future grout treatment and disposal options for INEEL low-activity waste (LAW) require investigation of conditioning steps to ensure that grout forms will properly cure and meet performance criteria, as well as minimizing the volume of the grout product. INEEL must develop a process to directly treat wastes from the spent fuel pools and process equipment waste evaporators to prevent their addition 
treat wastes from the spent fuel pools and process equipment waste evaporators to prevent their addition to the HLW tanks to comply with state requirements to cease use of the tanks. TFA is supporting the demonstration of a pilot-scale process to grout this waste for offsite disposal.

AEAT is transferring LAW grout technology used in the Untied Kingdom for application on INTEC Newly Generated Liquid Waste (NGLW). AEAT has developed a grout formulation suitable for the INTEC waste stream that meets the waste acceptance criteria for Envirocare, the preferred disposal site. INEEL is providing significant levels of co-funding to this project and has established a project team to support development and demonstration of a pilot-scale grout plant. The INEEL project team recently completed a feasibility study for design,, construction and demonstration of the grout plant to be conducted under EM-40. The recommended baseline for this project is to use the AEAT grout formulation with an in-drum mixing system to produce grout drums that will be shipped to Envirocare. A cost-benefit assessment determined the cost of installing a radionuclide separations operation and disposing of a secondary wastes stream outweighed the benefit of waste volume reduction for this demonstration. The site contractor and the DOE-Idaho Operations Office (DOE-ID) have approved the project to proceed with the conceptual design.

A Gate 5 review was conducted in FY99, and an ASME review is planned in August 2000. FY00 funding for the project includes $\$ 1700$ from TFA and $\$ 1500$ from the user. The user is pursuing a Research, Development, and Demonstration permit for the grouting demonstration. A pilot-scale deployment of the LAW grout technology is planned for FY01.

User Acceptance: User expectations were consistent with project status. INEEL is actively involved in the management and execution of this project.

\subsection{8, Specify and Enhance Design of High-Level Waste Glass Melters}

TFA is supporting current and planned vitrification operations at SRS and INEEL by funding a number of tasks related to improved melter technology through University partners. Projects underway at FIU and Clemson University include developing an improved melter pour spout for Defense Waste Processing Facility (DWPF), developing melter feed chemistry enhancements, developing test melter design enhancements, and conducting pilot-scale melter operations with proposed feed streams.

Melter testing to support DWPF melter improvements and recommendations for INEEL melter development was conducted in FY99 and is continuing in FY00. Melter testing for robustness using new pour spout designs is scheduled to begin in March 2000. A planning meeting for the INEEL melter runs was held in February 2000, with the run plan scheduled for June 2000. Reports are due on the results of the various tests in FY00. The DWPF pour spout testing is currently at Gate 5, but testing is falling behind due to delays in fabricating the inserts. DWPF melt rate improvements are in Stage 4, and are a high priority with the site. NNEEL melter development and waste loading verification is in Stage 3, as data and testing will be used to support a down select and cost analysis of treatment options. FY00 TFA and University funding to support these immobilization tasks is $\$ 1488 \mathrm{~K}$, supplemented by site funding of $\$ 1795 \mathrm{~K}$. Future scope in this area will be modified to address new Hanford needs submitted for FY01. 
Development of the melt rate furnace has uncovered issues associated with crucible materials selection. Also, the data provided to date is relative, rather than quantitative. These issues are important for improving the melt rate in DWPF, as well as allowing for reduction oxidation (REDOX) adjustment in INEEL melter runs. TFA is working with DWPF staff to resolve glass chemistry and melt rate issues. Results of the INEEL direct calcine vitrification have been excellent; however, results of the sodiumbearing waste (SBW) pretreatment step could impact the test planned for late in FY00.

User Acceptance: User expectations were consistent with project status.

\subsection{3, Improve Waste Loading in High-Level Waste Glasses}

TFA is formulating glasses based on statistical studies to better estimate the property-composition relationships for anticipated SRS, Hanford and INEEL waste glasses. These formulations will be evaluated for performance (crystallization and phase separations) and operations under higher temperatures.

Improvements in the liquidus database for DWPF showed an approximate $2 \%$ increase in life cycle waste loading. When implemented into the DWPF process controls, this waste loading increase is expected to result in significant saving sin processing and disposal costs. In addition, potential frit composition modifications have been identified for higher waste loading for sludge-only feed. These new compositions are undergoing tests for process ability and durability. Evaluations are also underway on phase separation types identified in SRS and INEEL waste compositions, with Hanford HLW to be added later. These studies are geared toward determining compositional constraints that will preclude phase separation, greatly simplifying process constraints. Technical reports on the above analysis will be issued in September 2000. TFA FY00 funding to support these tasks is $\$ 1600 \mathrm{~K}$, with an additional $\$ 1555 \mathrm{~K}$ provided by the user sites. The SRS liquidus temperature work is in Stage 5; phase separation studies are in Stage 3; Hanford liquidus temperature work is in Stage 4; and the Idaho project applications are in Stage 2.

The improved liquidus model for DWPF provides an overall improvement in waste loading, but not in the near term on sludge-only feed using the current frit. As agreed to by the user, TFA is developing a new frit composition. The direct calcine glass for INEEL formed crystals upon cooling. TFA recommends an evaluation on whether there is an allowable percentage of crystallization that does not affect glass durability.

User Acceptance: User expectations were consistent with project status.

\subsection{3, Enhanced Grout Formulations for Tank Closure}

TFA is supporting INEEL tank closure needs by holding a tank closure workshop, and assisting in the development/demonstration of tank closure processes and closure acceptance criteria via a "Tank WM182 Closure Demonstration." The workshop was held in February 2000, focusing on the status of closure efforts and lessons learned at other sites, and compliance with DOE Order 435.1, "Radioactive Waste Management." In preparation for the demonstration, a tank closure sequence has been identified and 
initial mockup tank tests performed to demonstrate heel displacement by grout. In addition, heel samples obtained from tanks WM-182 and WM-183 showed more solids than anticipated, which presents questions for planned retrieval and treatment activities.

TFA originally funded this project at $\$ 600 \mathrm{~K}$ for FY00. This funding was reduced by $\$ 200 \mathrm{~K}$, resulting in deletion of some project items and milestones. The site plans to focus the remaining $\$ 400 \mathrm{~K}$ of TFA funds on mockup testing of key elements in the closure sequence process. These elements including bench scale tests of materials for stabilizing free liquids in the tank; construction of a boxed mockup tank area for process testing; and construction of a full-scale, half-circle mockup tank for equipment testing. This technology is in Stage 5, Engineering Development, with plans to proceed to Stage 6, Hot Demonstration, in FY03.

An issue with the delay in release of the $\$ 400 \mathrm{~K}$ of funds to the site was identified and will be worked by TFA to determine the cause of the delay. Late and reduced TFA funding impacted a number of FY00 project milestones. EM-40 funding will cover completion and submittal of the INTEC Tank Closure Plan. No additional gate reviews will be conducted, as TFA funding for INEEL closure has been restructured. This work is expected to be completed in FY00. Outyear needs submitted by INEEL will be responded to based on technical issues/commonality with other site needs, rather than as a closure demonstration activity. The discovery of additional heel solids will likely involve more TFA retrieval, pretreatment and immobilization activities.

User Acceptance: User expectations were consistent with project status.

\subsection{5, Demonstration of Grout Injection Technology for Tank Closure}

In situ grouting technology is being readied for deployment in the ORR Old Hydrofracture (OHF) tanks, and is being evaluated for future use in the SRS Old Radioactive Waste Burial Ground solvent tanks. This technology will entrain tank residues in a stable form, uniformly emplace grout within the tanks, and stabilize the tanks, supporting their structure and future surface barriers to prevent tank collapse. This technology may also be applicable for stabilizing the hundreds of small-volume ( $1500 \mathrm{gal})$ tanks requiring RCRA closure at INEEL.

Multi-Point Injection ${ }^{\mathrm{TM}}$ (MPI ${ }^{\mathrm{TM}}$ ) technology was successfully demonstrated by Ground Environmental Services during a cold demonstration at Duncan, Oklahoma in 1998, and again at Odessa, Texas in 1999. Although MPI ${ }^{\mathrm{TM}}$-type grout mixing is not required by Tennessee regulators, a hot deployment of the MPI ${ }^{\mathrm{TM}}$ grouting technology at ORR is planned for later in FY00 to provide additional assurance of long-term stabilization of the OHF tanks and to demonstrate its applicability to tank stabilization and closure of horizontal tanks. A hot deployment of the grout injection technology is also planned for GAAT TH-4 in FY01. The MPI ${ }^{\mathrm{TM}}$ technology passed a Stage 5 gate review in August 1999, and is currently in Stage 6, Demonstration.

User Acceptance: User expectations were consistent with project status. ORR has committed to deployment of the technology in FY00. 


\subsection{Salt Processing Project: A9570, Cesium Separations Using Crystalline Silicotitanate (CST); A9579, Tetraphenylborate (TPB) Process for Cesium Separations; and A9580, Actinide Separations using Monosodium Titanate (MST)}

Process systems are needed at SRS to remove cesium (Cs), strontium (Sr) and other soluble TRU components from soluble waste for subsequent treatment, to define downstream processing, and to meet regulatory requirements. TFA is evaluating three parallel paths for cesium removal: (1) continuous column ion exchange using CST, (2) small in-tank precipitation using TPB, and (3) caustic solvent extraction. Options for removal of Sr and TRU include using MST or developing an alternate material.

In FY99 Cs removal experiments, tall column tests using CST achieved desired decontamination factors (DF) and degradation limits. Follow-up testing in FY00-01 will evaluate CST resin stability, gas generation, resin transport, and sampling and engineering issues. FY99 small tank reactor tests using TPB also obtained desired DF, however, some foaming issues occurred when tested with real waste. In FY00-01, investigations into TPB materials, anti-foam development, identification and testing of potential catalysts, and sodium TPB (NaTPB) recovery will be incorporated into a modified 20-L reactor to permit enhanced testing and provide the operational capability necessary to validate TPB chemical and scale-up processes. Caustic-side solvent extraction studies in FY00 on chemical stability, radiolytic stability and solvent commercialization will lead to real waste testing in FY01.

FY99 work on $\mathrm{Sr}$ and actinide removal using MST indicated that while $\mathrm{Sr}$ removal criteria was achieved, slow plutonium $(\mathrm{Pu})$ removal rates determined MST requirements. Also, small particle size resulted in decreased flux rate across the filter, increasing the filter size. FY00-01 testing will focus on MST kinetics, adsorption rates, and filtration issues, as well as evaluating alternatives to MST for removal of uranium, $\mathrm{Pu}$ and $\mathrm{Sr}$.

SRS committed $\$ 15 \mathrm{M}$ in FY00 for ongoing studies and is adding approximately $\$ 5 \mathrm{M}$ in additional funds in support of solvent extraction process studies. DOE-Headquarters (DOE-HQ) recently established a Technical Working Group to manage these activities. With assistance from the TFA and DOE-Savannah River (DOE-SR), this group will manage the resolution of key technical uncertainties and advance development of all four technologies to a point that reasonably supports a preferred technology selection. Key issues identified are being worked based on identified risk and uncertainties.

User Acceptance: User expectations were consistent with project status. 


\subsection{References and Bibiliography}

DOE, 1998. "Environmental Management Research and Development Program Plan: Solution-Based Investments in Science and Technology" U.S. Department of Energy, Washington D.C.

DOE, 2000. "Implementing a Streamlined Gate Model in Focus Area Review Processes" G. Boyd letter, $2 / 10 / 00$.

PNNL-12264, “Midyear Program Plan FY00-04”, September 1999.

PNNL-SA-32935, TIM Project Reviews, Book 1, March 2000.

PNNL-SA-32936, TIM Project Reviews, Book 2, March 2000. 
Appendix A

Review Panels 


\section{Appendix A}

\section{Review Panels}

\section{Multiyear Technical Response Review}

TFA Technical Advisory Group (TAG) (resumes available on the TFA Technical Team Website at http://www.pnl.gov/tfa/org/tfa_tag.stm)

Wally Schulz, TAG Chair

Jimmy Bell, TAG Deputy Chair and Closure Subgroup

Dawn Kaback, TAG Characterization Subgroup

Bruce Kowalski, TAG Characterization Subgroup

George Vandergrift, TAG Pretreatment Subgroup

John Swanson, TAG Pretreatment Subgroup

Major Thompson, TAG Pretreatment Subgroup

Paul Scott, TAG Retrieval Subgroup

Tom Weber, TAG Immobilization Subgroup

Joe Gentilucci, TAG Immobilization Subgroup

Frank Woolley, TAG Immobilization Subgroup

Robert Erdmann, TAG Closure Subgroup

Larry Tavlarides, TAG Safety Subgroup

TFA Management Team

Kurt Gerdes, DOE Headquarters, EM-50

Cavanaugh Mims, DOE Headquarters, EM-40

Ken Picha, DOE HeadquartersEM-20

Joe Cruz, Site Representative, Hanford Site

John Drake, Site Representative, West Valley Demonstration Project

Tom Gutmann, Site Representative, Savannah River Site

Keith Lockie, Site Representative, Idaho National Engineering and Environmental Laboratory Jackie Noble-Dial, Site Representative, Oak Ridge Reservation

\section{TFA User Steering Group}

Fred Damerow, West Valley Nuclear Services, West Valley Demonstration Project

Jim Honeyman, CH2M Hill Hanford Group, Hanford Site

Jerry Morin, Westinghouse Savannah River Company, Savannah River Site.

Sharon Robinson, Oak Ridge National Laboratory, Oak Ridge Reservation

Jim Valentine, Bechtel BWXT Idaho, LLC . Idaho National Engineering and Environmental

Laboratory

Rod Quinn, Pacific Northwest National Laboratory

Susan Pickering, Sandia National Laboratories

Mike Baker, Los Alamos National Laboratory 


\section{Midyear Review Meeting}

Ted Pietrok, DOE Richland Operations Office (DOE-RL), TFA Program Manager

Kurt Gerdes, DOE Headquarters, EM-50, TFA Management Team

Cavanaugh Mims, DOE-Headquarters, EM-40, TFA Management Team

Ken Picha, DOE-Headquarters, EM-20, TFA Management Team

Tom Gutmann, DOE Savannah River Operations Office, TFA Site Representative

Keith Lockie, DOE Idaho Operations Office, TFA Site Representative

John Drake, DOE Ohio Operations Office, TFA Site Representative

Joe Cruz, DOE Office of River Protection, TFA Site Representative

Marcus Glasper, DOE-RL, TFA Program Integration Manager

Billie Mauss, DOE-RL, TFA Program Development Manager

Jerry Morin, Westinghouse Savannah River Company, TFA User Steering Group

Jim Honeyman, CH2M Hill Hanford Group, TFA User Steering Group

Sharon Robinson, Oak Ridge National Laboratory, TFA User Steering Group

Dan Meess, West Valley Nuclear Services, TFA User Steering Group

Jim Valentine, Bechtel BWXT Idaho, LLC, TFA User Steering Group

Rod Quinn, Pacific Northwest National Laboratory, User Steering Group

Wally Schulz, TFA TAG Chair

Jimmy Bell, TFA TAG Deputy Chair

\section{Environmental Management Science Program Review}

Glenn Bastiaans, Ames Laboratory, Characterization, Monitoring and Sensor Technology

Crosscutting Program Technical Lead

Marcus Glasper, DOE-RL, TFA Program Integration Manager

Bill Holtzscheiter, Savannah River Technology Center, TFA Immobilization Technology Integration Manager

Phil McGinnis, Oak Ridge National Laboratory, TFA Pretreatment Technology Integration Manager Cavanaugh Mims, DOE Headquarters, EM-40, TFA Management Team

Ken Picha, DOE-Headquarters, EM-20, TFA Management Team

Tom Thomas, Bechtel BWXT Idaho, Inc., TFA Characterization Technology Integration Manager Jack Watson, Lockheed Martin Energy Research, Efficient Separations and Processing Crosscutting

Program Technical Lead

Joe Westsik, Pacific Northwest National Laboratory, TFA Deputy Technical Integration Coordinator 
Appendix B

Multiyear Technical Responses 


\section{Appendix B}

\section{Multiyear Technical Responses}

\begin{tabular}{|c|c|c|c|c|}
\hline $\begin{array}{c}\text { FY01 } \\
\text { Technical } \\
\text { Response \# }\end{array}$ & Technical Response Title & $\begin{array}{c}\text { FY00 } \\
\text { Technical } \\
\text { Response \# }\end{array}$ & $\begin{array}{c}\text { TIM/ } \\
\text { TAG } \\
\text { Review }\end{array}$ & $\begin{array}{c}\text { Midyear } \\
\text { Review }\end{array}$ \\
\hline A9143 & HLW Tank Corrosion Control and Monitoring & 99043 & Yes & Yes \\
\hline A9171 & Alternative Air Filtration Technology & 99071 & & Yes \\
\hline A9175 & Tank Integrity Inspection Techniques & 99075 & Yes & \\
\hline A9246 & Waste Sampling and At-Tank Analysis & 99046 & Yes & Yes \\
\hline A9278 & Slurry Transfer and Tank Waste Mixing Monitors & 99078 & Yes & \\
\hline A9352 & Remote Pit Operations Enhancements & 99052 & & \\
\hline A9359 & Waste Mixing and Retrieval & 99059 & Yes & \\
\hline A9361 & Heel Retrieval from Obstructed Tanks & 99067 & & Yes \\
\hline A9362 & Salt Cake Dissolution Retrieval & 99062 & Yes & \\
\hline A9363 & Chemical Cleaning of Tanks & 99067 & & Yes \\
\hline A9365 & Waste Transfer Pumping & 99059 & Yes & \\
\hline A9367 & Unobstructed Tank Heel Retrieval & 99067 & & Yes \\
\hline A9376 & $\begin{array}{l}\text { Waste Transfer Line Plugging Prevention and } \\
\text { Unplugging Methods }\end{array}$ & 99076 & Yes & Yes \\
\hline A9382 & $\begin{array}{l}\text { Horizontal and Small Tank Sludge Mixing and } \\
\text { Retrieval }\end{array}$ & 99082 & Yes & \\
\hline A9501 & $\begin{array}{l}\text { INEEL Integrated Radionuclide Separations } \\
\text { Process }\end{array}$ & 99001 & Yes & Yes \\
\hline A9532 & Calcine Dissolution Solubility and Kinetics & 99032 & Yes & \\
\hline A9554 & Hanford Tank Waste Chemistry & $\begin{array}{l}99054 \mathrm{~A} \\
99054 \mathrm{~B}\end{array}$ & Yes & Yes \\
\hline A9570 & $\begin{array}{l}\text { Cesium Separations Using Crystalline } \\
\text { Silicotitanate }\end{array}$ & 99070 & Yes & Yes \\
\hline A9579 & $\begin{array}{l}\text { Tetraphenylborate Process for Cesium } \\
\text { Separations }\end{array}$ & 99070 & Yes & Yes \\
\hline A9580 & $\begin{array}{l}\text { Actinide Separations Using Mono Sodium } \\
\text { Titanate }\end{array}$ & 99070 & Yes & Yes \\
\hline A9584 & Solid Liquid Separation (Crossflow Filtration) & 99084 & & Yes \\
\hline A9586 & CIF Evaporator & 99086 & Yes & Yes \\
\hline A9719 & $\begin{array}{l}\text { Conditioning and Immobilization of Low- } \\
\text { Activity Waste }\end{array}$ & 99019 & Yes & Yes \\
\hline
\end{tabular}

B.1 


\begin{tabular}{|c|l|c|c|c|}
\hline $\begin{array}{c}\text { FY01 } \\
\text { Technical } \\
\text { Response \# }\end{array}$ & \multicolumn{1}{|c|}{ Technical Response Title } & $\begin{array}{c}\text { FY00 } \\
\text { Technical } \\
\text { Response \# }\end{array}$ & $\begin{array}{c}\text { TIM/ } \\
\text { TAG } \\
\text { Review }\end{array}$ & $\begin{array}{c}\text { Midyear } \\
\text { Review }\end{array}$ \\
\hline A9748 & $\begin{array}{l}\text { Prediction of Long-term Performance of } \\
\text { Immobilized Low-Activity Waste }\end{array}$ & 99048 & Yes & \\
\hline A9768 & $\begin{array}{l}\text { Specify and Enhance Design of HLW Glass } \\
\text { Melters }\end{array}$ & 99068 & Yes & Yes \\
\hline A9773 & Improve Waste Loading in HLW Glass & 99073 & Yes & Yes \\
\hline A9777 & $\begin{array}{l}\text { Remote Disassembly of HLW Melters and Other } \\
\text { Processing Equipment }\end{array}$ & 99077 & Yes & \\
\hline A9923 & Enhanced Grout Formulations for Tank Closure & 99023 & Yes & \\
\hline A9924 & Tank Closure Criteria / Decision Support & 99023 & Yes & Yes \\
\hline A9985 & $\begin{array}{l}\text { Demonstration of Grout Injection Technology for } \\
\text { Tank Closure }\end{array}$ & 99085 & Yes & Yes \\
\hline
\end{tabular}




\section{Appendix C}

Review Comments and Responses 


\title{
Appendix C
}

\section{Review Comments/Disposition}

\author{
99043, High Level Waste (HLW) Corrosion Control and Monitoring
}

(TAG) How are the data validated (against some other known technology)?

TFA Response: Linear Polar Resistance (LPR) will be used as a crosscheck mechanism.

(TAG) Does the probe tell anything about the tanks' history?

TFA Response: No, only what is presently going on.

(TAG) How do we get hooked up with the electrochemical noise (EN) data analysis?

TFA Response: The principal investigators (PIs) at Savannah River Site (SRS) and Hanford have been notified of the TAG interest and are in discussions regarding the data analysis.

(TAG) For the Oak Ridge Reservation (ORR) tanks, how do you solve the requirement to monitor throughout the tank when only one access port is available in the center of the tank?

TFA Response: The EN technology provides indication of the corrosion activity on the electrodes with inference that similar activity is occurring on the tank walls themselves. The material of the electrodes must therefore, be as close to the same composition as the tank steel as possible. Further, the electrodes indicate activity in the waste composition in which it is immersed only. Hence, we have multiple electrode arrays at varying elevations at Hanford, and a reel mechanism to raise and lower the probe at SRS. The exact configuration for the ORR probe is yet to be determined.

(TAG) Timelines only go to FY01. Is that adequate for ORR probe? Project scheduled to end in FY01.

TFA Response: It is anticipated that ORR will deploy a probe, based on the lessons learned from Hanford and SRS, in FY01. EM-50 will pay for initial testing and evaluation of the probe for use in stainless-steel tanks in FY01.

(TAG) The technical response applies to the needs statements. However, I believe that the needs statements are all related to the expected tank failure. It is difficult to understand how these measurements will assure the site of a tank expected failure. How these results can override other site requirements with respect to tank usage may not be functional. I.e., can a tank be taken out of business based on these measurements? Will a site construct secondary containment based on these results? However, the additional of chemicals can be based on these measurements.

TFA Response: Reviewer's observations noted. The primary purpose for the probes will be to evaluate the corrosion mechanisms and rates associated with specific tank chemistries and provide a modified basis upon which tank chemistry adjustments are made to inhibit corrosion. When used in conjunction with other tank integrity evaluation tools, the corrosion probes will provide additional information upon which tank integrity related decisions can be based. 
Office of River Protection (ORP) Summary of Need, $3^{\text {rd }}$ paragraph. Recommend rewording first two sentences as follows: "During FY99, localized wall thinning in tank 241-AN-105, in excess of prescribed reporting criteria, was detected by ultrasonic examination, even though waste chemistry in that tank had been maintained within the specified concentration limits. This has created increased interest in corrosion mechanisms beyond what may have been encountered at Hanford in the past."

TFA Response: Accepted, comment incorporated.

(ORP) Summary of Need, $5^{\text {th }}$ paragraph. Recommend rewording first sentence as follows: "Current Hanford needs include: assessing functionality of corrosion probes previously installed in 241 $A N-107$ and 241-AN-102 and troubleshooting..."

TFA Response: Accepted, comment incorporated.

(ORP) Technical Review Strategy. Add, "An additional review stage is planned prior to transfer of electrochemical noise monitoring technology for operational use."

TFA Response: Accepted, comment incorporated.

Oak Ridge National Laboratory (ORNL) No formal agreement between TFA and the site is needed since the funding is less than $\$ 1 \mathrm{M}$.

TFA Response: Accepted. The following revision has been made to the technical response. "ORR: No formal agreement between TFA and the site is needed since the funding is less than $\$ 1 \mathrm{M}$."

(ORNL) Technical Task Plan (TTP) for ongoing work is ORO-WT21. Mike Harper of Bechtel Jacobs Corporation (BJC) should be listed as the ORR PI.

TFA Response: Accepted. The revisions have been made to the technical response.

(ORNL) Marshall Johnson of Lockheed Martin Environmental Services (LMES) is not the ORR user contact for this work.

TFA Response: Accepted. Sharon Robinson, Lockheed Martin Energy Research (LMER) and Michael Harper (BJC) have been identified as the points of contact in the technical response.

(Hanford) Revise Technical Review Strategy as follows: "Hanford: Gate 4 and Peer Review completed March 1998. An additional review stage is planned prior to transfer of electrochemical noise monitoring technology for operational use."

TFA Response: Accepted, comment incorporated.

(Midyear) Why combine the Raman technology at SRS and not Hanford and ORR?

TFA Response: The EN Corrosion Probe was initiated at Hanford. SRS was subsequently interested in the EN corrosion probe but wanted to add Raman capability for corrosion species. Riser sizes are also different; SRS can raise and lower the probes with less difficulty.

(Midyear) Is the technology viewed as replacement or addition to baseline?

TFA Response: Could be one or the other. Depends on utility and the results of testing and demonstrations. 
(Midyear) What about failure of probe?

TFA Response: It would be relatively easy to fall back to baseline; but a replacement probe is inexpensive and fairly easy to build, deploy. System control/data package is the limiting factor. SRS will be running in parallel.

\section{1, Alternative Air Filtration Technology}

(SRS) Recent testing by Mott Corp. demonstrates tubular media with dirty air flow into the inside diameter (ID) of the tube, and wash spray applied to the ID of a 3" diameter tube. Test work at Savannah River Technology Center (SRTC) used an outside diameter (OD) to ID flow direction, but Mott is using an ID to OD flow direction, which allows for a more compact assembly of multiple tubes.

TFA Response: Revise "Progress to Date" inserting a new second paragraph as follows: "Recent testing by Mott Corp. demonstrates tubular media with dirty air flow into the ID of the tubular filter media. Wash spray is also applied to ID of $3 "$ diameter tube. The original test work at SRTC used an OD to ID flow direction, but Mott is using an ID to OD flow direction which allows for a more compact assembly of multiple tubes."

(SRS) The term backwash suggests that flow is reversed in an effort to clean filter media. SRTC testing shows that the smooth surface of the powdered metallurgy constructed filter (Mott) allows effective cleaning by spray directly onto the 'dirty' side of the media. Reverse flow is not as effective because high pressure drop through the media prevents effective removal.

TFA Response: The term "backwash" has been changed to "wash" throughout the technical response.

(SRS) The information describing work at Idaho National Engineering and Environmental Laboratory (INEEL) is probably using Pall sintered steel filters. These filters exhibit markedly different behavior from the Mott filters because the Pall filters are constructed from pleated wire mesh material versus the Mott filters which are smooth surface from very fine (1 micron average diameter) particles. Pall filters have much lower pressure drop per linear inch but have a much higher square inch area. During SRTC testing the Pall filters plugged when wetted and we were unable to vacuum dry in situ.

TFA Response: Comment noted. No changes have been made to the technical response. INEEL is indeed reviewing past work with Pall filters but is also evaluating more recent additions to the marketplace.

(Midyear) Need to certify as American Society for Testing and Materials (ASTM) standard; current revision includes metal, but not ceramic.

TFA Response: TFA has included this as part of the workscope.

(Midyear) Compare notes with Hanford regarding commercial vendor:

TFA Response: TFA is following up on some work performed by fabricators for Hanford. 


\section{5, Tank Integrity Inspection Techniques}

(TAG) This is connected to (Technical Response) A9143. Need to balance the nearly equal importance of both technical responses and their funding.

TFA Response: That A9143 could rightly be considered a subset of A9175 is clear. The proposed TFA funding for FY01 also reflects this in that effort for Tank Corrosion (A1943) is \$250K with matching site funding whereas the TFA portion for Tank Integrity Inspection Techniques is $\$ 2,960$ with $\$ 2,010$ in site funding.

(TAG) Look at ORR timing.

TFA Response: The technical response has been revised to reflect the current understanding of the timing. Any necessary revisions will be incorporated as a result of the site review process.

(TAG) Task 5 at ORR, the supernate is pumped by the contractor after 02 . The measurements as on pg $5 / 8$ cannot be done before processing. The tanks are not available in the $02-05$ timeframe. Task $\mathrm{G}$ on 5/8: it seems difficult to defend this work on emptied tanks that are at a level for closure.

TFA Response: This topic was discussed with the TAG reviewer during the session. The technical response is responsive to the need, as expressed by the site. The program to accomplish the requested sludge mapping is presently underway.

(SRS) First page lists Need SR00-2037 (Concentrate Transfer System [CTS] Inspection System), but I don't see any CTS tasks. Add "Deploy Inspection system for $1 \mathrm{~F}$ evaporator and CTS tank" in FY01.

TFA Response: Accepted. Reference to the "CTS Inspection System" has been deleted from the Need Title and replaced with "Tank Annulus Inspection." technical response AA203, Residual Waste Sampling addresses the CTS Inspection System. This need was broken out and assigned to the TFA characterization functional area. It is identified as SR00-2037Q "Tank Heel

Removal/Closure Technology - Part Q Sampling \& Inspection Methods for Evaporators and CTS Vessels". The technical response to this need is provided in AA203 "Residual Waste Sampling". A two-year task is described. In FY01, required site documentation and full-scale mock-up testing would be completed followed by delivery and hot deployment of sampling/inspection tool in FY02. Based on considerable TFA experience in hot deployment of new technology, this task could not be completed in one year.

(ORNL) Statement that ORNL transfers the Melton Valley Storage Tanks (MVSTs) to private sector in 2002 is incorrect. This occurs the first quarter of 2001. Sludge mapping and structural integrity tests must be completed prior to tank transfer.

TFA Response: Accepted. Revised "Summary of Need(s)" as follows: "At the Oak Ridge Reservation, the ORNL privatization schedule is to turn over 8 MVSTs to the private sector in the first quarter of 2001. These are 50,000-gal tanks about $12 \mathrm{ft}$ in diameter and $61 \mathrm{ft}$ long, and are used to store newly generated radioactive waste at ORNL: Before the turnover, ORNL wants to inspect the condition of the tanks (structural integrity) and quantify the volume of sludge under the supernatant." 
Also revised a later sentence in the need summary as follows: "A method to perform these measurements must be developed and deployed within the specified time..."

(ORNL) A nondestructive examination (NDE) assessment of the externals of the MVSTs is not needed. Drop the NDE subtask.

TFA Response: Partially accepted. Subsequent to receipt of this comment, guidance was provided at the Midyear Review to reduce the scope of the FY01 activities by deferring the actual procurement $(\$ 380 \mathrm{~K})$ to FY02. The following activities were added to the Key Products to clarify this change.

- Document Functions \& Requirements for MVST Annulus External NDE Inspection

Equipment. FY01

- Prepare Procurement Specifications for MVST Annulus External NDE Inspection

Equipment. FY01

- Procure MVST Annulus External NDE Inspection Equipment. FY02

- Deploy MVST Annulus External NDE Inspection Equipment (Cold \& Hot Test). FY02

Adjustments were also made to the funding profiles to agree with the Midyear Review direction.

(ORNL) TTP for ongoing work is ORO0WT21. Mike Harper of BJC should be listed as the ORR PI.

TFA Response: Accepted. Added TTP ORO0WT21 to the TTP for Ongoing Work section and updated PI for ongoing work to include Mike Harper, BJC

(INEEL) In the Technical Approach section, the description for Task 6 indicates that the INEEL contracted with a professional engineer (PE) for tank certification in FY99. This is not the case. The need for additional tankage has not been clear, based on the available information; some of the environmental impact statement (EIS) alternatives require it and others do not. However, the recent heel sampling events in tanks WM-188, WM-182, and WM-183 have demonstrated that additional tankage will be required, regardless of the EIS alternative chosen. Consequently, the INEEL HLW Program will be evaluating certification requirements more fully during the heel sampling efforts planned this summer, with the intent of contracting with a PE during FY01.

TFA Response: Accepted. Reference to FY99 PE evaluation has been rewritten as follows: "During FY01, the INEEL HLW Program will be evaluating certification requirements more fully during the heel sampling efforts planned this summer. As a result of these evaluations, INEEL intends to contract with a licensed PE to ascertain the exact requirements necessary for certification of Tanks WM-190 and WM-185."

99046, Waste Sampling and At-Tank Analysis

(TAG): I sure hope that this monster sampler works. Looks OK.

TFA Response: None required.

(INEEL) In the fifth paragraph in the Summary of Needs section, the text indicates that an investigation of need ID-2.1.44 for heel solids sampling will be completed under TTP ID77WT22; however, TFA has issued a stop work on that TTP and is requesting the funding be returned. 
TFA Response: A subcontract with SAIC was placed and this work was completed prior to the TFA stop work request. There were insufficient funds left in the TTP to warrant return of funding and the effort by TFA to do so was dropped.

\section{8, Slurry Transfer and Tank Waste Mixing Monitors}

(TAG) All needs not met. Focus is on density and wt\% solids which is okay. The Dual Coriolis work looks good. The monitor must be well characterized (range, accuracy). Opportunity; connect monitor to control (dilution, recycle, etc.)

TFA Response: The difficulty with meeting all stated needs is that they are often times out of date or ill defined. To resolve these issues, the points of contact (POCs) on each of the needs were contacted to get a better definition of the needs.

The slurry monitoring needs stated in ORR-TK04 have not changed in the past three years and they have been addressed via TFA/CMST funding since FY97. However, the need statement is now out of date because all major cross-site transfers are scheduled for completion in FY00. The single Coriolis density monitor and Lasentec particle size analyzer will be used through out FY00 during transfers from Gunite Tank W9. The dual Coriolis density/wt $\%$ solids monitor system will be demonstrated in the solid-liquid separation (SLS) facility for the MVSTs beginning in March. However, operation of the SLS is also scheduled for shut-down in FY00. Our POC has confirmed that there are no other process needs in the near future that will require slurry monitoring.

The slurry/rheology monitoring need statements in SR00-2044A and SR00-2037E are basically the same but very non-specific. By working with the SRS POCs, the real need was flushed out, which is to design a wt $\%$ solids monitoring system for in-tank use. This is being addressed via the collaborative work among SRS, ORNL, and Florida International University (FIU).

The slurry monitoring needs in need statement ID-2.1.67B are not well defined because decisions on what to retrieve and what treatment processes to use for tank heels and calcine waste have not been made. It is anticipated that the POC will be able to provide better guidance on the need after the Record of Decision is issued at the end of this year.

Regarding the development of the dual Coriolis approach, ORNL is providing guidance to FIU based on its extensive cold and field testing experience and the TFA/CMST is serving as oversight managers on the experimental test plan. The test plan is being set up with sufficient replication of measurements to allow an analysis of variance and major effects to be done on the test variables ( $w t \%$ solids, supernatant density, temperature, and introduction of air bubbles). Precision and accuracy will be determined for these test variables. Regarding the opportunity to build in control feed back loops, TFA will watch for that opportunity. However, for the current application at SRS to replace dip sampling of a waste feed staging tank, it isn't needed. 
(TAG) Have you considered controlling the stream you're monitoring based on data from sensors? -- Focus is on data monitoring; should evaluate need for a control tie-in - link to mixing and transfer process controls

-- Need to look at this from a systems perspective

-- Need to tie to a control strategy

- Sites have simpler, more pragmatic view

- This may be longer-term when systems are proven

TFA seems to be putting a lot of money into things that should be commercially available; or modifications of existing systems

TFA Response: This observation is accurate for this response. A good deal of comparative testing of commercial and developmental instrumentation has been done, and the commercial instruments tested much better. For this application, the site users want well-tested equipment that is reliable. The development here is the adaptation of commercial devices to radioactive environments and to deployment through narrow openings into large tanks. This design task is not trivial and is worth the attention of TFA and CMST.

(TAG) Company (Coriolis) does not seem interested in doing design/test work for rad environment TFA Response: A representative from Endress and Hauser did attend the first slurry workshop in 12/99. $\mathrm{He}$ is interested in selling monitors to the Department of Energy (DOE), but Endress and Hauser does not have the interest (profit motive) or resources to design specifically for DOE needs.

(TAG) The technical response apparently meets the needs of the four sites. However, the write-up does not include recent advances in slurry monitoring and transfer as is so obvious in the recent American Institute of Chemical Engineers journal.

TFA Response: The technical response was revised to indicate that a wide variety of technologies would be reviewed for applications at Hanford and INEEL. Also the option of doing an industry call for fabrication of monitor systems at Hanford and INEEL was added.

(TAG) Need more vigorous search of work that has been done in other industries.

TFA Response: The technical response was revised to indicate that work done in other industries will be presented by FIU Hemispheric Center for Environmental Technology (HCET)at the next workshop.

CH2M Hill Hanford Group (CHG) No comment. (Hanford interests seem to be secondary in this response.)

TFA Response: The reasons for not generating a technical response to RL-WT031-S are given in AA202 in the $3^{\text {rd }}$ paragraph under "Summary of Needs." This paragraph concludes "However, the need for in-tank characterization at Hanford appears to be a non-existent or very low priority need at this time." Hanford did not submit a need statement but TFA has attempted to be proactive in this technical response and build in potential workscope for Hanford beyond FY01. TFA plans to meet with points of contact at Hanford this summer to assist them in the Site Needs generation/collection process. 
(ORNL) The ORR need for in-line slurry monitors has already been met. This response, therefore, does not directly address an ORR need.

TFA Response: TFA agrees. However, TFA has been funding an ORNL principal investigator (PI) to assist FIU and SRS in design of experiments for and field demonstration of wt $\%$ solids slurry monitoring.

(ORNL) Cross-site sludge and slurry transfers will not be completed by the 2 nd quarter of FY00 as stated in the technical response. The integrated SLS system, or TRIAD, operations are expected to be complete in the 3rd quarter of FY00. However, the schedule for TFA tasks appears to be okay.

TFA Response: This will be corrected in the technical response. Referenced time period changed to $3^{\text {rd }}$ quarter of FY00.

\section{Waste Mixing and Retrieval}

(TAG) The Advanced Design Mixer Pump is too powerful for SRS tanks with coils; demo Tank 18 proposed - need Hanford OK.

TFA Response: Tom Gutmann, DOE-SR, will take this up with Joe Cruz, DOE-ORP.

(TAG) AEA Technology's (AEAT) organic layer mixer could be included in the small tank mixing technical response.

TFA Response: Agree. This part of this technical response has been moved to A9382.

(TAG) Trying to solve problems with hardware. Trying to understand dynamics of system performance. Effort on this area is not sufficient. Need good dynamics model.

-- Consider adding scope to look at developing good dynamic modeling capability

-- Model motion of system fundamental performance of system

-- Data from testing can be used to validate modeling

-- Once model is proven could reduce amount of testing required.

-- Possible strategic task.

-- Need to add to technical response.

TFA Response: Agree. Completion of a dynamic mixing model has been added to this technical response.

(TAG) Decon and disposal of long length equipment can be more expensive than first cost (mixer pumps). Is that being considered while new concepts are developed?

TFA Response: Agree. These considerations will be considered. Words to that effect have been added to the technical response.

(TAG) Need to ensure "institutional" knowledge capability is captured or maintained. Need to share information among sites. Tanks Technology Guide is important to maintain.

TFA Response: Agree. That is the focus of TFA data records availability. (Tanks Technology Guide)

(TAG) Can hydraulic pumps (impeller) replace long-shaft pumps? This technical response has tried to respond to all the two site needs. Surely, Pete will need special travel allowance to execute these tasks. Also, will the site-to-site travel be greater than DOE allows? 
TFA Response: Hydraulic pumps will be considered as part of this activity. Travel restrictions (both site staff and TFA) will reduce the efficiency of these activities.

(SRS) General information - Task B (Replacement of long shaft slurry pumps) is the primary direction that HLW Division wants to go. We would prefer not to use long shaft slurry pumps after our current inventory has been used.

TFA Response: Accepted. This emphasis has been clarified.

(SRS) Accelerate the proposed Task B schedule to perform feature testing in FY01 and hot testing in FY04.

TFA Response: Accepted. Schedule has been adjusted accordingly.

(ORNL) Funding for parametric cold tests should be $\$ 375 \mathrm{~K}$, not $\$ 150 \mathrm{~K}$.

TFA Response: Accepted. Change has been made to the MYTR

(ORNL) We need to understand the justifications for two reports and differences between the ORR and Pacific Northwest National Laboratory (PNNL) reports on the Russian pump performance.

TFA Response: Accepted. There is only one report collaborated on between ORNL and PNNL. Proportion of funding will be reviewed as Program Execution Guidance (PEG) is generated.

(ORNL) We question the reasonableness of funding PNNL at $\$ 250 \mathrm{~K}$ to write an assessment report, and ORR at the same level to complete deployment of the technology, perform parametric cold studies to support other sites, and write a performance report on the technology.

TFA Response: Accepted. PNNL has been reduced to $\$ 200 \mathrm{~K}$ and ORR is at $\$ 525 \mathrm{~K}$

\section{7, Heel Retrieval from Obstructed Tanks}

West Valley Demonstration Project (WVDP) Technical Approach. AWRS reach is 20 feet rather than 30 feet.

TFA Response: Accepted: Change has been entered

(WVDP) Editorial changes to indicate that systems may be needed rather than are needed.

TFA Response: Accepted: Change has been entered

(WVDP) Progress to date. "The Advanced Waste Retrieval System (AWRS) design for WVDP is completed and the equipment has been fabricated and is being tested."

TFA Response: Accepted: Response has been updated.

(WVDP) Task A2 and A2-1. "Evaluate effectiveness of AWRS System and/or sampler."

TFA Response: Accepted: Correction has been made

(WVDP) Task A6-2 should include $\$ 100 \mathrm{~K}$ in FY01 and $\$ 0 \mathrm{~K}$ in FY02.

TFA Response: Accepted: Schedule has been adjusted. 
(WVDP) Task A6-3 should include $\$ 100 \mathrm{~K}$ in FY02

TFA Response: Accepted: Schedule has been adjusted.

\section{2 - Salt Cake Dissolution Retrieval}

(TAG) Comments: Don't do leaking tank tests identified in the response.

TFA Response: Agree. This has been removed from the technical response.

(CHG) Under the "Summary of Needs" it might be helpful to include a reference to the Low Volume Density Gradient (LVDG) concept. It is: Jeffrey S. Hertzel, "Investigation of Low Volume Density Gradient (LVDG) For Waste Recovery in Hanford's Single-shell Tanks," HNF-3554, Rev. 0, Numatec Hanford Corp., Richland, Washington (December 9, 1998).

TFA Response: Accepted: Reference has been added.

(CHG) Among other questions that could be addressed in this study are:

(1) How should the process control system be designed?

(2) What is the minimum leak rate that could be detected by the monitoring and control system associated with the LVDG equipment? (i.e., how well do you know that the tank hasn't sprung a leak while you are operating the system?) How long would it be before you knew the tank was leaking?

(3) Is recirculation of the leaching liquid a good idea? What are the benefits and disadvantages? What is the best balance between waste removal rate and waste dilution for a system without recirculation? For a system with recirculation?

TFA Response: Accepted: These questions have been added.

\section{7, Chemical Cleaning}

(Midyear): What kind of data do you have from the Russians regarding corrosivity? Have you considered the by-product stream from the Caproclaptam process? What about increase in volume?

TFA Response: These issues will be studied as part of the scope.

(Midyear): Have there been Environmental Safety and Health (ES\&H)/Regulator discussions at SRS?

User Response: Some. They know about residual waste content - will not meet the performance assessment. Don't have specific recipe yet for further discussion. Regulator approval is not required for the current waste water treatment permit.

\section{9, Waste Transfer Pumping}

(TAG) Technical response meets needs. No specific issues to respond. Need to review progress.

TFA Response: Agree. Review will be scheduled in FY01 to assess progress.

\section{7, Unobstructed Tank Heel Retrieval}

(ORNL) We need to understand the justifications for two reports and differences between the ORR and PNNL reports on Gunite and Associated Tanks (GAAT) retrieval performance. 
TFA Response: Accepted: These are a collaboration to produce a single report.

(ORNL) We question the reasonableness of funding PNNL at $\$ 150 \mathrm{~K}$ to write a report and ORR $\$ 100 \mathrm{~K}$ for a similar report.

TFA Response: Accepted: In planning the collaboration of this joint report it was expected that ORR GAAT staff would be less available than present and that PNNL would ensure that the documentation would be recorded. This balance will be adjusted as PEGs are drawn up.

(ORNL) The need for the GAAT residual waste retrieval task will be determined by input from the regulators on GAAT closure requirements.

TFA Response: Noted: Residual waste retrieval from GAAT has not been included in the technical response. If required by regulators, it should be considered for future responses.

No significant Midyear issues or comments.

99076, Waste Transfer Line Plugging Prevention and Unplugging Methods

(TAG) What is the history of plugging? Have there been any significant plugs?

TFA Response: Hanford has had and continues to have pipelines blocked by gel formation. SRS has reported sludge blockages in the past. The Russian facilities also have experienced sludge transfer blockages. These are exacerbated by dips or traps in the flow path.

(TAG) Discuss with sites ways of controlling transfer (pump performance, etc.)

TFA Response: Agree. SRS and Hanford have operating parameters they must maintain, but pump motor current is currently the main indicator of trouble. Both sites are interested in affordable alternatives.

(TAG) Detection methods to prevent plugging?

TFA Response: Instruments have been proposed. The most promising that do not require pipeline instrument penetrations are instrumented loops that recycle material to the source tank until properties look good. Instrumented jumpers are also being investigated.

(TAG) Should this task be merged with the chemistry task?

TFA Response: The chemistry task (Pretreatment Solids Formation work) will be closely coordinated with this task. This task is specifically looking for physical ways to unplug a blocked line, whether sludge or gel in origin.

(TAG) Characterization instruments should be integrated into studies.

TFA Response: Agree. Characterization is setting up a transfer instrumentation center of excellence at FIU this year.

(TAG) technical response answers needs.

(CHG) Reviewed. No comment.

TFA Response: None Required 
(Midyear) The request for proposals (RFP) is approximately four months behind schedule.

TFA Response: The RFP should have been issued in December. The National Energy Technology Laboratory (NETL) should issue the RFP in March; with an award expected in June. The RFP will contain both pieces; unblocking and detection. Vendors can bid on one or all of the tasks.

\section{2, Horizontal and Small Tank Sludge Mixing and Retrieval}

(TAG) Look at Deactivitation and Decommissioning Focus Area (DDFA) and AEAT as a source of technologies.

TFA Response: Agree. The Robotics group will be used as the focus of understanding what the D\&D Focus Area has to offer in this area. AEAT will be considered for any new small tank retrieval activity. The possibility of moving the AEAT Mobile Retrieval System from ORR to another site is being evaluated.

(TAG) Should consider method to verify homogeneity of mixing in (horizontal) cylindrical tanks. Geometry different than in vertical for which "adequate" mixing performance determined. Gormer had different injection methods.

TFA Response: Agree. This is now determined by how much residue is left in the tanks after pump down. Deposits will be located differently in the different shape tanks. An in-process method would be desirable.

(WVDP) Modify item B under the summary of need to: "The West Valley Demonstration Project has HLW transfer piping and smaller tanks that require further evaluation and cleaning as required to complete the retrieval of waste sludges and resins from the facility. These tanks include Tanks 8D-3, 8D-4, the LWTS Evaporator, the Submerged Bed Scrubber (vitrification recycle), the vitrification feed tank, and ion exchange vessels in Tank $8 \mathrm{D}-1$ and possibly other process building tanks and piping."

TFA Response: Comments incorporated

(WVDP) Change West Valley Nuclear Services (WVNS) to WVDP.

TFA Response: Text has been modified.

(WVDP) Task B2-1 funding should be $\$ 100 \mathrm{~K}$ in FY01 and Task B2-2 should be $\$ 200 \mathrm{~K}$ in FY01. TFA Response: Accepted: Schedule has been adjusted

(ORNL) The schedule for this need is not adequately addressed by the response. A mixture of sludge and resin must be retrieved and treated from the T-1 and T-2 High Flux Isotope Reactor (HIFR) tanks in FY2001. The response provides $\$ 150 \mathrm{~K}$ to develop a retrieval plan in FY2001. The scope should be change to support selection, procurement, and operation of retrieval equipment for FY2001 deployment. The Technology Integration Manager (TIM) has been made aware of this, and the response is being revised.

TFA Response: Accepted: Schedule has been adjusted 
(ORNL) Waste being removed and treated from HIFR tanks is not HLW. It is high-activity, low-level waste.

TFA Response: Accepted: Correction has been entered.

(ORNL) Progress to date described work from A9359, A9367, and A9367, not this response. AEAT system was deployed in $\mathrm{C}-1$ and $\mathrm{C}-2$. Transportable AEAT system was deployed in $3001 \mathrm{~A}$, not $\mathrm{C}-1$ and $\mathrm{C}-2$.

TFA Response: Accepted: Change has been completed.

\section{1, INEEL Integrated Radionuclide Separations Process}

(TAG) INEEL requested work be focused on sodium bearing waste (SBW) - the site needs to be out of the SBW tanks by 2012.

TFA Response: Technical response revised.

(TAG) Downselect:

- Transuranic (TRU) extraction (TRUEX) vs. universal solvent extraction (UNEX)

- Crystalline silicotitanate (CST) vs. ammonium molybdophosphate (AMP) -polycrylonitrile (PAN)

- No separations - calcine direct treatment

- Response will be focused on priorities based on 3/00 decision/downselect on SBW.

TFA Response: This is a placeholder that will be tailored to the site decision.

(TAG) TAG questions need for scale-up testing on ion exchange columns - revisit for TFA investment.

TFA Response: Large scale testing is needed for long term flow studies to understand the life of the sorbent and the robustness of the columns. This larger scale testing was conducted for ORR and SRS and uncovered surprises at each site. The system at INEEL is significantly different than the previous work, leading to the decision this task is critical. The TIM discussed this with INEEL after the TAG meeting, resulting in an affirmation that this testing is necessary.

(TAG) Question validity of need

- Is it politically driven

- General consensus that must meet state requirements in consent order

- INEEL waste volume is trivial and may not be worth the investment - significant cost difference on disposal

- Need to look at need with respect to entire complex

TFA Response: The cost estimate for the treatment options ranges from $\$ 100 \mathrm{M}$ to $\$ 580 \mathrm{M}$. We are proposing spending $\$ 1 \mathrm{M}$ to assist in the decision making process and to provide technology support. This is similar to the effort we are doing at SRS for the Salt Processing Project, on a proportional basis. It is possible that TFA can provide more cost effective solutions than the remote operation currently being considered, such as the Hanford Compact Processing Unit which is the model for the TRIAD demo at ORR and the Consolidated Incineration Facility (CIF) Evaporator at Savannah River. TFA believes this is a need that should be addressed.

(Midyear) Don't you need to test the UNEX flowsheet for dissolved calcine to support the EIS? 
User Response: Not enough time or resources - we have the data we need, but would be nice to have more.

(Midyear) When do you plan to conduct a gate review on the separation alternatives?

TFA Response: We will wait on any gate review until INEEL decides which alternative to use.

\section{Calcine Dissolution Solubility and Kinetics}

(INEEL) The budget table does not identify the performer for the calcine dissolution work, although it is assumed to be INEEL. Is this correct, or should this be a "to be determined" (TBD)?

TFA Response: The PIs will be determined through the TFA's performer selection process. For the technical response, INEEL is assumed to be the performer, with modeling help from AEAT. AEAT has done similar calcine dissolution, however, this work needs to be done on actual real wastes, and INEEL has the waste and the hot cells to do it.

INEEL staff has informed TFA that this work can be postponed because the near term need is to work on SBW. Due to this guidance, this task fell below the funding line, and is not expected to be funded for FY01.

\section{4, Hanford Tank Waste Chemistry}

(TAG) It is not clear that all listed needs are being addressed.

TFA Response: In the technical responses, the TFA is identifying related science needs and Environmental Management Science Program (EMSP)-funded projects that may be related to the science needs submitted by the sites, but is not directly funding the work. Related science projects were added to the response including "The mechanics of bubbles in sludges and slurries," "Precipitation and deposition of aluminum-containing phases," and "Numerical modeling of mixing of chemically reacting, non-Newtonian slurry for tank waste retrieval."

(TAG) Some needs are supporting equipment and process needs.

TFA Response: The solids monitor equipment activities are covered in A9278. The scope and budget for this work was deleted from this response.

(TAG) In Hunt report, clarify statement regarding $\mathrm{Al} / \mathrm{Si}$ solubility and small additions of $\mathrm{Al} / \mathrm{Si}$ (stoichiometry). (ORNL/TM-1999/263)

TFA Response: Although not related to the technical response, this comment is acknowledged and will be addressed by the PI.

(TAG) Very good! Much improved!

TFA Response: Thank you, we've been working very closely with the site users at Hanford and SRS and believe this is a critical project.

(SRS) Comment: Add the following for progress to date: "SRS developed a non-Newtonian model for SRS sludge based on models used by industry to provide higher accuracy for flow characteristics, 
particularly in the transition region between laminar and turbulent flow. Data will be collected during the Tank 8 to Tank 40 transfer in FY00 to validate the model."

TFA Response: This was added to the technical response.

(CHG) Funding profile: In FY2000, the actual EM-50 total is $\$ 1375$, per Phil McGinnis. $\$ 500 \mathrm{~K}$ of the TFA core $\$ 1500$ was never released, and now has been reallocated. There is an extra $\$ 100 \mathrm{~K}$ in University funding that wasn't here before. Is this new?

TFA Response: The TFA core funding is $\$ 1,425$ after the $\$ 500 \mathrm{~K}$ that was never released is deducted from the original $\$ 1,925$. FIU has university grant funding of $\$ 150 \mathrm{~K}$ (Slurry transport tests) and Diagnostic Instrument Analytical Laboratory has university grant funding of $\$ 100$ (Feed Stability Chemistry and transport modeling) $+\$ 100 \mathrm{~K}$ (Saltcake dissolution). The university funding to support slurry transport tests and feed stability chemistry is new for FY00. The saltcake dissolution work is continued from FY99.

(CHG) "TFA contacted...." section: the name of Ken Hodgson is misspelled.

TFA Response: Spelling was corrected in the technical response.

(ORNL) The ORR need for slurry transfers has already been met. This response, therefore, does not directly address an ORR need.

TFA Response: Activities related to ORR slurry transfers were deleted from the response.

No significant Midyear comments.

\section{0, Cesium Separations Using Crystalline Silicotitanate}

(TAG) Needs statement missing table 2 re CST (SR00-2034).

TFA Response: This will be discussed with SRS. Has no impact on this response.

(TAG) Larry Bustard to provide Sandia National Laboratory (SNL) documentation on temperature effects on CST.

TFA Response: The Salt Disposition team possesses all known SNL documents regarding CST for Cs removal. SNL to provide a bibliography of their documents so we can verify the team has a complete set of documentation.

(TAG) Clarify CST precipitation to mean precipitation on CST bed.

TFA Response: Response has been modified. There are two types of precipitation that are issues: 1) precipitation of HLW supernate components and 2) precipitation of materials that leach from the CST.

(TAG) Add monitoring to response.

TFA Response: Please clarify the comment.

(TAG) Expand 2001 description.

TFA Response: Response has been updated. 
(TAG) Consider other advisors (Clearfield, Linda Wang)

TFA Response: The need for these particular individuals was considered by the Salt Alternatives Team. The team has a contract with Texas A\&M University for the services of Ray Anthony. If Clearfield's services are required they can be added to this contract. Linda Wang subject matter expertise is in column sizing. No work is planned for this area in FY00 or 01 . We have contracted with Dr. Wang in the past and can do so again if the program needs require this.

(TAG) Consider solvent extraction under TFA (strategic?)

TFA Response: The DOE approved the Solvent Extraction Workscope matrix verbally on 2/9/00 and will provide EM-30 funding to support this program in FY00.

(TAG) Idaho need at low pH not addressed.

TFA Response: Idaho will benefit from these studies and their evaluation of CST. INEEL and TFA's responses to these issues are given in Technical Response A9501.

(TAG) Structure products to clarify lead for precipitation issue.

TFA Response: Changed text in Tasks 2 and 7.

(TAG) Meaning of "gas disengagement" equipment is not clear. I thought the write-up meant "within the column." Major says it means "outside the column." At any rate, the dollar amount seems to be high.

TFA Response: Clarified text in Task 3. This is not very expensive for pilot-scale work involving roundthe-clock operation and data collection, and expensive materials such as the CST.

(TAG) Under "Key Products" - report on alternate CST column configurations. This is a FY01 product, but is given as FY00 product as I interpret from text.

TFA Response: Deleted the deliverables for FY00 concerning alternate column configurations. This work was delayed to FY01 at the request of DOE-SR. Text was clarified.

(TAG) Thermal and radiation stability testing. HFIR - will tests be designed to reflect actual service conditions (dose rate and temperature) and thermal excursion conditions (same dose rate - higher temperature for shorter time). Need to carefully consider whether extra high dose and high temperatures - as an accelerated reaction effects test - are valid bases to assess performance. Service conditions would seem to be most meaningful tests (with realistic off-normal thermal excursion).

TFA Response: The Salt Disposition team agrees that service conditions provide the most meaningful test results. No change to the document. Temperature will be controlled during the test in the range of $25-30 \mathrm{C}$ which has been shown not to have an effect on cesium loading of CST. The amount of gas generated has been carefully calculated to ensure it is representative of the real case. We should be able to determine the quality of this estimate by collecting, quantifying, and analyzing the gas generated during the test. 
(TAG) In Alt Salt work, removal of "soluble TRU" is a need. In fact, TRU removal is required soluble or not.

TFA Response: Technical Response A9580 describes the work to demonstrate monosodium titanate (MST) to remove $\mathrm{Sr}, \mathrm{U}, \mathrm{Pu}$, and $\mathrm{Np}$. Removal criteria have been established for each of these key radionuclides. The resulting decontaminated salt solution meets all criteria for disposal as Saltstone at SRS.

(ORNL) The ORR need for cesium removal is met under the A9586 deployment response. This response, therefore, does not specifically address an ORR need.

TFA Response: This comment is correct. TFA was showing that the Alternative Salt task has benefited from the work of the TRIAD. ORNL does not benefit from this work.

(SRS) Task 1: FY00 work should include evaluation and testing (TBD) for the modified/optimized CST product. Although it is likely that the majority of this work will not occur until FY01, it should be our goal to at least initiate this work in FY00.

TFA Response: We agree. The text.in Task 1 has been modified to indicate testing of the revised product will begin as soon as it is available.

(SRS) Task 3: Column gas disengagement is an engineering issue (believed to be solvable) and is not a technology issue that needs to be resolved in FY00 or FY01 to support a technology decision. The scope of this task needs to be eliminated for FY00 and the funds used for other activities that support a technology decision.

TFA Response: This is a very logical follow-on task to the tall-column work that was performed in FY99. In FY99, critical technical issues associated with the physical stability of CST and the behavior of the CST under gas generation conditions were studied and resolved using the tallcolumn system. Collection of a potentially flammable gas within the head space of a column is a critical issue that may not be easy to solve. The behavior of the gas in terms of tendency to coalesce and separate from simulated HLW liquid needs to be studied. If bubbles resist coalescence and remain small or tend of cause foaming, separation will be difficult. The design and efficiency of separation by the disengagement device are factors we should evaluate now, not later when problems in this area with prototype equipment become large cost adders.

(SRS) Task 5: Substitute "Optimization" for "Re-engineering" wherever used in this technical response. Re-engineering implies a major process rework and/or a paradigm shift in processing strategies. All we are requesting is that UOP tweak their process for efficiencies and verify resin stability for our application.

TFA Response: This change has been made. However it should be noted that the magnitude of the manufacturing changes is not currently known. This may be a "tweak" or may be substantial.

(SRS) Task 5: Remove the statement about "eliminate or reduce chloride through use of nitrate form" since this change has already been completed by UOP. In fact, since we know that we do not want to use the chloride form of the resin in our process, from this point forward all of our testing should be with the nitrate form of the resin, unless a conscious decision is made to request the chloride form for production. 
TFA Response: This statement has been retained. To date the use of the nitrate form has not met product specifications without rework. The Salt Disposition Team has not reviewed any Cs removal performance data for these batches and has not concluded the nitrate form is acceptable. We agree that a change to the nitrate form has several positive attributes and is a goal of the scope of work with UOP.

(SRS) Task 5: The lot-to-lot variability issue is not recognized as such by UOP. They do not believe there have been enough lots produced to make an assessment, and SRS would need to define the acceptable variability for UOP when they are producing multiple lots.

TFA Response: A lot to lot variability of about $20 \%(800$ to $1000 \mathrm{Kd})$ is recognized by UOP. The most recent purchase of CST had a Kd of 805 and UOP requested Westinghouse Savannah River Company (WSRC) concurrence of acceptability prior to shipping (which was granted). The Salt Disposition team desires to understand the fundamental cause for this variation in an effort to better understand the science of Cs removal by CST. The Salt Disposition team is currently performing calculations, which provides the bases for a minimum Kd specification.

(SRS) Modifying CST to remove alpha should be eliminated. This scope was agreed to be future work unless the MST or alternatives did not produce acceptable results in FY00. This may be future work if determined to be needed later in the research and development (R\&D) program.

TFA Response: Agreed.

(SRS) See note on Task 1 above. If at all possible, testing activities for modified/optimized CST material should be initiated in FY00.

TFA Response: Agreed. See above.

(SRS) Task 9: The scope of this task needs to be more descriptive.

TFA Response: Task 9 is traditionally paid by EM-40 co-funding. It has been deleted.

\section{0, Tetraphenylborate Process for Cesium Separations}

(TAG) Need integrated process demonstration (with real waste, $>1$ liter, extended time run)

TFA Response: Task 1 includes additional real waste testing. The Salt Disposition team agrees that the $0.5 \mathrm{~L}$ scale used previously is problematic and should be increased to as large as practical. May be done in out years.

(TAG) Add 2001 detail.

TFA Response: Done.

(TAG) Identify where ESP work is going.

TFA Response: See revised Task 1 text.

(TAG) Is there any way to use late wash facility for scale-up? (rad pilot unit late wash foaming)

TFA Response: The Salt Disposition team has prepared a position paper on the scale and possible location for a pilot plant for both the tetraphenylborate (TPB) and CST technologies. This position paper recognizes the existing late wash facility as a prime location for the pilot plant. 
Authorization by the DOE for pilot plant construction is not expected until after a technology is selected, and is beyond FY01.

(TAG) In Alt Salt work, removal of "soluble TRU" is a need. In fact, TRU removal is required soluble or not.

TFA Response: A9580 describes the work to demonstrate MST to Remove Sr, U, Pu, and Np. Removal criteria have been established for each of these key radionuclides. The resulting decontaminated salt solution meets all criteria for disposal as Saltstone on the Savannah River Site.

(SRS) Task 1: This task should not ignore the possibility of other significant catalysts besides palladium and copper.

TFA Response: Agreed. As noted in the task description, $\mathrm{Cu}$ and $\mathrm{Pd}$ are known catalysts. Synergistic influences of other metals are also being explored.

(SRS) Task 3: The scope of this task needs to be more descriptive.

TFA Response: See revised text.

(SRS) Task 5: Following "raw materials for operations", add "and years of process operation." TFA Response: Agreed.

(SRS) Task 6: The investigation of the amount of copper catalyst to be used in the hydrolysis process seems appropriate; and additionally, the efficacy of the hydrolysis kinetics should be quantitatively assessed using analytical techniques for the soluble boron and TPB intermediates. However, it does not appear that the scope associated with proper sizing of the flowsheet to incorporate the hydrolysis process should be a TFA funded activity. Why would this scope not be considered a normal conceptual design optimization? This is not really a technical or scientific issue.

TFA Response: The application of results is typically an EM-40 co-funded activity. It was described here for completeness.

(SRS) Task 7: Does the formation of a mixed crystal present the possibility of a potential "show stopper"? If so, should this not be investigated in FY2000?

TFA Response: Available data indicates the mixed crystal is limited to about $10 \%$ of the excess NaTPB. This is not considered a show stopper.

(SRS) Task 8: The scope of this task needs to be more descriptive.

TFA Response: Task 8 is traditionally paid by EM-40 co-funding. It has been deleted.

(SRS) Task 9: Describe the deficiencies identified in the FY99 studies. Also, the primary intent is not process optimization (for simulants), but rather to demonstrate process viability under decomposition reactions representative of real waste.

TFA Response: Agree that the term "deficiencies" is misleading and has been deleted. The deficiencies referred to were operational in nature (e.g. level probe performance), not programmatic. 
(SRS) Key Products "Palladium-catalyzed" does not reflect the potential for non-palladium catalysts, as noted in Task 1 comment above.

TFA Response: See task 1.

\section{0, Actinide Separations Using Monosodium Titanate}

(TAG) Bring forward work to look at alternatives (look at literature).

TFA Response: As indicated in Task 2 paragraph 2, alternatives to MST will be studied. This will be a literature review of alternate approaches used around the complex. This work will be completed in FY00 and is currently underway. A key product will be a report on alternatives considered.

(TAG) $\mathrm{Np}$, Am need to be removed to lower levels than $\mathrm{Pu}+\mathrm{Am}$ to meet Saltstone criteria.

TFA Response: Am's contribution to the total alpha criteria is included. SRS waste has such small quantities of Am that removal is not required.

(TAG) If Am rate is as low as Pu rate, don't study Pu oxidation states' effect.

TFA Response: Am removal has not been studied and is not required.

(TAG) Chemical equilibrium and chemical kinetics model should be developed rather than empirical model (e.g., pitzer).

TFA Response: We agree with the desire to have a first principles model for MST removal of $\mathrm{Sr}, \mathrm{U}, \mathrm{Pu}$ and Np. However given the different removal mechanism for the different species this task is difficult as evidenced by prior attempts. Therefore, the current focus is on an empirical approach. As more information is obtained on the various mechanisms a return to the first principles approach will be considered.

(TAG) Define 2001 work.

TFA Response: Done.

(TAG) Look at combining MST and an oxidant $\left(\mathrm{KMnO}_{4}\right.$, permanganate) to enhance Pu capture while taking advantage of MST effectiveness for Sr removal. Prefer doing $\mathrm{Sr}$, actinide removal in series with TPB precipitation, - avoid complexity/uncertainty for simultaneous capture process

TFA Response: The literature study cited in comment 1 will include consideration of permanganate strike.

(TAG) In Alt Salt work, removal of "soluble TRU" is a need. In fact, TRU removal is required soluble or not.

TFA Response: As described in this response statement soluble TRU is removed by MST adsorption the Insoluble TRU is removed by filtration. Work items remaining for filtration are described in Task 1 .

(SRS) Task 2 - it should be clear that "alternative alpha removal technologies" includes the investigation of other chemical separation technologies (ion exchange, precipitation, sorption, etc.), besides MST-based sorption/filtration.

TFA Response: Clarified the text. 
(SRS) Task 2. The studies of MST alternatives will likely continue into FY01 and should be included in the description of tasks.

TFA Response: Agreed and clarified.

(Midyear) Have you considered a titanium coating on zeolite as a substitute for MST?

TFA Response: Deferred that option.

(Midyear) How will spent solvent be disposed? How will they handle salt washing?

TFA Response: These issues will be considered in upcoming activities.

\section{4, Solid Liquid Separation}

No significant Midyear comments.

\section{6, CIF Evaporator}

(SRS) The new schedule now shows the evaporator delivery in early August instead of May. As we had discussed, given the uncertainty of CIF operation, SRS didn't release Ionics to procure the expensive Hastelloy stainless steel for about six weeks. So, between the material delivery delay and arranging for a new fabrication window in their shop, the new date is early August. On page 3 under Key Products for FY00, SRS is shown as installing the evaporator and performing demonstration testing. Currently, we will be in the equipment installation phase at the end of the fiscal year, but definitely not to the point of doing any demonstration testing.

TFA Response: The milestones and deliverables for this task have been changed to reflect the delay in receipt of the evaporator until the end of the FY, and the checkout and installation occurring in FY01. This has been worked through the EM-50 oversight system at SRS and ORR and is being modified by the TFA Technical Team.

(ORNL) This response addresses two ORR needs: SLS under TK-05 and CsR/OTE under TK-11. TFA Response: Yes. We will note this on the PEG.

(Midyear) If small tank TPB is not chosen, is CIF dead?

DOE SR Response: Not a current DOE position. Cost savings by using evaporator.

(Midyear): What do you do with steam and concentrate?

TFA Response: Overheads are sent up the stack. Condensate goes into blowcrete, then is grouted and stored as solid waste.

\section{9, Conditioning and Immobilization of Low-Activity Waste}

(TAG) If the technical response is based on no separations, need to revise description to remove discussion of rad removal - state this as an assumption. Don't use or include rad removal in discussion of "conditioning" -cover separately. 
TFA Response: The current approach is to use no separations. Rather than constraining the approach to include no possibility of separations, some flexibility was introduced to provide the option of separations in case it was needed. The final decision depends on many inputs, including waste acceptance criteria at Envirocare, actual sample analysis, etc. The text has been changed to better convey this approach.

(TAG) Need to update portion of need dealing with ORTK-06 - base on recent discussions.

TFA Response: The scope of the task has been reviewed with the ORR user and it is consistent with the site's requirements.

(TAG) Remove reference to "AEAT grant" - no longer exists.

TFA Response: Okay.

(TAG) Add table to clarify how technical response products relate to specific waste streams.

TFA Response: Details of the scope will be provided in the PEG

(TAG) Need to better describe what silica gel task is supporting - not clear how this relates to waste stream - tie to grout tasks better. Need to re-evaluate and update need for this based on the decision for SBW.

TFA Response: Silica gel is a possibility for immobilization of the SBW. Clarified in the scope.

(TAG) Funding sludge undissolved solids (UDS) in SBW tanks is not addressed - need to speak to what the plan is.

TFA Response: The SBW task is a follow-on to the current task of immobilizing newly generated liquid waste (NGLW). If the current approach is implemented and no solid/liquid separations are required, then the solids in the NGLW will be incorporated directly into the grouted waste form. For SBW, a solids/liquid separation will be required prior to ion exchange, for example. These solids and the solid left in the tank (not sludge) will be characterized and treated accordingly. Again, this is scope for future work and not part of the near term work. Specific scope is dependent on characterization of the UDS

(TAG) Page 1: AMP-PAN is not an (easily) elutable resin - and they don't plan on doing so.

TFA Response: We have changed the text. See response below.

(TAG) Page 2: There is not plan to dispose of AMP-PAN by grouting.

TFA Response: See response below.

(TAG) What they are thinking of is dissolving the AMP and sending the resulting solution to highactivity waste (HAW) vitrification and the PAN portion to grout. .

TFA Response: The text has been changed to reflect this.

(TAG) What is "Hanford's mixed waste facility?" (included on vu-graph). Is it made clear whether it is the private disposal facility that happens to be located there, but is not part of the Hanford complex, or is it a facility that is part of the Hanford complex? McGinnis used the term "Hanford Facility" to denote the facility. I don't' think that's what Bill means.

TFA Response: This is the Hanford Site Solid Waste Disposal Facility. The actual disposal site is in Trenches 31 and 34 of the 218-W-5 Burial Ground. We have included this in the text. 
(TAG) This technical response appears to meet the expressed site needs. It is not clear why the work on the ORR Foster Wheeler product is done.

TFA Response: The task is one of validation of the approach taken by Foster Wheeler at ORR. This is a need expressed by ORR. It was associated with the INEEL need since both focus on ensuring that the final waste form meets the land disposal restriction requirements.

(Midyear) Has there been any connection with Mixed Waste Focus Area in this effort; (silica gel)?

TFA Response: Bill (Holtzscheiter) has been in touch to ensure duplication is not occurring.

(Midyear) What is the goal of the demonstration?

TFA Response: Disposal, not storage. This subject was covered at the Closure Workshop in February; treating as mixed waste to meet Envirocare disposal criteria.

(Midyear) Does INEEL plan to do any removal from SBW, other than Cs?

TFA Response: Separations will be in part based on the acceptance criteria for the destination disposal site.

99048, Prediction of Long Term Performance of Immobilized Low Activity Waste Glasses

(TAG) On the issue of $\mathrm{Na}$ ion exchange and its influence on $\mathrm{pH}$ in disposal system: Corning did extensive work on composition effects on ion exchange in glasses. I suggest asking them for help on this topic. Initial contact could be with Dr. Ben Bausal (607-974-3772), or Dr. Charles Craig (607-974-3610)

TFA Response: We will follow up as soon as we can. Thank you. This also relates to Pete McGrail's EMSP effort.

99068, Specify and Enhance Design of High-Level Waste Glass Melters

(TAG) Look at Argon (Ar) purge of pour spout (siphon break)

TFA Response: An Ar purge, intended as a siphon break, was included in the design of Defense Waste Processing Facility (DWPF) melters \#1 and \#2. A short time after startup the Ar purge line plugged. Although this was identified by SRTC as a notable difference between the prototype and the production melter, I believe it was considered inconsequential and nothing was ever done to resolve the problem and restore flow. The technical response will incorporate this issue into the program (if the equipment is not compatible), and evaluation will be performed. The concern of the TAG will be communicated to DWPF personnel.

(TAG) Send copies of reports to TAG

TFA Response: We will send copies of the test plans and technical reports generated from this task to the TAG. August, 1999 (WSRC-TR-99-00305, Rev. 0) summarizes Clemson pour spout work and will also be sent.

(TAG) I believe I could be of some help with Clemson \& FIU programs if I had any information about them. 
TFA Response: Arrangements will be made for Frank Woolley to visit Clemson when the technical team is together for either planning or performing a run.

(TAG) No mention of extensive work on melting rate by GTS Duratek \& Vitreous States Laboratory (VSL) - how is program to improve DWPF melting rate connected to GTS Duratek/VSL?

TFA Response: This work supports the BNFL (a U.S. subsidiary to British Nuclear Fuels Limited of the United Kingdom) privatization contract at Hanford and is not currently available to the TFA.

(TAG) Melting rate is primarily determined by the rate of heat transfer from the melt to the feed, and by the energy requirement to evaporate water in the feed. Heat transfer from melt to cold cap is primarily determined by the amount of foam formed in the lower layer of the cold cap. Foaming is the result of gas release at high temperature, largely the result of excessive amounts of unstable oxide in the feed (e.g. sulfates, ferric oxide) which decompose only at near-melt temperatures. It is sensitive to small changes in the feed makeup, and especially to changes in components that affect the redox conditions in the cold cap. Melting rate is largely influenced by foam formation in lower part of the cold cap. Hrma, Perez \& others studied this in early 1990 . Is this information incorporated in DWPF practice? Could I see a copy of the report on this?

TFA Response: Under the Hanford Waste Vitrification Plant (HWVP) project and the Nuclear Waste Treatment Program (NWTP), engineering modeling, laboratory studies, and pilot-plant vitrification tests were performed between 1989 and 1994. A partial bibliography of the work that has been conducted at PNNL is provided below. Joe Perez is trying to determine whether any work was continued after this report by the NWTP. The evaluation consisted of several activities. A statistical analysis was performed using nonradioactive tests conducted world-wide (for which data could be obtained), e.g., WVDP, SRTC, PNNL, Kernforschungszentrum Karlsruhe (KfK), etc. Modeling and laboratory studies were also conducted to assess composition and concentration effects on melt rate and the use of plenum heaters. In general, the results were not sufficiently quantitative to make any firm recommendations. Probably the most influence the work had was in initiating a significant amount of research by HWVP and NWTP of cold cap chemistry and the effects of glass former selection, rheology, etc. The remaining references were gleaned from a quick review of available literature sources and discussions with PNNL staff that conducted much of the research. The total list of work is about twice the number. Based on the publication dates of the literature it is likely that the results came too late to effect current DWPF operations. From 1990 to 1994, DWPF and SRTC were conducting plant commissioning activities and responding to significant HLW flowsheet changes. Therefore, the research conducted during this period should be assessed by the SRTC and PNNL TFA staff as part of the initial activities. To answer the question whether this work was incorporated into DWPF practice is not a simple matter. There are many factors that affect the DWPF flowsheet so the answer is probably partially.

1. "Preliminary Studies of Vitrification Rate Enhancement" 1989 (unpublished - there may be a journal article summarizing this work), ML Elliott, CC Chapman, LL Eyler, and DD Yasuda, PNNL.

2. "Melt Rate Predictions for Slurry-Fed Glass Melters" 1993, (unpublished), CJ Freeman, HWVP Report: PHTD-C93-04.15K, PNNL. 
3. "Physical Modeling Studies of the HWVP (i.e., DWPF) melter and an Alternate (i.e., WVDP) Design," 1990, (unpublished - there may be a journal article summarizing this work), RD Peters, HWVP Report: HWVP-90-1.2.2.04.08A, PNNL.

4. "The Effects of Melting Reactions on Laboratory-scale Waste Vitrification," 1995, PA Smith, JD Vienna, and P Hrma, PNNL, published in Journal of Material Research, Vol. 10, No. 8, pp. 2137 $-2149$.

5. "The Role of Frit in Nuclear Waste Vitrification," 1995 (?), JD Vienna, PA Smith, DA Dorn, and P Hrma, PNNL, published in Environmental and Waste Management Issues in the Ceramic Industry II, pp. 311 - 325.

6. "Feed Process Studies - Research-Scale Melter," 1996, KF Whittington, DK Seiler, J Luey, JD Vienna, and WA Sliger, PNNL-11333

7. "Effect of Cold Cap Chemistry on Waste Melter Vitrification Kinetics," 1995 (?), HD Smith, GL Smith, EM Tracey, PNNL and DK Peeler, SRTC, Published (but couldn't determine reference at this time)

8. In Ceramic Transactions, Nuclear Waste Management IV, Vol 23:

- "The Effect of Slurry Rheology on Melter Cold Cap Formation," DD Yasuda and P Hrma, PNNL, pp. 349 - 359

- "Drainage of Primary Melt In a Glass Batch," P Hrma, CE Goles, and DD Yasuda, PNNL, pp. $361-367$

- "Computer Modeling of Ceramic Melters to Assess Impacts of Process and Design Variables on Performance," LL Eyler, ML Elliott, DL Lessor, and PS Lowery, PNNL, pp. 395 407

- "Results of a Pilot-Scale Melter Test to Attain Higher Production Rates," ML Elliott, JM Perez, and CC Chapman, PNNL, pp. 409 - 418

(TAG) Need a major program on melting rate and foaming.

TFA Response: The program outlined by Dan Lambert in response to Technical Task Request (TTR) \#HLW/DWPF/TTR-00-0006 (a site internal technical request) is aimed at exploring methods for increasing melt rate in DWPF. Areas to be evaluated include more reducing melter feeds, less refractory frits (higher alkali), increased alkali concentration in the sludge, and alternative reductants. This program is integrated with the TFA task.

(TAG) A program is needed to understand foaming under the specific feed conditions of DWPF. The results will not be easily extrapolated to other feeds (e.g. Hanford or INEEL), but the method of study should be applicable. Foaming can be produced and studied on a small scale, but it is necessary to feed and melt continuously over long enough times to establish steady- state conditions in the cold cap. 
TFA Response: The program identified above will attempt to understand foaming for DWPF feeds in crucible melts and small batch melters. INEEL feeds will be looked at in glass formulation work and subsequent pilot scale melter work at Clemson. A small scale slurry fed mini-melter will be available later this year and could be used with DWPF feeds to evaluate melt rate over long enough times to establish steady state conditions in the cold cap. These tests are extremely expensive and it doesn't appear the money is available for that at the present time.

(TAG) A program is also needed to find ways to maximize solids loading in the feed, since melting rate is very strongly influenced by the amount of water that must be evaporated.

TFA Response: There are efforts underway already by DWPF personnel to look at this. They have made some improvement by modifying flushing volumes, etc. One item that causes low solids is frequently stopping feeding and having to re-prime the feed pumps when you start again. Improving melt rate and reducing foaming will help this.

(TAG) Need to share experimental methods and results between sites (including Hanford).

TFA Response: The data and test results documented through out this program are openly available to all the sites, including the privatization vendors.

(TAG) Pour spout on DWPF melter 1-present design has such serious flaws that consideration should be given to rebuilding melter 2 and changing the purchase specs for meiter 3.

TFA Response: The second melter is not considered available for major modification, because it is a standby spare. Since the first melter near end of life, significant modifications are not likely to melter 2 .

(TAG) Present efforts aimed at testing design improvements should be redirected to testing new approaches.

TFA Response: There has never been sufficient personnel allocation and funding to redesign and test an alternative spout mated to the existing melter. The closest was design studies conducted by HWVP with collaboration from DWPF. The alternatives all create substantial schedule risk.

The existing spout is not as big an issue as it may seem. The main issue is that changing it out requires changing the whole melter. Functionally the spout has operated for 6 years. Issues now facing it are erosion/corrosion of the spout, insert design to accommodate corrosion, improved insert mating for future melters, leveling temperature gradients in the spout, and replaceable heaters. All, with the possible exception of replaceable heaters, can be accomplished by evolutionary changes of the existing design.

(TAG) What exactly is the program at FIU on glass flow dynamics and how is it expected to impact delivery system designs for DWPF, Hanford, INEEL? What has been accomplished so far?

TFA Response: The main objective of the FIU program is to determine the region of stable glass flow conditions for various eroded pour spout knife edge conditions. More specifically they are looking at the deflection of molten glass pouring over the pour spout knife edge, performing flow visualization tests under transient conditions, and determining conditions conducive to wicking. The information will be utilized in insert design and future pour spout modifications. 
(TAG) What specific design features are being tested at Clemson? What results have been obtained so far? How will results be scaled up to production melter flow rates?

TFA Response: The Clemson tests are at full DWPF scale, and have steady state operation at 25 to 180 pounds per hour, with instantaneous rates at $1000+$ pounds per hour. Internals are identical to DWPF except for wear. Tests have studied wetting of the spout, changes in pour rate, surging response, glass temperature, spout temperature, insert designs, and insert alignment, as well as siphoning. Programs are underway for better imaging of the spout for melter diagnostics, and 5 alternative spout insert designs will be tested as soon as they are fabricated. A report is out on the initial year's testing, and one is in draft on siphoning \& dynamic pouring.

(TAG) In considering platinum claddings in DWPF pour spout designs, how is destruction of the Pt by even brief contact with reduced glasses to be avoided?

TFA Response: We are currently considering packing type seals. The are generally no reduced metals or sulfides, except for noble metals and noble metal tellurides. A packing seal should prevent interaction.

(TAG) How are changes in melter feed chemistry expected to affect corrosion in the pour spout?

TFA Response: It has been proposed that the super-oxidizing condition from excess nitrate removes $\mathrm{Cr}_{2} \mathrm{O}_{3}$ by oxidizing it. The protective layer is thereby removed, and another starts to form, leading to relatively rapid loss, especially under flowing and intermittent wetting conditions.

(TAG) Has consideration been given to adopting for DWPF the pouring system concept used by WVDP and planned by BNFL/Duratek for Hanford? It appears to be robust and is much closer to commercial glass melter delivery systems than the design of DWPF-1.

TFA Response: We believe the WVDP spout to be less precise in pour stream direction control. For engineering reasons they are closer to the can. They also have a larger can opening that cannot be accommodated in DWPF without reengineering the canister closure, canister turntable, transfer devices, the decon cell, and the canister transporter. The canister welder would need redesign and re-certification, possibly including drop testing.

(TAG) The fundamental principle of glass delivery is to minimize heat loss (and hence viscosity increase) from lip to receiver. The present DWPF pour spout design violates this principle. In my opinion, the DWPF pour spout design should be replaced, not refined.

TFA Response: Redesigning the spout heaters and insulation package is possible. However, the only thing that might free up time and money for a total redesign is noble metal effects.

(TAG) Melter life-noble metals accumulation in DWPF and should be investigated by intentionally feeding high-noble metals waste for some time, then shut down and examine the melter.

- Cold be run to failure by noble metals shorting

- Consideration should be given to feeding high noble metals waste to DWPF-1 during the period prior to its removal. A careful examination/autopsy of the melter could be much more instructive than a large number of crucible and pilot tests in predicting future problems with the production melter. 
TFA Response: This would be nice to do but we can't intentionally feed high noble metals waste to the melter. That involves the whole HLW system planning process - waste removal, etc. Part of the next sludge batch (Tank 8) has high noble metals so we're hoping it makes it into melter 1 but there's no guarantee. Also, we can't autopsy the melter because it will contain highly radioactive HLW glass. The facilities and equipment to do an autopsy on a radioactive melter don't currently exist. We're trying to put together a proposal/program for a brief look at certain components (primarily from a materials perspective).

(TAG) Conditioning HAW: Why is waste to be dried to a granular solid? All the HLW feeding technology used to date is base on pumping slurries. Commercial glass melting operations universally employ solid feeds, but are notoriously prone to plugging and losses of dusts. A solid feed for INEEL will require development of feeding systems to overcome difficult problems of transport and metering of particulates.

TFA Response: The INEEL calcine waste already exists as a granular solid. The liquid HLW from processing operations is calcined and then stored in stainless steel bins. The solids handling problems would need to be evaluated against those problems associated with slurry handling to arrive at the best alternative. The advantages of reverting back to a liquid waste are not readily apparent.

(Midyear) Why are you doing this since the EIS is deferring the decision on calcine disposition?

TFA Response: Idaho is deferring the decision on calcine due to lack of data; need to characterize the bin sets in order to bound the options.

\section{3, Improve Waste Loading in High-Level Waste Glass}

(TAG) Look at $\mathrm{Ca}$ addition for halides.

TFA Response: Added to the technical response, technical approach.

(TAG) Blending of Idaho calcines to take advantage of $\mathrm{CaF}_{2}$

TFA Response: Added to the technical response.

(TAG) Validate need for phosphate work with Hanford wastes.

TFA Response: Will be done as part of the evaluation of problem constituents and input from blending.

(TAG) Address comment regarding the cost of pretreatment/separations.

TFA Response: Technical response modified.

(TAG) Hanford performance requirements - is this Phase I or Phase II - specify.

- Hanford 2d paragraph - any high crystalline glass would probably be non conforming?

- Hanford $2 \mathrm{~d}$ paragraph - It is more than the impact of insoluble phases on durability. It relates primarily in demonstrating the mechanism for radionuclide release from the system

TFA Response: technical response modified to incorporate comments.

(TAG) Excellent that composition work for all three sites is in an integrated program. 
TFA Response: Thank you.

(TAG) Liquidus is more difficult to predict than other properties, since it involves the thermodynamic stability of a number of unrelated phases, and in practice also involves the kinetics of crystallization of these many phases

- $\quad$ Prediction of liquidus should be separated into two approaches: a compositional model for rough estimation of liquidus and of expected phases, and a rapid laboratory test procedure to experimentally determine more precisely the liquidus and phases present in compositions close to a waste composition of specific interest.

TFA Response: This is the approach used to narrow in on the expected liquidus temperature during experimentation. Both PNNL and SRTC have operable liquidus models. The one resulting from this work is being incorporated into the DWPF process control system after some additional work on appropriate frit compositions for sludge only operation.

(TAG) This two step approach, combined with a strategy of producing waste glasses with insoluble phases, has the potential to substantially reduce the volume of waste.

TFA Response: As mentioned above, the part with insoluble phases is subject to verification that the concerns raised can be addressed and basically that the phases are sufficiently understood to be predictable.

(TAG) An accompanying effort is needed to evaluate means of gently stirring the bath during melting, to keep insolubles in suspension until they can be discharged. This approach also has a high potential as a strategy for dealing with noble metals.

TFA Response: Stirring or mixing is an option being evaluated as part of A9768-Melter Development and Improvement.

No significant Midyear comments.

99077, Remote Disassembly of High-Level Waste Melters and Other Processing Equipment

(WVDP) This technical response will require significant travel, which will need to be addressed in the TTP.

TFA Response: Technical response modified to indicate significant travel requirements.

(WVDP) In other comments, change Federal Energy Technology Center (FETC) to NETL.

TFA Response: Accepted; technical response modified.

(WVDP) Change task titles in spreadsheet as follows:

2.1.1 Develop and Define Key Process and Facility Functional Performance Requirements

2.1.1.1 Functional Performance Requirements for WVDP \$50K in FY01

2.1.1.1.1 Benchmark technologies and methods through interviews and performance of site and vendor visits (includes travel) $\$ 30 \mathrm{~K}$ in FY01.

2.1.2 Develop a test plan to demonstrate technology for decontamination, size reduction, and disposal of melter parts. 
TFA Response: Spreadsheet was modified to incorporate the content of the above comments.

(WVDP) $\$ 1200 \mathrm{~K}$ in FY01 of site funding are rollups from SRTC and not WVDP funding.

TFA Response: Co-funding in both the technical response and the spreadsheet was modified to show matching funding for WVDP per input from Steve Barnes. The drafts reviewed prior to midyear did not have complete co-funding information.

\section{3, Enhanced Grout Formulations for Tank Closure}

(TAG) The grout formulation without assurance that adequate in-tank mixing can be attained would negate the formulation.

- Grout formulation for tank closure should include a vast literature survey of grout formulations. After all, an immobilized grout waste form is what is needed for tank closure. This one year expenditure (01) seems unusual for any development program. Can it be finished? If so, great. Will there be a report that tells how to prepare a grout for closure?

- Look at DWPF Saltstone analysis lab as suggestion for WVDP toxicity characteristic leach procedure/distribution coefficient analysis on hot grout samples.

- Not clear what technology development element is.

- Consider providing technical assistance only to recommend a lab/process to go to.

- Need to tie the Idaho technical response with A9719 grout formulation work.

- Has literature search on grout formulation for acid waste been done?

- Need to look at this as the maintenance of technical capability in grouting for tank closure.

- Centralize capability and make it available across complex.

- Don't anticipate waste heel will be acidic.

- Important to validate this assumption.

- Need to update following next week's closure workshop.

TFA Response: The TFA held a joint closure / immobilization meeting on February 10, 2000 in Las Vegas, Nevada. One outcome of the meeting was a clear articulation that grouts are formulated for a specific purpose. For example, frequently tank closure operations require that grouts have no free water after injection. Such a requirement may not apply to other grouting needs. Within this context it was recognized that an important role for the TFA would be the development of an improved understanding of grout chemistry. This would be accomplished by summarizing the literature information, through interactions with other grout experts, and by performing a matrix of surrogate grout tests that are designed to determine the relative importance of various grout additives and sorbents for in-tank grout stabilization. A second role would be comparison testing of new enhanced grout formulations for tank closure (such as WVDP's enhanced grout that contains sorbents as well as reducing agents) to more established tank closure formulations such as SRS's reducing grout. Technical Response A9923 has been revised to reflect these two activities.

It is the intent of the TFA to select the performer for the A9923 effort via a competitive process. SRTC, ORNL, PNNL, Brookhaven National Laboratory, and others will be contacted to determine their interest in the effort and associated expertise. 
TFA's A9923 effort to develop an improved understanding of grout chemistry would support grout formulation efforts of A9719. The grout community's experience with grouting acidic wastes has been examined as part of the TFA A9719 effort.

(WVDP) How much of the $\$ 450 \mathrm{~K}$ in FY01 is for WVDP? WVDP would use $\$ 250 \mathrm{~K}$.

TFA Response: The performer for A9923 will be competitively chosen by the TFA. It is likely that funding will not directly be provided to WVDP. The strategy for the A9923 response was discussed with WVDP personnel during a Closure/Immobilization Meeting on March $10^{\text {th }}$ in Las Vegas, Nevada.

(ORNL) The response does not adequately separate the specific tasks and funding for each site. Additional input is needed before comments can be made.

TFA Response: Consistent with TFA policy on new start efforts, the performer for this activity will be selected competitively. Note that the goal of the work is to develop an improved science understanding of grout chemistry. A key contribution to this understanding will be achieved by performing a matrix of surrogate grout tests that are designed to determine the relative importance of various grout additives and sorbents for in-tank stabilization of alkaline and acid wastes. A second key contribution will be comparison testing of several grout formulations (SRS' reducing grout, WVDP's enhanced grout, etc).

(INEEL) Site Technology Coordination Group need ID-2.1.65 Treatment/Disposition of Removed Tank Solids should be removed from Technical Response A9709 and added to Technical Response A9923.

TFA Response: Technical Response A9923 deals with grout formulations for in-tank closure operations. Treating and dissolving of tank solids once removed from a tank is not directly addressed in Technical Response A9923.

\section{4, Tank Closure Criteria/Decision Support}

Combined with Technical Response A9923.

\section{5, Demonstration of Grout Injection Technology for Tank Closure}

(TAG) What are adequate performance requirements?

- $\quad$ ORR has none.

- Grouting of Old Hydrofracture Facility (OHF) tanks is above state requirements; extra assurance.

- What was done with the two grouted tanks in Odessa, Texas?

- $\quad$ With the FY00 work completion, why does TFA provide $\$ 1.1 \mathrm{M}$ for FY01? Does the grout recipe change? Once the Multipoint Injection ${ }^{\mathrm{TM}}\left(\mathrm{MPI}^{\mathrm{TM}}\right)$ technology is demonstrated in a tank - that should be good for all tanks?

TFA Response: ORR and the TFA originally began their investigation of MPI ${ }^{\mathrm{TM}}$ because ORR wanted to close its 20 -foot diameter TH-4 tank without retrieving the residual waste in the tank. The waste was viewed as being more benign than waste in the other GAAT tanks, did not have the access ports to support a Modified Light Duty Utility Arm (MLDUA) retrieval operation, and the tank 
was isolated from the rest of the GAAT tanks. Hence, ORR desired a technology that would thoroughly mix the grout with a few feet of residual waste. They hoped to convince their regulators that this would be an acceptable tank closure approach. Cold testing of MPI ${ }^{\mathrm{TM}}$ for a TH-4 application was performed in December 1997. It demonstrated that MPI ${ }^{\mathrm{TM}}$ would achieve mixing of the waste with grout.

At about this time, the contractor for environmental restoration efforts at ORR changed. The new team, in conjunction with DOE-OR, decided that the most prudent path forward would be to attempt to retrieve the waste from TH-4 prior to closure. A Russian Pulsating Mixer Pump technology will be utilized for this retrieval operation during FY2000. Depending on how successful the retrieval operation is, there may or may not be substantial residuals left in TH-4. If significant residuals remain, ORR has indicated their desire to use MPITM during FY2001 for closing TH-4. This would be a hot deployment demonstration of MPI ${ }^{\mathrm{TM}}$ for a vertical tank and represent the completion of vertical tank activities begun by the TFA in 1997. The reason for deploying MPITM in such a situation would be to present to the state regulators that the residual waste is well mixed with grout.

During FY1999 the TFA cold demonstrated the MPI ${ }^{\mathrm{TM}}$ technology for application to horizontal tanks. This was in response to need statements from both ORR and SRS. Both sites had underground horizontal tanks with small quantities of residual waste. Both sites wanted a grout injection / mixing technology that they could present to their regulators during negotiations on closing the tanks. Ultimately, ORR's regulators declared the OHF tanks to be clean and the' extent to which the residuals are mixed with the grout used to fill the tank is not a performance requirement. ORR has decided to utilize $\mathrm{MPI}^{\mathrm{TM}}$ to ensure that the OHF tank residuals do mix with the grout as the OHF tanks are closed. SRS has not yet completed its negotiations with its regulators. Its goal is to argue that mixing grout with the residuals is acceptable and preferable to attempting to retrieve the residuals.

During the MPI ${ }^{\mathrm{TM}}$ horizontal tank cold demonstration, both ORR and SRS personnel visually watched MPI ${ }^{\mathrm{TM}}$ in-tank mixing on a video display. It was clear that the turbulent mixing produced by the MPI ${ }^{\circledR}$ process would result in a grout, residual mixture. Hence, when the grout set unexpectedly early and the planned core sampling was no longer feasible, that portion of the test plan was not done because attendees at the cold demonstration were already convinced of MPI $^{\mathrm{TM}}$ 's mixing effectiveness. As part of the MPI ${ }^{\mathrm{TM}}$ purchasing agreement for the cold demonstration, disposal of the filled tanks became the responsibility of the Odessa Company supporting the cold demonstration. ORR does plan on retrieving core samples from its OHF hot deployment so that the mixing effectiveness can be better evaluated.

Upon completion of the FY2000 hot deployment of MPI ${ }^{\mathrm{TM}}$ for the ORR OHF tanks, horizontaltank hot deployments will have been demonstrated for tanks with reasonable size access risers. The FY2001 hot deployment at SRS will show that horizontal tanks with small 4-inch limited risers can be closed with MPI ${ }^{\mathrm{TM}}$. The FY01 hot deployment at ORR on TH-4 will show that vertical tank closures can be accomplished. 
(WVDP) WVDP does not plan to participate in this technical response. No funding for the WVDP is necessary here.

TFA Response: The funding mentioned in A9985 is for hot deployments of MPI ${ }^{\mathrm{TM}}$ at ORR and at SRS.

(ORNL) The technical response does not adequately separate the specific tasks and funding for each site. Additional input is needed before comments can be made. Based on FY2000 activities at the OHF, the budget for this response appears to be too low. ORR will require $\$ 750-950 \mathrm{~K}$ to complete the task at TH-4.

TFA Response: The MYTR FY01 budget estimate for the TH-4 MPI ${ }^{\mathrm{TM}}$ demonstration effort was increased to $\$ 750 \mathrm{~K}$.

(ORNL) Regulatory approval for use of this technology on TH-4 will be required after sludge retrieval using the Russian Pulsating Mixer Pump is completed.

TFA Response: The TFA agrees that hot deployments do require regulatory approval before implementation.

\section{ADDITIONAL TAG COMMENTS}

- Time for DOE to inform shareholders that DOE sites will not be returned to greenfield condition. Can TFA prepare some statement that would provide the magnitude of costs to return a DOE site to greenfield conditions?

- Every technology that TFA works with should include a lifecycle cost analysis. 


\section{Appendix D}

Action Tracking 


\section{Appendix D}

\section{Action Tracking}

\begin{tabular}{|c|l|c|c|}
\hline $\begin{array}{c}\text { IECHNICAL } \\
\text { RESPONSE }\end{array}$ & ACTION & ASSICNED TO & STATUS \\
\hline 99046 & $\begin{array}{l}\text { Check on status of funding for Fluidic } \\
\text { Sampler }\end{array}$ & J. Cruz & In progress \\
\hline 99067 & $\begin{array}{l}\text { Investigate discrepancy in funding for } \\
\text { WVDP AWRS }(\$ 4.75 \text { funding came in as } \\
\text { opposed to \$600) }\end{array}$ & Technical Team & Complete \\
\hline 99068 & Review melter task with K. Picha & B. Holtzscheiter & Complete \\
\hline 99076 & $\begin{array}{l}\text { Determine impact of delay in Pipeline } \\
\text { Unplugging procurement }\end{array}$ & Technical Team & Complete \\
\hline 99085 & $\begin{array}{l}\text { Find out how small an opening could be } \\
\text { used with MPI }- \text { get back to J. Roach }\end{array}$ & L. Bustard & In progress \\
\hline
\end{tabular}

D. 1 


\section{E Level 1 Heading}

THIS PAGE CONTAINS A LEVEL 1 HEADING WHICH ACTIVATES THE APPENDIX LETTER IN THE PAGE NUMBER. THE HEADING 1 STYLE MUST BE MODIFIED IN ORDER TO CHANGE THE APPENDIX LETTER.

PLEASE RECYCLE THIS PAGE. 
Appendix E

Project Checklists/Maturity Evidence 


\section{Project Maturity Status Determination}

Title: 99043 Hanford EN Corrosion Probe

\section{Tech ID: 1985 Corrosion Probe}

Stage: Demonstration Last Gate:

$5^{1}$

\begin{tabular}{|c|c|c|c|c|c|c|c|}
\hline $\begin{array}{l}\text { MATURITY } \\
\text { STAGE }\end{array}$ & $\begin{array}{c}\text { TECHNICAL } \\
\text { NEED }\end{array}$ & $\begin{array}{c}\text { END-USER } \\
\text { INVOLVEMENT }\end{array}$ & $\begin{array}{l}\text { TECHNICAL } \\
\text { MERIT }\end{array}$ & COST & ES\&H RISK & $\begin{array}{l}\text { STAKEHOLDER, } \\
\text { REGULATORY, } \\
\text { TRIBAL ISSUES }\end{array}$ & $\begin{array}{l}\text { COMMERCIAL } \\
\text { VIABILITY }\end{array}$ \\
\hline Demonstration & $\begin{array}{l}\text { Need still } \\
\text { exists }\end{array}$ & $\begin{array}{l}\text { Demonstration } \\
\text { cost-sharing }\end{array}$ & $\begin{array}{l}\text { Demonstration } \\
\text { plan } \\
\text { Favorable peer } \\
\text { review }\end{array}$ & $\begin{array}{l}\text { Demonstration } \\
\text { plan } \\
\text { Favorable peer } \\
\text { review }\end{array}$ & $\begin{array}{l}\text { Demonstration } \\
\text { plan } \\
\text { Favorable } \\
\text { peer review }\end{array}$ & $\begin{array}{l}\text { Demonstration } \\
\text { permits completed }\end{array}$ & $\begin{array}{l}\text { Vendor } \\
\text { participates in } \\
\text { demonstration }\end{array}$ \\
\hline
\end{tabular}

Indicates criterion is satisfied

$\square$ Indicates criterion/evidence is not yet satisfied

"N/A" Indicates criterion is not applicable or satisfied by other means; justification provided in evidence table

Date:

TFA Technology Delivery Manager:

\footnotetext{
${ }^{1}$ Although several corrosion probe designs have been tested in-tank at Hanford, the work in FY00 is focused on installing an integrated corrosion monitoring station, which has not yet been deployed. Therefore, the project is still in viewed as in the demonstration phase until the final probe design is completed and deployed along with the monitoring station.
} 


\section{Evidence Demonstrating Entrance Requirements are Met}

\section{Title: Hanford EN Corrosion Probe}

\section{Stage: Demonstration}

\section{Technical Need/Site Need ID(s):}

RL-WT04 DST Corrosion Monitoring

\section{End User Involvement:}

$\checkmark$ User approved MYTR 99043

$\checkmark$ User accepted technology and deployed at Hanford; ASTD Project 99-ASTD-38

$\checkmark$ Hanford has established a technology insertion point in the MYWP for this technology

$\checkmark$ User cofunding per TFA IPL; document reference below:

Letter TPP/99-STP-440 DOE-RL Robert M. Rosselli, Assistance Manager for Science and Technology to Richard T. French, Manager Office of River Protection "Fiscal Year (FY) 2000 Tanks Focus Area (TFA) Support to the Office of River Protection (ORP) dated October 5,1999

\section{Technical Merit:}

$\checkmark$ ASME Peer Review conducted in June 1998, which is documented Institute for Regulatory Science CRTD-Vol. 50

$\checkmark$ Hanford Site and TFA are planning technical review in early FY01 to support moving to operational baseline status; TFA and Hanford engineering/operations staff and subject matter experts on corrosion detection, monitoring and applicable codes and regulations.

$\checkmark \quad$ ASME Peer Review Exemption: Project was previously peer reviewed by ASME and has been accepted by site end user. Work is focused on finalizing operational aspects and validating method as baseline for corrosion monitoring.

$\checkmark$ Technical and operational requirements and procedures for deployment of the technology are documented in Hanford Work Packages 2E-99-01934 " Excavation and Conduit Installation for 241-AN-105 Corrosion Probe" and 2E-99-01014 "Install Corrosion Probe into Tank 241-AN-105". 
Cost:

$\checkmark$ Documented under ASTD Project 99-ASTD-38 for Hanford application

$\checkmark$ Innovative Technology Summary Report DOE/EM-0430 "Corrosion Probe" May 1999

$\checkmark$ Cost analysis prepared by Vista Research, Inc. "Cost of Corrosion at Department of Energy Radioactive Waste Tank Sites" dated September 29, 1997

\section{ES\&H Risk:}

$\checkmark$ Satisfactorily addressed; technology approved for deployment at site.

$\checkmark$ Innovative Technology Summary Report DOE/EM-0430 "Corrosion Probe" May 1999

\section{Stakeholder, Regulatory, Tribal Issues:}

$\checkmark$ Satisfactorily addressed; technology approved for deployment at site.

$\checkmark$ WA-DOE and stakeholders have been briefed on the technology (through Hanford STCG presentation); no issues were identified.

\section{Commercial Viability:}

$\checkmark$ HiLine Engineering \& Fabrication, Inc. is the commercial partner supplying the system equipment and supporting site deployment.

$\checkmark$ System uses commercially available hardware and software for data collection and analysis.

$\checkmark$ There are no intellectual property issues. 


\section{Status Questions for Progress Reviews:}

\section{Title: Hanford EN Corrosion Probe}

\section{Stage: _Demonstration}

1) Has the project been reviewed for advancement through a gate during the past year? No.

2) Has an end user made at least a conditional commitment to implement the technology? User has deployed technology and is supporting process to implement this as the site baseline for corrosion monitoring.

3) Has a technical peer review been completed and is the work highly rated? Yes in FY98 (see above).

4) Has a cost-benefit analysis been performed for this technology and does it show potential savings compared to the baseline? Are user requirements for cost data identified and satisfied? Yes (see above).

5) Will this technology meet or exceed current environmental, safety, health, (ES\&H) protection levels and/or reduce the risk to the public, workers, and the environment compared to the baseline? Yes. Are user requirements for ES\&H and technological risk identified and satisfied? Yes, documented in ITSR (see above).

6) Briefly discuss any activities and/or interactions with stakeholders, regulators, and tribal organizations relative to the continued research and utilization of this technology. Are user requirements for stakeholder, regulator, and tribal concerns identified and satisfied?

Washington Dept. of Ecology has been briefed and is familiar with the technology and Hanford's deployment of the prototype systems. Hanford STCG sponsored a briefing on the technology that included participants from stakeholders and regulators.

7) Have invention disclosure and intellectual property issues been addressed? None have been identified. Briefly discuss the measures taken to include private industry in development and application of the technology. Industry is manufacturing and participating in deployment of technology.

8) Has an appropriate vendor (or other provider) for this technology been identified? Yes. (see above) 


\section{Project Maturity Status Determination}

Title: 99043 SRS EN/EIC Corrosion Probe

Tech ID: 1985 Corrosion Probe; 2015 Raman Sensor for Tank Corrosion Chemistry Stage: Entering Demonstration FY00

Last Gate: 4

\begin{tabular}{|c|c|c|c|c|c|c|c|}
\hline $\begin{array}{l}\text { MATURITY } \\
\text { STAGE }\end{array}$ & $\begin{array}{l}\text { TECHNICAL } \\
\text { NEED }\end{array}$ & $\begin{array}{c}\text { END-USER } \\
\text { INVOLVEMENT }\end{array}$ & $\begin{array}{l}\text { TECHNICAL } \\
\text { MERIT }\end{array}$ & COST & ES\&H RISK & $\begin{array}{l}\text { STAKEHOLDER, } \\
\text { REGULATORY, } \\
\text { TRIBAL ISSUES }\end{array}$ & $\begin{array}{l}\text { COMMERCIAL } \\
\text { VIABILITY }\end{array}$ \\
\hline Development & $\begin{array}{l}\text { Need still } \\
\text { exists }\end{array}$ & $\begin{array}{l}\text { Addresses } \\
\text { performance } \\
\text { requirements } \\
\text { Available when } \\
\text { needed }\end{array}$ & $\begin{array}{l}\text { Improved } \\
\text { solution (enabling or } \\
\text { significantly more } \\
\text { effective) } \\
\text { Favorable peer } \\
\text { review rating }\end{array}$ & $\begin{array}{l}\text { Improved } \\
\text { solution (enabling or } \\
\text { significantly less } \\
\text { costly) } \\
\square \text { Demonstration } \\
\text { and operating } \\
\text { costs estimated }\end{array}$ & $\begin{array}{l}\text { Improved } \\
\text { solution (enabling } \\
\text { or sigifificantly lower } \\
\text { risk) } \\
\text { Favorable } \\
\text { peer review } \\
\text { rating }\end{array}$ & $\begin{array}{l}\text { Peer review finds } \\
\text { data valid for use } \\
\text { with regulators and } \\
\text { stakeholders }\end{array}$ & $\begin{array}{l}\text { Potential } \\
\text { vendor identified }\end{array}$ \\
\hline
\end{tabular}

Indicates criterion is satisfied

$\square$ Indicates criterion/evidence is not yet satisfied

"N/A" Indicates criterion is not applicable or satisfied by other means; justification provided in evidence table

Date:

TFA Technology Delivery Manager: 


\section{Evidence Demonstrating Entrance Requirements are Met}

Title: 99043 SRS EN/EIC Corrosion Probe

Technical Need/Site Need ID(s):

SR99-2045 In-Situ Waste Tank Corrosion Probe

\section{End User Involvement:}

$\checkmark$ User approved MYTR 99043

$\checkmark$ User preparing for deployment of technology in FY00/01

$\checkmark$ User cofunding per TFA IPL; document reference below:

Letter TPP/99-STP-440 DOE-RL Robert M. Rosselli, Assistance Manager for Science and Technology to R. J. Schepens, Assistant Manager for High-Level Waste DOE-SR "Fiscal Year (FY) 2000 Tanks Focus Area (TFA) Support to the Savannah River Operations Office (SR) High-Level Waste Program” dated October 5, 1999

Technical Merit:

$\checkmark$ ASME Review of Raman 10/96 - Proposal Review

$\checkmark$ ASME Peer Review 9/98 of Raman technology in development stage

$\checkmark$ ASME Peer Review FY98 on EN corrosion probe

$\checkmark$ No additional ASME reviews are deemed necessary as site end user is making deployment decision in FY00.

$\checkmark$ TFA Gate 5 Review planned for FY00 (tentative for July)

$\checkmark$ Test report in progress on hot cell testing of Raman probe; TTP milestone A.1-1 due end of April (SR09WT41)

$\checkmark$ Test acceptance criteria for acceptance of the system from EIC is currently being developed; site PI has defined 12 test steps that must be addressed to show the technology meets requirements; a cold test plan will be issued by SRS (est. complete by 7/00)

$\checkmark$ Technical requirements defined in U-PMT-H-044484 "Task Requirements \& Criteria - Install Corrosion Probe on Tank 43 Riser H" by Terry Phillips (SRS) dated 7/27/99 
Cost:

$\checkmark$ Related Hanford cost benefit documented under ASTD Project 99-ASTD-38

$\checkmark$ Innovative Technology Summary Report DOE/EM-0430 "Corrosion Probe" May 1999

$\checkmark$ Cost analysis prepared by Vista Research, Inc. "Cost of Corrosion at Department of Energy Radioactive Waste Tank Sites" dated September 29, 1997

\section{ES\&H Risk:}

$\checkmark$ Will be addressed as part of the design review process; SRS will document design reviews

$\checkmark$ Reference: U-PMT-H-044484 “Task Requirements \& Criteria - Install Corrosion Probe on Tank 43 Riser H” by Terry Phillips (SRS) dated 7/27/99

\section{Stakeholder, Regulatory, Tribal Issues:}

$\checkmark$ Reference: U-PMT-H-044484 “Task Requirements \& Criteria - Install Corrosion Probe on Tank 43 Riser H” by Terry Phillips (SRS) dated $7 / 27 / 99$

\section{Commercial Viability:}

$\checkmark$ Two commercial vendors, EIC Laboratories and HiLine Engineering and Fabrication, Inc., are under contract to design and build the probe technology. Adriel Brothers is subcontracted by EIC to fabricate the deployment platform.

$\checkmark$ HiLine Engineering and Fabrication, Inc. is also the vendor performing work on the Hanford EN corrosion probe and is providing technology transfer of expertise to assist SRS. 


\section{Status Questions for Progress Reviews:}

\section{Title: 99043 SRS EN/EIC Corrosion Probe}

\section{Stage: ____ Development}

1) Has the project been reviewed for advancement through a gate during the past year? No. Gate 5 review planned for FY00.

2) Has an end user made at least a conditional commitment to implement the technology? Yes. SRS planning for deployment of technology in HLW tank 43 in FYO1.

3) Has a technical peer review been completed and is the work highly rated? Yes. Peer reviews on both Raman and EN technologies have been performed in FY96 and FY98.

4) Has a cost-benefit analysis been performed for this technology and does it show potential savings compared to the baseline? Cost analysis for corrosion monitoring for DOE tanks has been done. Hanford Waste Minimization ASTD project also documented cost data in proposal (see above). Are user requirements for cost data identified and satisfied? Will be evaluated as part of gate review.

5) Will this technology meet or exceed current environmental, safety, health, (ES\&H) protection levels and/or reduce the risk to the public, workers, and the environment compared to the baseline? This will be evaluated as part of gate review, no issues have been identified. Are user requirements for ES\&H and technological risk identified and satisfied? See reference above.

6) Briefly discuss any activities and/or interactions with stakeholders, regulators, and tribal organizations relative to the continued research and utilization of this technology. Are user requirements for stakeholder, regulator, and tribal concerns identified and satisfied? Will be determined as part of the gate review preparations. Interaction with these organizations is the responsibility of SRS and is not part of the TFA funded workscope. SRS will address this as part of the preparations for deployment. There are no known issues at this time.

7) Have invention disclosure and intellectual property issues been addressed? Yes, as part of the vendor contracts. Briefly discuss the measures taken to include private industry in development and application of the technology. Several vendors are participating in the development (see above). 
8) Has an appropriate vendor (or other provider) for this technology been identified? Yes. EIC/Highline Engineering and Fabrication Inc. are designing and fabricating the probe. Adriel Brothers providing deployment platform. SRS will provide some components in-house. 


\section{Project Maturity Status Determination}

Title: 99043 ORNL Tank Corrosion Monitor

\section{Tech ID: 1985 Corrosion Probe}

\section{Stage: Development}

Last Gate: 3

\begin{tabular}{|c|c|c|c|c|c|c|c|}
\hline $\begin{array}{l}\text { MATURITY } \\
\text { STAGE }\end{array}$ & $\begin{array}{c}\text { TECHNICAL } \\
\text { NEED }\end{array}$ & $\begin{array}{c}\text { END-USER } \\
\text { INVOLVEMENT }\end{array}$ & $\begin{array}{l}\text { TECHNICAL } \\
\text { MERIT }\end{array}$ & COST & ES\&H RISK & $\begin{array}{l}\text { STAKEHOLDER, } \\
\text { REGULATORY, } \\
\text { TRIBAL ISSUES }\end{array}$ & $\begin{array}{l}\text { COMMERCIAL } \\
\text { VIABILITY }\end{array}$ \\
\hline Development & $\begin{array}{l}\text { Need still } \\
\text { exists }\end{array}$ & $\begin{array}{l}\text { Addresses } \\
\text { performance } \\
\text { requirements } \\
\text { Available when } \\
\text { needed }\end{array}$ & $\begin{array}{l}\text { Improved } \\
\text { solution (enabling or } \\
\text { significantly more } \\
\text { effective) } \\
\text { Favorable peer } \\
\text { review rating }\end{array}$ & $\begin{array}{l}\text { Improved } \\
\text { solution (enabling or } \\
\text { significantly less } \\
\text { costly) } \\
\square \text { Demonstration } \\
\text { and operating } \\
\text { costs estimated }\end{array}$ & $\begin{array}{l}\text { Improved } \\
\text { solution (enabling } \\
\text { or significantly lower } \\
\text { risk) } \\
\text { Favorable } \\
\text { peer review } \\
\text { rating }\end{array}$ & $\begin{array}{l}\text { Peer review finds } \\
\text { data valid for use } \\
\text { with regulators and } \\
\text { stakeholders }\end{array}$ & $\begin{array}{l}\text { Potential } \\
\text { vendor identified }\end{array}$ \\
\hline
\end{tabular}

Indicates criterion is satisfied

$\square$ Indicates criterion/evidence is not yet satisfied

"N/A" Indicates criterion is not applicable or satisfied by other means; justification provided in evidence table

Date:

TFA Technology Delivery Manager: 


\section{Evidence Demonstrating Entrance Requirements are Met}

Title: ORNL Corrosion Monitor

\section{Technical Need/Site Need ID(s):}

OR-TK-01 Tank Waste Characterization

\section{End User Involvement:}

$\checkmark$ User approved MYTR 99043

$\checkmark$ User has provided functional requirements to guide development Letter J.W. Goskowicz, Bechtel Jacobs to J. Noble-Dial, DOE-ORO "Functions and Requirements for a Stainless Steel Waste Tank Corrosion Monitoring System at ORNL" dated January 4, 2000.

$\checkmark$ User planning to deploy at Melton Valley Capacity Increase Tanks (MVCIT), if technology proves feasible

$\checkmark$ User not currently co-funding project

\section{Technical Merit:}

$\checkmark$ ASME Peer Review conducted in June 1998 on EN technology; documented in Institute for Regulatory Science CRTD-Vol. 50

$\checkmark$ TFA investigating expanding technology application for stainless steel materials; may be candidate for future peer review

$\checkmark$ Technical requirements documented in E\&CS-00-0927 "Functions and Requirements for a Stainless Steel Waste Tank Corrosion Monitoring System at Oak Ridge National Laboratory" January 4, 2000 (Bechtel Jacobs)

\section{Cost:}

$\checkmark$ Documented under ASTD Project 99-ASTD-38 for Hanford application of EN technology

$\checkmark$ Innovative Technology Summary Report DOE/EM-0430 "Corrosion Probe" May 1999

$\checkmark$ Cost analysis prepared by Vista Research, Inc. "Cost of Corrosion at Department of Energy Radioactive Waste Tank Sites" dated September 29, 1997

\section{ES\&H Risk:}

$\checkmark$ Site established ES\&H requirements are provided in functions and requirements (See above reference) 
Stakeholder, Regulatory, Tribal Issues:

$\checkmark$ None known at this time. Site will evaluate issues as part of decision on applying this technology at MVCIT facility.

Commercial Viability:

$\checkmark$ HiLine Engineering \& Fabrication, Inc. is the commercial partner for Hanford, SRS and now supporting ORNL in developing an ENbased technology for stainless steel tanks. 


\section{Status Questions for Progress Reviews:}

\section{Title: ORNL Corrosion Monitor}

\section{Stage: _Development}

1) Has the project been reviewed for advancement through a gate during the past year? No, project just started in FY00 as an extension of prior work for Hanford and SRS.

2) Has an end user made at least a conditional commitment to implement the technology? Yes. ORNL evaluating feasibility of deploying technology at MVCIT.

3) Has a technical peer review been completed and is the work highly rated? Yes. EN technology reviewed by ASME 6/98.

4) Has a cost-benefit analysis been performed for this technology and does it show potential savings compared to the baseline? No specific data from ORNL has been developed, as this project is just starting in FYO0. See reference to other cost data above. Are user requirements for cost data identified and satisfied? Yes, for Hanford application.

5) Will this technology meet or exceed current environmental, safety, health, (ES\&H) protection levels and/or reduce the risk to the public, workers, and the environment compared to the baseline? Yes, it is expected to meet or exceed current levels. As tanks are stainless steel, corrosion monitoring is considered an enhancement to ensure tank protection. Are user requirements for ES\&H and technological risk identified and satisfied? Will be determined as part of site evaluation of technology. Design-related requirements are specified in $F \& R$ document, it is too early to determine outcome.

6) Briefly discuss any activities and/or interactions with stakeholders, regulators, and tribal organizations relative to the continued research and utilization of this technology. Are user requirements for stakeholder, regulator, and tribal concerns identified and satisfied? None to date. ORNL will address these issues as part of decision for deployment at MVCIT.

7) Have invention disclosure and intellectual property issues been addressed? Yes, for baseline EN technology these issues were addressed as part of contract development. None expected for modifications. Briefly discuss the measures taken to include private industry in development and application of the technology. Commercial supplier is under contract and supporting ORNL. 
8) Has an appropriate vendor (or other provider) for this technology been identified? Yes. HiLine Engineering \& Fabrication, Inc. is the commercial partner supporting Hanford, SRS, and ORNL in development of EN probe 


\section{Project Maturity Status Determination}

Title: 99046 Hanford/INEEL Fluidic Sampler Tech ID: 2119 Nested, Fixed-depth Fluidic Sampler ${ }^{1}$ Stage: Development Last Gate: 3

\begin{tabular}{|c|c|c|c|c|c|c|c|}
\hline $\begin{array}{c}\text { MATURITY } \\
\text { STAGE }\end{array}$ & $\begin{array}{l}\text { TECHNICAL } \\
\text { NEED }\end{array}$ & $\begin{array}{c}\text { END-USER } \\
\text { INVOLVEMENT }\end{array}$ & $\begin{array}{l}\text { TECHNICAL } \\
\text { MERIT }\end{array}$ & COST & ES\&H RISK & $\begin{array}{l}\text { STAKEHOLDER, } \\
\text { REGULATORY, } \\
\text { TRIBAL ISSUES }\end{array}$ & $\begin{array}{c}\text { COMMERCIAL } \\
\text { VIABLITY }\end{array}$ \\
\hline Development & $\begin{array}{l}\text { Need still } \\
\text { exists }\end{array}$ & $\begin{array}{l}\text { Addresses } \\
\text { performance } \\
\text { requirements } \\
\text { Available when } \\
\text { needed }\end{array}$ & $\begin{array}{l}\text { Improved } \\
\text { solution (enabling or } \\
\text { significantly more } \\
\text { effective) } \\
\square \text { Favorable peer } \\
\text { review rating }\end{array}$ & $\begin{array}{l}\text { Improved } \\
\text { solution (enabling or } \\
\text { significantly less } \\
\text { costly) } \\
\square \text { Demonstration } \\
\text { and operating } \\
\text { costs estimated }\end{array}$ & $\begin{array}{l}\text { Improved } \\
\text { solution (enabling } \\
\text { or significantly lower } \\
\text { risk) } \\
\square \text { Favorable } \\
\text { peer review } \\
\text { rating }\end{array}$ & $\begin{array}{l}\square \text { Peer review finds } \\
\text { data valid for use } \\
\text { with regulators and } \\
\text { stakeholders }\end{array}$ & $\begin{array}{l}\text { Potential } \\
\text { vendor identified }\end{array}$ \\
\hline
\end{tabular}

Indicates criterion is satisfied

$\square$ Indicates criterion/evidence is not yet satisfied

"N/A" Indicates criterion is not applicable or satisfied by other means; justification provided in evidence table

Date: $\quad$ TFA Technology Delivery Manager:

\footnotetext{
${ }^{1}$ Need to revise TMS ID name to be consistent with revised system concept.
} 


\section{Evidence Demonstrating Entrance Requirements are Met}

\section{Title: 99046 Hanford/INEEL Fluidic Sampler}

\section{Stage:__Development}

\section{Technical Need/Site Need ID(s):}

ID-2.1.26 Nested Array Fluidic Sampler for Tank Solution

ID-2.1.43 Certify LDUA Sampler as EPA-Approved Method of Sampling

ID-2.1.44 Certify LDUA Sampler as EPA-Approved Method of Sampling

RL-WT09 Representative Sampling and Associated Analysis to Support

\section{End User Involvement:}

$\checkmark$ User approved MYTR 99046

$\checkmark$. User developing functions \& requirements and component specifications

$\checkmark$ HNF-2906 Nested Fixed-Depth Fluidic Sampler and At-Tank Analysis System Deployment Strategy and Plan Rv $12 / 00$

$\checkmark$ User cofunding per TFA IPL; reference document below

Letter TPP/99-STP-440 DOE-RL Robert M. Rosselli, Assistance Manager for Science and Technology to J.T. Case, Program Director Idaho Operations Office "Fiscal Year (FY) 2000 Tanks Focus Area (TFA) Support to the Idaho Operations Office (ID) High-Level Waste Program" dated October 5, 1999

\section{Technical Merit:}

$\checkmark$ No ASME Peer Review has been conducted; candidate for FY01 technical peer review

$\checkmark$ TFA may recommend technical project review in FY00 to support decision to proceed

$\checkmark$ User Technical Requirements provided in documents below:

$\checkmark \quad$ HNF-3024 Test Plan for Evaluating the Operational Performance of the Prototype Nested, Fixed-Depth Fluidic Sampler 12/99

$\checkmark \quad$ HNF-3483 Rv 1 Preliminary Level 2 Specification for Nested, Fixed-Depth Sampling System 5/99

$\checkmark \quad$ HNF-3864 Nested Fixed-Depth Fluidic Sampler Supplementary Testing - AEAT Doc 2926-2-002 3/99

\section{E.16}


$\checkmark \quad$ HNF-4545 Alternative Generation and Analysis Study for a Waste Sample Container-Filling System for Nested, Fixed-Depth Sampling System 7/99

$\checkmark \quad$ HNF-4883 "Phase II Test Plan for the Evaluation of the Performance of Container Filling Systems 9/99

$\checkmark \quad$ HNF-4404 Design Compliance Matrix Waste Sampler Container Filling System for Nested, Fixed-Depth Sampling System $9 / 99$

$\checkmark$ AEAT TFA/PF/17V1 Report on the Nested Fixed-Depth Sampler Tests and Conceptual Design 10/98

$\checkmark$ AEAT TFA/PF/17 V1 Design, Fabrication, and Demonstration of a Nested Fixed-Depth Fluidic Sampler 12/98

$\checkmark$ AEAT TFA/PF/28 V1 Test Implementation Plan for Evaluating the Performance of the Prototype Nested Fixed-Depth Fluidic Sampler $12 / 99$

$\checkmark$ ITSR Innovative Technology Summary Report for AEA Fluidic Sampler (2007) 7/99

$\checkmark$ AEAT TFA/PF/28V1 Phase II Implementation Plan for Evaluation of Performance of the Container Filling Systems 9/99

Cost:

$\checkmark$ A cost estimate will be developed as part of the conceptual design package

$\checkmark$ This technology is an improvement over baseline technology; need to further evaluate cost as part of TFA review

$\checkmark$ HNF-2906 Nested Fixed-Depth Fluidic Sampler and Analysis System - Deployment Strategy and Plan 7/98

$\checkmark$ HNF-2056 Engineering Task Plan for Development, Fabrication, and Deployment of the Nested, Fixed-Depth Fluidic Sampling System and At-Tank Analysis Systems $1 / 99$

\section{ES\&H Risk:}

$\checkmark$ Need to evaluate these issues as part of TFA review

$\checkmark$ ES\&H issues are identified in user component specification documentation; draft document available

$\checkmark$ HNF-3483 Rv 1 Preliminary Level 2 Specification for Nested, Fixed-Depth Sampling System 5/99

\section{Stakeholder, Regulatory, Tribal Issues:}

$\checkmark$ There are no known issues

\section{Commercial Viability:}

$\checkmark$ AEA Technology is developing the fluidic sampler for this project based on proprietary technology developed 


\section{Status Questions for Progress Reviews:}

\section{Title: 99046 Hanford/INEEL Fluidic Sampler}

\section{Stage: _Development}

1) Has the project been reviewed for advancement through a gate during the past year? No.

2) Has an end user made at least a conditional commitment to implement the technology? No. A decision to proceed is expected after completion of concept design.

3) Has a technical peer review been completed and is the work highly rated? No technical peer review has been conducted.

4) Has a cost-benefit analysis been performed for this technology and does it show potential savings compared to the baseline? Are user requirements for cost data identified and satisfied? See above

5) Will this technology meet or exceed current environmental, safety, health, (ES\&H) protection levels and/or reduce the risk to the public, workers, and the environment compared to the baseline? Needs to be addressed as part of design. RCRA compliance testing is underway. Are user requirements for ES\&H and technological risk identified and satisfied? Some information available in user requirements documents. See above.

6) Briefly discuss any activities and/or interactions with stakeholders, regulators, and tribal organizations relative to the continued research and utilization of this technology. Are user requirements for stakeholder, regulator, and tribal concerns identified and satisfied? This is a site responsibility.

7) Have invention disclosure and intellectual property issues been addressed? AEAT fluidic technology is proprietary. Intellectual property issues are being addressed by managing distribution of materials. Issues will be addressed as part of contract with AEAT. Briefly discuss the measures taken to include private industry in development and application of the technology. AEAT is under contract to DOE to provide the fluidic technology to support this project.

8) Has an appropriate vendor (or other provider) for this technology been identified? Yes. 


\section{Project Maturity Status Determination}

Title: 99052 Hanford Pit Operations Enhancements

Tech ID:2195 Tank Riser Pit Decontamination System; 2181 Equipment Pit D\&D System

\section{Stage: Development Last Gate:} 3

\begin{tabular}{|c|c|c|c|c|c|c|c|}
\hline $\begin{array}{l}\text { MATURITY } \\
\text { STAGE }\end{array}$ & $\begin{array}{l}\text { TECHNICAL } \\
\text { NEED }\end{array}$ & $\begin{array}{c}\text { END-USER } \\
\text { INVOLVEMENT }\end{array}$ & $\begin{array}{l}\text { TECHNICAL } \\
\text { MERIT }\end{array}$ & $\cos T$ & ES\&H RISK & $\begin{array}{l}\text { STAKEHOLDER, } \\
\text { REGULATORY, } \\
\text { TRIBAL ISSUES }\end{array}$ & $\begin{array}{l}\text { COMMERCIAL } \\
\text { VIABILITY }\end{array}$ \\
\hline Development & $\begin{array}{l}\text { Need still } \\
\text { exists }\end{array}$ & $\begin{array}{l}\text { Addresses } \\
\text { performance } \\
\text { requirements } \\
\text { Available when } \\
\text { needed }\end{array}$ & $\begin{array}{l}\text { Improved } \\
\text { solution (enabling } \\
\text { or significantly } \\
\text { more effective) } \\
\\
\text { Favorable peer } \\
\text { review rating }\end{array}$ & $\begin{array}{l}\text { Improved } \\
\text { solution (enabling } \\
\text { or significantly } \\
\text { less costly) } \\
\text { Demonstration } \\
\text { and operating } \\
\text { costs estimated }\end{array}$ & $\begin{array}{l}\text { Improved } \\
\text { solution } \\
\text { (enabling or } \\
\text { significantly } \\
\text { lower risk) } \\
\text { Favorable peer } \\
\text { review rating }\end{array}$ & $\begin{array}{l}\text { Peer review finds } \\
\text { data valid for use } \\
\text { with regulators and } \\
\text { stakeholders }\end{array}$ & $\begin{array}{l}\text { Potential } \\
\text { vendor identified }\end{array}$ \\
\hline
\end{tabular}

Indicates criterion is satisfied

$\square$ Indicates criterion/evidence is not yet satisfied

"N/A" Indicates criterion is not applicable or satisfied by other means; justification provided in evidence table

Date:

TFA Technology Delivery Manager: 


\section{Evidence Demonstrating Entrance Requirements are Met}

\section{Title: 99052 Hanford Pit Operations Enhancements}

\section{Technical Need/Site Need ID(s):}

RL-WT021 Cleaning, Decontaminating and Upgrading Hanford Pits

\section{End User Involvement:}

$\checkmark$ User Approved MYTR 99052

$\checkmark$ User cofunding per TFA IPL; document references below:

Letter TPP/99-STP-440 DOE-RL Robert M. Rosselli, Assistance Manager for Science and Technology to R. J. Schepens, Assistant Manager for High-Level Waste DOE-SR "Fiscal Year (FY) 2000 Tanks Focus Area (TFA) Support to the Savannah River Operations Office (SR) High-Level Waste Program" dated October 5, 1999

Letter TPP/99-STP-440 DOE-RL Robert M. Rosselli, Assistance Manager for Science and Technology to Richard T. French, Manager Office of River Protection "Fiscal Year (FY) 2000 Tanks Focus Area (TFA) Support to the Office of River Protection (ORP) dated October 5,1999

$\checkmark$ Hanford ORP and RPP have signed a Memorandum of Understanding with TFA documenting commitment to deploy system to support project W314.

Technical Merit:

$\checkmark$ Report ASME/CRTD-RP-99-25, Technical Peer Review Report, Report of the Review Panel, Remote Equipment Pit Operations, August 10-13, 1999, Columbia, Maryland.

Cost:

$\checkmark \quad$ A cost analysis has not yet been prepared 


\section{ES\&H Risk:}

$\checkmark$ This technology is an alternative to the baseline operations capability, which is a significant source of exposure to tank farm workers; technology represents a significant improvement to safety and health over the baseline

\section{Stakeholder, Regulatory, Tribal Issues:}

$\checkmark$ None have been identified at this time.

\section{Commercial Viability:}

$\checkmark$ The project plans to competitively procure a remote technology against a specification developed by RPP and PNNL; a vendor has not yet been selected. 


\section{Status Questions for Progress Reviews:}

\section{Title: 99052 Hanford Pit Operations Enhancements}

\section{Stage: ___ Development}

1) Has the project been reviewed for advancement through a gate during the past year? No.

2) Has an end user made at least a conditional commitment to implement the technology? Yes. Hanford ORP/RPP signed an MOU with TFA committing to deployment of system.

3) Has a technical peer review been completed and is the work highly rated? Yes. A new project review was conducted by ASME in FY99.

4) Has a cost-benefit analysis been performed for this technology and does it show potential savings compared to the baseline? No. Are user requirements for cost data identified and satisfied? No.

5) Will this technology meet or exceed current environmental, safety, health, (ES\&H) protection levels and/or reduce the risk to the public, workers, and the environment compared to the baseline? Yes. Are user requirements for ES\&H and technological risk identified and satisfied? Requirements will be defined in specifications developed in FY0O.

6) Briefly discuss any activities and/or interactions with stakeholders, regulators, and tribal organizations relative to the continued research and utilization of this technology. Are user requirements for stakeholder, regulator, and tribal concerns identified and satisfied? Has not yet been determined. This technology represents an improvement over the baseline.

7) Have invention disclosure and intellectual property issues been addressed? None have been identified. A technology has not yet been selected. Briefly discuss the measures taken to include private industry in development and application of the technology. $A$ competitive procurement will be conducted to acquire the specified technology.

8) Has an appropriate vendor (or other provider) for this technology been identified? Not yet. A contract is expected to be placed in FY00. 


\section{Project Maturity Status Determination}

Title: 99067 Hanford SST Retrieval

Tech ID: 2117 Enhanced Sluicing; 2012 Vehicle-based Waste Retrieval

Stage: Development Last Gate: 3

\begin{tabular}{|c|c|c|c|c|c|c|c|}
\hline $\begin{array}{l}\text { MATURITY } \\
\text { STAGE }\end{array}$ & $\begin{array}{c}\text { TECHNICAL } \\
\text { NEED }\end{array}$ & $\begin{array}{c}\text { END-USER } \\
\text { INVOLVEMENT }\end{array}$ & $\begin{array}{l}\text { TECHNICAL } \\
\text { MERIT }\end{array}$ & COST & ES\&H RISK & $\begin{array}{l}\text { STAKEHOLDER, } \\
\text { REGULATORY, } \\
\text { TRIBAL ISSUES }\end{array}$ & $\begin{array}{l}\text { COMMERCIAL } \\
\text { VIABILITY }\end{array}$ \\
\hline Development & $\begin{array}{l}\text { Need still } \\
\text { exists }\end{array}$ & $\begin{array}{l}\text { Addresses } \\
\text { performance } \\
\text { requirements } \\
\text { n Available when } \\
\text { needed }\end{array}$ & $\begin{array}{l}\text { Improved } \\
\text { solution (enabling or } \\
\text { significantly more } \\
\text { effective) } \\
\square \text { Favorable peer } \\
\text { review rating }\end{array}$ & $\begin{array}{l}\text { Improved } \\
\text { solution (enabling or } \\
\text { significantly less } \\
\text { costly) } \\
\\
\square \text { Demonstration } \\
\text { and operating } \\
\text { costs estimated }\end{array}$ & 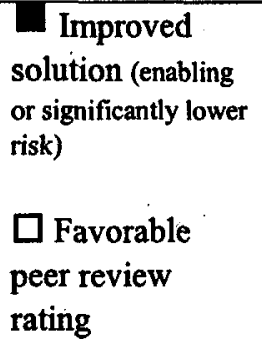 & $\begin{array}{l}\text { Peer review finds } \\
\text { data valid for use } \\
\text { with regulators and } \\
\text { stakeholders }\end{array}$ & $\begin{array}{l}\text { O Potential } \\
\text { vendor identified }\end{array}$ \\
\hline
\end{tabular}

Indicates criterion is satisfied

$\square$ Indicates criterion/evidence is not yet satisfied

"N/A" Indicates criterion is not applicable or satisfied by other means; justification provided in evidence table

Date:

TFA Technology Delivery Manager: 


\section{Evidence Demonstrating Entrance Requirements are Met}

\section{Title: Hanford SST Retrieval}

Technical Need/Site Need ID(s):

RL-WT013 Establish Retrieval Performance Evaluation Criteria

RL-WT027 Tank Leak Mitigation Systems

RL-WT064 PHMC Retrieval and Closure - Hanford Past Practice Sluicing

\section{End User Involvement:}

$\checkmark$ User approved MYTR 99067

$\checkmark$ User providing functional requirements to guide development.

$\checkmark$ User cofunding per TFA IPL; document reference below:

Letter TPP/99-STP-440 DOE-RL Robert M. Rosselli, Assistance Manager for Science and Technology to Richard T. French, Manager Office of River Protection "Fiscal Year (FY) 2000 Tanks Focus Area (TFA) Support to the Office of River Protection (ORP) dated October 5,1999

\section{Technical Merit:}

$\checkmark$ No ASME Peer Review has been conducted.

$\checkmark$ Project is candidate for FY01 technical peer review; however this work is new in FY00

$\checkmark$ Technical requirements are being developed in FY00

$\checkmark$ HNF-SD-HTI-TX-002 Hanford tanks initiative - test implementation plan for demonstration of in-tank retrieval technology 9/22/97

$\checkmark$ Additional technical references available at www.tanks.org search for "HTI"

Cost:

$\checkmark$ The HTI project conducted a procurement solicitation for arm-based and vehicle-based retrieval systems; procurement data would provide cost data, however this information may be proprietary/protected

$\checkmark$ HNF-2693-Rev.1 AX Tank Farm waste retrieval alternatives cost estimates 7/21/98 


\section{ES\&H Risk:}

$\checkmark$ ES\&H requirements being provided in user developed functions \& requirements

$\checkmark$ Hanford is developing requirements in FY00; will include ES\&H

$\checkmark$ Hanford Tank Initiative documents included significant investigation of this area (see Tanks Technology Guide references at www.tanks.org )

\section{Stakeholder, Regulatory, Tribal Issues:}

$\checkmark$ Supports meeting TPA milestone M-45-05-T01 Provide Initial SST Retrieval System by 11/30/03

$\checkmark$ Supports meeting TPA milestone M-45-05-T01 Initiate Tank Waste Retrieval from one Single Shell 12/31/2003

$\checkmark$ Tank leakage is the primary regulatory issue; technology must address issues of above/below ground leakage

$\checkmark$ HNF-SD-HTI-EV-001 Permitting Plan for Hanford Tanks Initiative 2/10/97

\section{Commercial Viability:}

$\checkmark$ Retrieval system vendors have provided concept demonstrations under ACTR and HTI; demonstrated viability of adapting commercial systems for SST retrieval

$\checkmark$ WHC-SD-WM-TD-016 Hanford tanks initiative technology demonstration and waste retrieval acquisition strategy 10/14/96

$\checkmark$ HTI selected a retrieval vendor to design an SST vehicle-based retrieval system for Hanford SST heel retrieval; contract suspended due to HTI cancellation

$\checkmark$ Data on industry involvement and capabilities can be found in the Tanks Technology Guide references at www.tanks.org 


\section{Status Questions for Progress Reviews:}

\section{Title: Hanford SST Retrieval}

\section{Stage: _Development}

1) Has the project been reviewed for advancement through a gate during the past year? No.

2) Has an end user made at least a conditional commitment to implement the technology? Site had not yet selected a specific technology to demonstrate as part of this project. See above TPA milestones related to SST retrieval; this work supports evaluation of technologies to support meeting this milestone.

3) Has a technical peer review been completed and is the work highly rated? Has not yet been peer reviewed.

4) Has a cost-benefit analysis been performed for this technology and does it show potential savings compared to the baseline? Yes. (see above) Are user requirements for cost data identified and satisfied? Cost analysis was conducted as part of the HTI retrieval system procurement package. Data is business sensitive, but provides cost comparison between alternatives. (see above)

5) Will this technology meet or exceed current environmental, safety, health, $(\mathrm{ES} \& \mathrm{H})$ protection levels and/or reduce the risk to the public, workers, and the environment compared to the baseline? A specific technology has not yet been identified. Work is currently in requirements definition. Are user requirements for $\mathrm{ES} \& \mathrm{H}$ and technological risk identified and satisfied? User is currently establishing requirements in functions and requirements documentation being developed.

6) Briefly discuss any activities and/or interactions with stakeholders, regulators, and tribal organizations relative to the continued research and utilization of this technology. Are user requirements for stakeholder, regulator, and tribal concerns identified and satisfied? The Hanford Tanks Initiative and Hanford STCG had extensive interactions with these groups during the HTI project. These issues will be addressed as part of the overall Hanford Site Phase 2 SST retrieval planning.

7) Have invention disclosure and intellectual property issues been addressed? Yes, as addressed in HTI procurement process. If other technologies are chosen, then this will have to be addressed. Briefly discuss the measures taken to include private industry in development and application of the technology. Extensive evaluation of commercial technologies was done by ACTR and HTI projects. 
8) Has an appropriate vendor (or other provider) for this technology been identified? A potential supplier was selected by the HTI project. As updated SST retrieval requirements are established a decision will be made on selecting the preferred retrieval technology and an industrial partner. 


\section{Project Maturity Status Determination}

Title: 99067 SRS Chemical Cleaning

Tech ID: 2967 Chemical Cleaning

Stage: Development

Last Gate:

\begin{tabular}{|c|c|c|c|c|c|c|c|}
\hline $\begin{array}{l}\text { MATURITY } \\
\text { STAGE }\end{array}$ & $\begin{array}{c}\text { TECHNICAL } \\
\text { NEED }\end{array}$ & $\begin{array}{c}\text { END-USER } \\
\text { INVOLVEMENT }\end{array}$ & $\begin{array}{l}\text { TECHNICAL } \\
\text { MERIT }\end{array}$ & COST & ES\&H RISK & $\begin{array}{l}\text { STAKEHOLDER, } \\
\text { REGULATORY, } \\
\text { TRIBAL ISSUES }\end{array}$ & $\begin{array}{l}\text { COMMERCIAL } \\
\text { VIABILITY }\end{array}$ \\
\hline Development & $\begin{array}{l}\text { Need still } \\
\text { exists }\end{array}$ & $\begin{array}{l}\text { Addresses } \\
\text { performance } \\
\text { requirements } \\
\text { Available when } \\
\text { needed }\end{array}$ & $\begin{array}{l}\text { Improved } \\
\text { solution (enabling or } \\
\text { significantly more } \\
\text { effective) } \\
\begin{array}{l}\text { Favorable peer } \\
\text { review rating }\end{array}\end{array}$ & $\begin{array}{l}\text { Improved } \\
\text { solution (enabling or } \\
\text { significantly less } \\
\text { costly) } \\
\square \text { Demonstration } \\
\text { and operating } \\
\text { costs estimated }\end{array}$ & $\begin{array}{l}\text { E Improved } \\
\text { solution (enabling } \\
\text { or significantly lower } \\
\text { risk) } \\
\square \text { Favorable } \\
\text { peer review } \\
\text { rating }\end{array}$ & $\begin{array}{l}\square \text { Peer review finds } \\
\text { data valid for use } \\
\text { with regulators and } \\
\text { stakeholders }\end{array}$ & $\begin{array}{l}\text { Potential } \\
\text { vendor identified }\end{array}$ \\
\hline
\end{tabular}

Indicates criterion is satisfied

$\square$ Indicates criterion/evidence is not yet satisfied

"N/A" Indicates criterion is not applicable or satisfied by other means; justification provided in evidence table

Date:

TFA Technology Delivery Manager: 


\section{Evidence Demonstrating Entrance Requirements are Met}

Title: SRS Chemical Cleaning

\section{Technical Need/Site Need ID(s):}

SR99-2037 Tank Heel Removal/Closure Technology

\section{End User Involvement:}

$\checkmark$ User approved MYTR 99067

$\checkmark$ User cofunding per TFA IPL; document reference below:
Stage:

Letter TPP/99-STP-440 DOE-RL Robert M. Rosselli, Assistance Manager for Science and Technology to R. J. Schepens, Assistant Manager for High-Level Waste DOE-SR "Fiscal Year (FY) 2000 Tanks Focus Area (TFA) Support to the Savannah River Operations Office (SR) High-Level Waste Program" dated October 5, 1999

Technical Merit:

$\checkmark$ TFA conducted a project technical review with representatives of the TFA Technical Advisory Group and members of SRS user representatives in November 1999; Letter TFA00-094 T.M. Brouns to T.P Pietrok "Savannah River Site Tank Chemical Cleaning Review Results" dated April 6, 2000.

$\checkmark$ TFA planning to conduct a Gate review in late FY00 to support SRS decision to proceed to large scale in-tank demonstration in Russia or at SRS

$\checkmark$ As this project has received an independent (TAG) review and TFA TAG will participate in upcoming Gate Review, an ASME Peer Review may not be required. TFA will evaluate this as a candidate for FY01 peer review, based on outcome of Gate Review, however as the Pretreatment subgroup of the TFA TAG has considerable technical expertise in this area, an ASME peer review may not provide significant additional benefit.

$\checkmark$ Results and recommendations of Russian experimental work is reported in a letter report to SRS/TFA; V.G. Radium Institute and Mining-Chemical Combine Final Report for Russian Chemical Decontamination of Tanks (Phase 2) issued by R. Lubtsev, Y. Revenko, V. Popik, E. Kostin, V. Zamanskiy 
Cost:

$\checkmark$ Enabling technology; costs cannot be fully evaluated until a preferred method is down-selected. This technology is being evaluated as an alternative for tanks where mechanical retrieval would be cost prohibitive. (See project review report - listed above)

$\checkmark$ SRS is evaluating conducting a full-scale demonstration in Russia as part of an NN-40 program, which will be represent a significant cost savings over conducing such a demonstration at SRS. TFA is supporting development of planning for this demonstration option.

\section{ES\&H Risk:}

$\checkmark$ Will be evaluated as part of FY00 Gate Review. Was discussed at project technical review (see reference above).

$\checkmark$ Issues dealing with criticality safety as relates to the SRS Safety Authorization Basis are a primary focus of this work. (see reference above).

\section{Stakeholder, Regulatory, Tribal Issues:}

$\checkmark$ No interactions have been yet started. This will not occur until SRS has down-selected a preferred method and completed confirmatory testing.

$\checkmark$ Will be reviewed again as part of FY00 gate review.

\section{Commercial Viability:}

$\checkmark$ Development work is being conducted by Khlopin Radium Institute in Russia

$\checkmark$ Availability of commercial suppliers will not be established until a feasible chemical formulation is established

$\checkmark$ In response to TFA TAG the project will be evaluating availability of recommended chemical formulations from U.S. suppliers 


\section{Status Questions for Progress Reviews:}

\section{Title: SRS Chemical Cleaning}

Stage: 3

1) Has the project been reviewed for advancement through a gate during the past year? No, but a technical progress review was conducted by TFA. If yes, what was the result? Results and recommendations documented in letter report. (See above reference)

2) Has an end user made at least a conditional commitment to implement the technology? Yes. SRS is planning to make a deployment decision on performing an in-tank demonstration in FYO1. SRS is seeking to perform an in-tank demonstration at a Russian facility in conjunction with a DOE-NN program. TFA is supporting planning for this potential demonstration.

3) Has a technical peer review been completed and is the work highly rated? TFA conducted a technical project review with the TFA Technical Advisory Group in November 1999. Results documented in letter report (see above).

4) Has a cost-benefit analysis been performed for this technology and does it show potential savings compared to the baseline? No. Are user requirements for cost data identified and satisfied? This work is being pursued to provide an alternative to mechanical methods, which are cost prohibitive for some SRS tank configurations. Costs will be evaluated following down-selecting a preferred method and the Russian demonstration. Conducting the tank demonstration in Russia will be significantly more cost-effective than performing the work at SRS.

5) Will this technology meet or exceed current environmental, safety, health, (ES\&H) protection levels and/or reduce the risk to the public, workers, and the environment compared to the baseline? This has not yet been determined. Will be evaluated as part of continuing workscope. Are user requirements for ES\&H and technological risk identified and satisfied? Has not yet been determined. SRS is conducting confirmatory testing at SRTC labs and is proposing a Russian in-tank demonstration to try and address technical and ES\&H questions.

6) Briefly discuss any activities and/or interactions with stakeholders, regulators, and tribal organizations relative to the continued research and utilization of this technology. Are user requirements for stakeholder, regulator, and tribal concerns identified and satisfied? SRS has not yet conducted discussions with these groups. This is premature until additional data is available. 
7) Have invention disclosure and intellectual property issues been addressed? None have yet been identified. Briefly discuss the measures taken to include private industry in development and application of the technology. Work being performed under contract with Khlopin Radium Institute in Russia. It is too early to evaluate further industry involvement.

8) Has an appropriate vendor (or other provider) for this technology been identified? Not yet. Will be evaluated based on results of FY00 testing program. Will be evaluated as part of FY00 gate review. 


\section{Project Maturity Status Determination}

Title:SRS Tank 19 Heel Retrieval

Tech ID:2097 Heel Retrieval for SRS; 2232 Flygt Mixer; 2366 Disposable Crawler

Stage: Demonstration Last Gate: 5

\begin{tabular}{|c|c|c|c|c|c|c|c|}
\hline $\begin{array}{l}\text { MATURITY } \\
\text { STAGE }\end{array}$ & $\begin{array}{c}\text { TECHNICAL } \\
\text { NEED }\end{array}$ & $\begin{array}{c}\text { END-USER } \\
\text { INVOLVEMENT }\end{array}$ & $\begin{array}{l}\text { TECHNICAL } \\
\text { MERIT }\end{array}$ & COST & ES\&H RISK & $\begin{array}{l}\text { STAKEHOLDER, } \\
\text { REGULATORY, } \\
\text { TRIBAL ISSUES }\end{array}$ & $\begin{array}{l}\text { COMMERCIAL } \\
\text { VIABILITY }\end{array}$ \\
\hline Demonstration & $\begin{array}{l}\text { Need still } \\
\text { exists }\end{array}$ & $\begin{array}{l}\text { Demonstration } \\
\text { cost-sharing }\end{array}$ & $\begin{array}{l}\text { Demonstration } \\
\text { plan } \\
\text { Favorable peer } \\
\text { review }\end{array}$ & $\begin{array}{l}\text { Demonstration } \\
\text { plan } \\
\text { reavorable peer } \\
\text { review }\end{array}$ & $\begin{array}{l}\text { Demonstration } \\
\text { plan } \\
\text { Favorable peer } \\
\text { review }\end{array}$ & $\begin{array}{l}\text { Demonstration } \\
\text { permits completed }\end{array}$ & $\begin{array}{l}\text { O Vendor } \\
\text { participates in } \\
\text { demonstration }\end{array}$ \\
\hline
\end{tabular}

Indicates criterion is satisfied

$\square$ Indicates criterion/evidence is not yet satisfied

"N/A" Indicates criterion is not applicable or satisfied by other means; justification provided in evidence table

Date:

TFA Technology Delivery Manager: 


\section{Evidence Demonstrating Entrance Requirements are Met}

\section{Title: $\underline{\text { SRS Tank } 19 \text { Heel Retrieval }}$}

\section{Stage: _Demonstration}

Technical Need/Site Need ID(s):

SR99-2037 Tank Heel Removal/Closure Technology

\section{End User Involvement:}

$\checkmark$ User approved MYTR 99067

$\checkmark$ User planning to deploy in FY00

$\checkmark$ User cofunding per TFA IPL; document reference below:

Letter TPP/99-STP-440 DOE-RL Robert M. Rosselli, Assistance Manager for Science and Technology to R. J. Schepens, Assistant Manager for High-Level Waste DOE-SR "Fiscal Year (FY) 2000 Tanks Focus Area (TFA) Support to the Savannah River Operations Office (SR) High-Level Waste Program" dated October 5, 1999

\section{Technical Merit:}

$\checkmark$ TFA conducted Gate Review in November 1999 resulting in recommendation to proceed to Stage 6 Letter TFA00-057 Thomas M. Brouns, PNNL, to Theodore P. Pietrok, DOE-RL "Savannah River Site Tank 19 Heel Retrieval Gate Review Results" dated February 25, 2000.

$\checkmark$ User will deploy in FY00, therefore ASME Peer Review is not needed

Cost:

$\checkmark$ Enabling technologies; cost evaluated as part of Gate review (see reference above)

\section{ES\&H Risk:}

$\checkmark$ Evaluated as part of Gate review (see reference above)

\section{Stakeholder, Regulatory, Tribal Issues:}

$\checkmark$ Evaluated as part of Gate review (see reference above) 


\section{Commercial Viability:}

$\checkmark$ SRS is using several commercially technologies that have been modified for application in Tank 19. Specific commercial products: Flygt Mixers (ITT Flygt actively involved in development)

\section{Pitbull ${ }^{\mathrm{TM}}$ Pump}

Inuktun ${ }^{\circledR}$ crawler treads

Bibo ${ }^{\text {TMPump }}$ 


\section{Status Questions for Progress Reviews:}

\section{Title: SRS Tank 19 Heel Retrieval_ Stage: _ Demonstration}

1) Has the project been reviewed for advancement through a gate during the past year? Yes. If yes, what was the result? Review recommended advancement to Stage 6.

2) Has an end user made at least a conditional commitment to implement the technology? Yes. SRS plans to deploy in FYOO.

3) Has a technical peer review been completed and is the work highly rated? ASME Peer Review has not been conducted. Site user will make deployment decision in FYOO, therefore peer review is not required. The TFA Technical Advisory Group participating as part of the gate review evaluated the technologies being used for Tank 19 heel retrieval.

4) Has a cost-benefit analysis been performed for this technology and does it show potential savings compared to the baseline? Are user requirements for cost data identified and satisfied? Enabling technologies required to complete retrieval operations. Gate review of cost criterion was satisfied.

5) Will this technology meet or exceed current environmental, safety, health, (ES\&H) protection levels and/or reduce the risk to the public, workers, and the environment compared to the baseline? Yes. No issues were identified in the gate review. Are user requirements for ES\&H and technological risk identified and satisfied? Yes, as documented in Gate Review report.

6) Briefly discuss any activities and/or interactions with stakeholders, regulators, and tribal organizations relative to the continued research and utilization of this technology. Are user requirements for stakeholder, regulator, and tribal concerns identified and satisfied? No issues have been identified. State has approved deployment of technologies.

7) Have invention disclosure and intellectual property issues been addressed? Yes. Briefly discuss the measures taken to include private industry in development and application of the technology. Retrieval will be conducted with modified commercial technologies. ITT Flygt the supplier of the primary retrieval system, Flygt Mixers, is actively involved in the testing and development. Other technologies were procured from commercial suppliers as "off-the-shelf" equipment being modified onsite to meet specific site configurations.

8) Has an appropriate vendor (or other provider) for this technology been identified? Yes. 


\section{Project Maturity Status Determination}

Title: 99067 West Valley Advanced Waste Retrieval System

Tech ID: 2948 Advanced Waste Retrieval System

Stage: _ Development _ Last Gate: 4

\begin{tabular}{|c|c|c|c|c|c|c|c|}
\hline $\begin{array}{l}\text { MATURITY } \\
\text { STAGE }\end{array}$ & $\begin{array}{l}\text { TECHNICAL } \\
\text { NEED }\end{array}$ & $\begin{array}{c}\text { END-USER } \\
\text { INVOLVEMENT }\end{array}$ & $\begin{array}{l}\text { TECHNICAL } \\
\text { MERIT }\end{array}$ & COST & ES\&H RISK & $\begin{array}{l}\text { STAKEHOLDER, } \\
\text { REGULATORY, } \\
\text { TRIBAL ISSUES }\end{array}$ & $\begin{array}{l}\text { COMMERCIAL } \\
\text { VIABILITY }\end{array}$ \\
\hline Development & $\begin{array}{l}\text { Need still } \\
\text { exists }\end{array}$ & $\begin{array}{l}\text { Addresses } \\
\text { performance } \\
\text { requirements } \\
\text { Available when } \\
\text { needed }\end{array}$ & 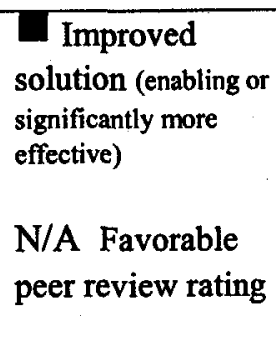 & $\begin{array}{l}\text { Improved } \\
\text { solution (enabling or } \\
\text { significantly less } \\
\text { costly) } \\
\square \text { Demonstration } \\
\text { and operating } \\
\text { costs estimated }\end{array}$ & 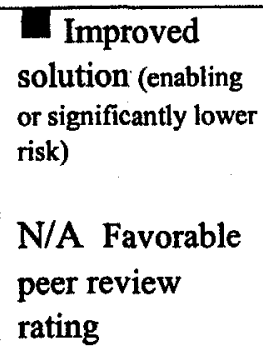 & $\begin{array}{l}\text { N/A Peer review } \\
\text { finds data valid for } \\
\text { use with regulators } \\
\text { and stakeholders }\end{array}$ & $\begin{array}{l}\text { Potential } \\
\text { vendor identified }\end{array}$ \\
\hline
\end{tabular}

Indicates criterion is satisfied

$\square$ Indicates criterion/evidence is not yet satisfied

"N/A" Indicates criterion is not applicable or satisfied by other means; justification provided in evidence table

Date:

TFA Technology Delivery Manager: 


\section{Evidence Demonstrating Entrance Requirements are Met}

\section{Title: 99067 West Valley Advanced Waste Retrieval System}

\section{Stage: Development}

\section{Technical Need/Site Need ID(s):}

OH-WV-905 Retrieval from Obstructed Tanks

\section{End User Involvement:}

$\checkmark$ User approved MYTR 99067

$\checkmark$ User planning to prepare technology for deployment as needed to complete retrieval operations

$\checkmark$ User cofunding per TFA IPL; document reference below:

Letter TPP/99-STP-440 DOE-RL Robert M. Rosselli, Assistant Manager for Science and Technology to B.A. Mazurowski, Director West Valley Demonstration Project "Fiscal Year (FY) 2000 Tanks Focus Area (TFA) Support to the West Valley Demonstration Project (WVDP) High-Level Waste Program" dated October 5, 1999.

\section{Technical Merit:}

$\checkmark$ An ASME Peer Review has not been conducted. User will make decision on deployment in FY01, therefore an ASME Peer Review is not required.

$\checkmark$ Specifications and test plans/acceptance criteria; design verification planned to be conducted by WVDP when design modifications are complete

$\checkmark$ WVDP will conduct a technical evaluation in FY00 to verify equipment is ready for turnover to operations; this action will verify system design meets technical specifications and requirements

Cost:

$\checkmark$ Enabling technology; site user funded initial development and has determined cost/benefit meets requirements 


\section{ES\&H Risk:}

$\checkmark$ Site is addressing these issues as part of their overall retrieval project preparations and readiness reviews

$\checkmark$ Site has conducted standard hazard analyses; need document reference

\section{Stakeholder, Regulatory, Tribal Issues:}

$\checkmark$ Site is addressing these issues as part of their overall retrieval project preparations and readiness reviews.

$\checkmark$ WV is developing this technology to meet regulatory requirements for tank cleanliness; technology must achieve the required level of cleaning to support tank closure

\section{Commercial Viability:}

$\checkmark$ WVDP developed the technology; is contracting with SMCI of Lakeland, FL to produce the equipment to site specifications 


\section{Status Questions for Progress Reviews:}

\section{Title: 99067 West Valley Advanced Waste Retrieval System Stage: Development}

1) Has the project been reviewed for advancement through a gate during the past year? No.

2) Has an end user made at least a conditional commitment to implement the technology? Yes. WVDP plans to deploy equipment as a backup technology if initial retrieval with other equipment does not meet performance requirements. Deployment is contingent on requirements for additional cleaning to meet "to be determined" tank cleanliness criteria

3) Has a technical peer review been completed and is the work highly rated? No. User will make deployment decision in FY00, therefore a peer review is not required.

4) Has a cost-benefit analysis been performed for this technology and does it show potential savings compared to the baseline? No. Are user requirements for cost data identified and satisfied? WV has not defined cost requirements for this project, other than as provided within their procurement strategy. This is an enabling technology under development for meeting "to be determined" requirements for tank cleanliness.

5) Will this technology meet or exceed current environmental, safety, health, (ES\&H) protection levels and/or reduce the risk to the public, workers, and the environment compared to the baseline? Technology is being developed to meet "to be determined" requirements for tank closure. There are no known issues at this time. Are user requirements for ES\&H and technological risk identified and satisfied? WVDP has not provided requirements to TFA; technology is being developed onsite at WV.

6) Briefly discuss any activities and/or interactions with stakeholders, regulators, and tribal organizations relative to the continued research and utilization of this technology. Are user requirements for stakeholder, regulator, and tribal concerns identified and satisfied? WVDP will address these issues as part of their overall retrieval project preparations.

7) Have invention disclosure and intellectual property issues been addressed? There are no IP issues. Briefly discuss the measures taken to include private industry in development and application of the technology. WV issued a specification and has hired a commercial fabricator to produce the AWRS hardware. 
8) Has an appropriate vendor (or other provider) for this technology been identified? Yes (see above) 


\section{Project Maturity Status Determination}

Title: 99076 Waste Transfer Line Plugging Prevention/Unplugging

Tech ID: 2367 Pipeline Unplugging

Stage: Development Last Gate: 3

\begin{tabular}{|c|c|c|c|c|c|c|c|}
\hline $\begin{array}{l}\text { MATURITY } \\
\text { STAGE }\end{array}$ & $\begin{array}{l}\text { TECHNICAL } \\
\text { NEED }\end{array}$ & $\begin{array}{c}\text { END-USER } \\
\text { INVOLVEMENT }\end{array}$ & $\begin{array}{l}\text { TECHNICAL } \\
\text { MERIT }\end{array}$ & COST & ES\&H RISK & $\begin{array}{l}\text { STAKEHOLDER, } \\
\text { REGULATORY, } \\
\text { TRIBAL ISSUES }\end{array}$ & $\begin{array}{l}\text { COMMERCIAL } \\
\text { VIABILITY }\end{array}$ \\
\hline Development & $\begin{array}{l}\text { Need still } \\
\text { exists }\end{array}$ & $\begin{array}{l}\text { Addresses } \\
\text { performance } \\
\text { requirements } \\
\text { Available when } \\
\text { needed }\end{array}$ & $\begin{array}{l}\text { Improved } \\
\text { solution (enabling or } \\
\text { significantly more } \\
\text { effective) } \\
\\
\square \text { Favorable peer } \\
\text { review rating }\end{array}$ & $\begin{array}{l}\text { Improved } \\
\text { solution (enabling or } \\
\text { significantly less } \\
\text { costly) } \\
\square \text { Demonstration } \\
\text { and operating } \\
\text { costs estimated }\end{array}$ & $\begin{array}{l}\text { Improved } \\
\text { solution (enabling } \\
\text { or significantly lower } \\
\text { risk) } \\
\square \text { Favorable } \\
\text { peer review } \\
\text { rating }\end{array}$ & $\begin{array}{l}\square \text { Peer review finds } \\
\text { data valid for use } \\
\text { with regulators and } \\
\text { stakeholders }\end{array}$ & $\begin{array}{l}\text { Potential } \\
\text { vendor identified }\end{array}$ \\
\hline
\end{tabular}

Indicates criterion is satisfied

$\square$ Indicates criterion/evidence is not yet satisfied

"N/A" Indicates criterion is not applicable or satisfied by other means; justification provided in evidence table

Date:

TFA Technology Delivery Manager: 


\section{Evidence Demonstrating Entrance Requirements are Met}

Title: 99076 Waste Transfer Line Plugging Prevention/Unplugging

\section{Stage: Development}

\section{Technical Need/Site Need ID(s):}

OR-TK-02 Tank Solid Waste Retrieval

RL-WT023 Prediction of Solid Phase Formation in Static and Dynamic Systems

SR99-2035 Develop Advanced Techniques for Life Extension of High Level Waste Tanks

SR99-2039 Methods to Unplug Waste Transfer Lines

\section{End User Involvement:}

$\checkmark$ User approved MYTR 99076

$\checkmark$ SRS user cofunding per TFA IPL; see document referenced below

Letter TPP/99-STP-440 DOE-RL Robert M. Rosselli, Assistance Manager for Science and Technology to R. J. Schepens, Assistant Manager for High-Level Waste DOE-SR "Fiscal Year (FY) 2000 Tanks Focus Area (TFA) Support to the Savannah River Operations Office (SR) High-Level Waste Program" dated October 5, 1999

\section{Technical Merit:}

$\checkmark$ An ASME Peer Review of this project is planned for FY00, but may not be conducted until 10/00

$\checkmark \quad$ NETL has issued an information package on the web containing technical information for vendors interested in responding to the RFP when released

$\checkmark$ FIU will issue test plan in FY00 for TFA review; NETL will include test requirements in procurement package

$\checkmark$ Results of testing will provide data to establish operational parameters and limitations of available technologies; information will be provided to site users for consideration 
Cost:

$\checkmark$ Technologies to be tested are considered enabling and providing opportunity for cost avoidance by providing a tool for response to future pipeline blockages to mitigate impacts from pipeline loss and impacts to operations and production schedules

$\checkmark$ A recent pipeline blockage in a Hanford saltwell pumping transfer line from tank U-103 caused a six-week delay in operations. Costs associated with such events vary greatly due to the specific circumstances, however a rough estimate for this case is an approximate cost impact of $\$ 800 \mathrm{~K}$ for increased operations and maintenance costs (opening valve pits, checking and removing jumpers, etc.) and loss of productivity. As these type of risks exist for many transfers, the potential cost savings from developing sound technical recommendations on waste preparation and operating envelopes for pipeline transfer could result in significant cost avoidance. [data provided by RPP staff via email].

$\checkmark$ The potential cost impact of a pipeline blockage during retrieval operations is potentially more serious. The TWRS Privatization Contract No. DE-AC06-96RL133308, Part 1, Section H, subsections H30 and H40 (See http://www.hanford.gov/doe/contracts/de-ac0696rl13308/sectionh-1.html) includes an idle facility penalty to DOE for delayed feed delivery to the contractor. These charges have not been established, but have been estimated at $\$ 2 \mathrm{M} /$ day or more. The investment in this project to provide technical basis data for improving pipeline waste transfers has a significant potential for cost avoidance related to feed delivery in the future vitrification operations.

$\checkmark$ The cost of constructing a new pipeline would be in the range of $\$ 50 \mathrm{M}$. This is based on the costs for the recent pipeline constructed at Hanford as documented in the "Construction Completion and Cost Closing Statement" DOE-HQ Project No. 93-D-182 that places final capital costs at $\$ 42.4 \mathrm{M}$ and associated expense costs at $\$ 7 \mathrm{M}$.

$\checkmark$ Cost estimate for a cross site transfer at Hanford is approximately $\$ 300 \mathrm{~K}$, based on recent Hanford data in RPP's "Cost Estimate Information Sheet" (CEIS) and Technical Baseline Results (TBR) 230.655.

\section{ES\&H Risk:}

$\checkmark$ Enabling technology that will likely reduce ES\&H risk related to plugging transfer lines and being able to unblock plugged lines.

$\checkmark$ FIU test plans will specify safety requirements for conducting the tests

$\checkmark$ Safety requirements for field deployments will be specific to the pipeline blockage situation and will be established as required to address the particular upset condition

Stakeholder, Regulatory, Tribal Issues:

$\checkmark$ None known at this time 


\section{Commercial Viability:}

$\checkmark$ TFA/NETL will conduct an industry call in FY00, viability of commercial technologies will be determined through testing at FIU

$\checkmark$ An information package has been issued by NETL and vendor responses indicating interest to bid are due 4/19/00; contracts to several vendors will be issued in FY00 to conduct testing at FIU 


\section{Status Questions for Progress Reviews:}

\section{Title: 99076 Waste Transfer Line Plugging Prevention/Unplugging}

Stage: Development

1) Has the project been reviewed for advancement through a gate during the past year? No.

2) Has an end user made at least a conditional commitment to implement the technology? Yes. SRS plans to demonstrate on plugged transfer line, if viable commercial system is identified.

3) Has a technical peer review been completed and is the work highly rated? Peer review scheduled for 10/00.

4) Has a cost-benefit analysis been performed for this technology and does it show potential savings compared to the baseline? See above. Are user requirements for cost data identified and satisfied? Specific cost requirements have not been established by user, however technology costs will be available from competitive bids this FY00 for review by site users.

5) Will this technology meet or exceed current environmental, safety, health, (ES\&H) protection levels and/or reduce the risk to the public, workers, and the environment compared to the baseline? Yes. Technologies will be used to recover from an upset condition. Ability of technologies to operate safely without further damage to pipeline will be determined as part of the test program. Are user requirements for ES\&H and technological risk identified and satisfied? No specific requirements have been identified.

6) Briefly discuss any activities and/or interactions with stakeholders, regulators, and tribal organizations relative to the continued research and utilization of this technology. None at this time. It would be premature as technologies have not been selected or tested. Are user requirements for stakeholder, regulator, and tribal concerns identified and satisfied? Responsibility for this resides with site user and is not part of the scope of this task.

7) Have invention disclosure and intellectual property issues been addressed? Will be addressed as part of the NETL contract with vendors selected to demonstrate technologies. Briefly discuss the measures taken to include private industry in development and application of the technology. Industry call planned for FYOO. 
8) Has an appropriate vendor (or other provider) for this technology been identified? Competitive call planned for FY00. Selected technologies will be demonstrated and a performance evaluation conducted. A second round of testing may be performed in FY01 depending on the outcome of FY00 testing. Downselect of preferred technology will not occur until FY01. 


\section{Project Maturity Status Determination}

\section{Title: 99082 ORNL FFA Tank Mobile Retrieval System}

\section{Tech ID: 2947 Mobile Retrieval System}

\section{Stage: Deployment}

\begin{tabular}{|c|c|c|c|}
\hline $\begin{array}{c}\text { MATURITY } \\
\text { STAGE }\end{array}$ & $\begin{array}{c}\text { TECHNICAL } \\
\text { NEED }\end{array}$ & $\begin{array}{c}\text { END-USER } \\
\text { INVOLVEMENT }\end{array}$ & $\begin{array}{c}\text { TECHNICAL } \\
\text { MERIT }\end{array}$ \\
\hline Demonstration & $\begin{array}{l}\text { Need still } \\
\text { exists }\end{array}$ & $\begin{array}{l}\text { Demonstration } \\
\text { cost-sharing }\end{array}$ & $\begin{array}{l}\text { Demonstration } \\
\text { plan } \\
\text { N/A Favorable } \\
\text { peer review }\end{array}$ \\
\hline
\end{tabular}

\section{Last Gate:} 6

Indicates criterion is satisfied

$\square$ Indicates criterion/evidence is not yet satisfied

"N/A" Indicates criterion is not applicable or satisfied by other means; justification provided in evidence table

Date:

TFA Technology Delivery Manager: 


\section{Evidence Demonstrating Entrance Requirements are Met}

\section{Title: 99082 ORNL FFA Tank Mobile Retrieval System}

\section{Technical Need/Site Need ID(s):}

OR-TK-02 Tank Solid Waste Retrieval

\section{End User Involvement:}

$\checkmark$ End user approved MYTR 99082

$\checkmark$ ASTD Project 99-ASTD-05 supported by site end user

$\checkmark$ User cofunding per TFA IPL; see document reference below

Letter TPP/99-STP-440 DOE-RL Robert M. Rosselli, Assistance Manager for Science and Technology to R.R. Nelson, Assistant Manager for Environmental Management, OR "Fiscal Year (FY) 2000 Tanks Focus Area (TFA) Support to the Oak Ridge Reservation (ORR)" dated October 5, 1999

Technical Merit:

$\checkmark$ See ASTD proposal for 99-ASTD-05

$\checkmark$ TFA technical progress review conducted in November 1999.

$\checkmark$ Technology deployed by end user

$\checkmark$ Other DOE sites evaluating potential application of technology for small tanks

\section{Cost:}

$\checkmark$ See ASTD proposal for 99-ASTD-05

$\checkmark$ Cost benefit presented in ASTD proposal will not likely be achieved as the system will only be used in one or two tanks versus the 20 that the cost benefit analysis was based on. 


\section{ES\&H Risk:}

$\checkmark$ See ASTD proposal for 99-ASTD-05

Stakeholder, Regulatory, Tribal Issues:

$\checkmark$ See ASTD proposal for 99-ASTD-05

\section{Commercial Viability:}

$\checkmark$ AEAT supplied the equipment and is supporting deployment of system in the FFA tanks 


\section{Status Questions for Progress Reviews:}

\section{Title: 99082 ORNL FFA Tank Mobile Retrieval System}

\section{Stage: Deployment}

1) Has the project been reviewed for advancement through a gate during the past year? No. ASTD project, entered in deployment stage. If yes, what was the result?

2) Has an end user made at least a conditional commitment to implement the technology? Yes, system is deployed.

3) Has a technical peer review been completed and is the work highly rated? $N / A$

4). Has a cost-benefit analysis been performed for this technology and does it show potential savings compared to the baseline? Are user requirements for cost data identified and satisfied? Yes, included in ASTD proposal. However, the basis of the cost comparison was for 20 tanks. Site changed strategy and is now only deploying in one or two tanks, therefore the cost savings projected may not be realized.

5) Will this technology meet or exceed current environmental, safety, health, (ES\&H) protection levels and/or reduce the risk to the public, workers, and the environment compared to the baseline? Yes. Are user requirements for ES\&H and technological risk identified and satisfied? Yes.

6) Briefly discuss any activities and/or interactions with stakeholders, regulators, and tribal organizations relative to the continued research and utilization of this technology. Are user requirements for stakeholder, regulator, and tribal concerns identified and satisfied? See ASTD proposal.

7) Have invention disclosure and intellectual property issues been addressed? Yes. Briefly discuss the measures taken to include private industry in development and application of the technology. AEAT designed, fabricated and is participating in deployment.

8) Has an appropriate vendor (or other provider) for this technology been identified? Yes. 


\section{Project Maturity Status Determination}

Title: 99001 Radionuclide Separations Processes for INEEL

Tech ID: 347 TRUEX/SREX; 2968 Cs Removal using AMP-PAN; 206 INEEL HLW Processing

\section{Stage: Development Last Gate: 3}

\begin{tabular}{|c|c|c|c|c|c|c|c|}
\hline $\begin{array}{l}\text { MATURITY } \\
\text { STAGE }\end{array}$ & $\begin{array}{l}\text { TECHNICAL } \\
\text { NEED }\end{array}$ & $\begin{array}{l}\text { END-USER } \\
\text { INVOLVEMENT }\end{array}$ & $\begin{array}{c}\text { TECHNICAL } \\
\text { MERIT }\end{array}$ & COST & ES\&H RISK & $\begin{array}{c}\text { STAKEHOLDER, } \\
\text { REGULATORY, } \\
\text { TRIBAL ISSUES }\end{array}$ & $\begin{array}{l}\text { COMMERCIAL } \\
\text { VIABILITY }\end{array}$ \\
\hline Development & $\begin{array}{l}\text { Need still } \\
\text { exists }\end{array}$ & $\begin{array}{l}\text { Addresses } \\
\text { performance } \\
\text { requirements } \\
\text { Available when } \\
\text { needed }\end{array}$ & $\begin{array}{l}\text { Improved } \\
\text { solution (enabling or } \\
\text { significantly more } \\
\text { effective) } \\
\text { Favorable peer } \\
\text { review rating }\end{array}$ & $\begin{array}{l}\text { Improved } \\
\text { solution (enabling or } \\
\text { significantly less } \\
\text { costly) } \\
\text { Demonstration } \\
\text { and operating } \\
\text { costs estimated }\end{array}$ & $\begin{array}{l}\text { Improved } \\
\text { solution (enabling } \\
\text { or significantly lower } \\
\text { risk) } \\
\text { Favorable } \\
\text { peer review } \\
\text { rating }\end{array}$ & $\begin{array}{l}\text { Peer review finds } \\
\text { data valid for use } \\
\text { with regulators and } \\
\text { stakeholders }\end{array}$ & $\begin{array}{l}\text { Potential } \\
\text { vendor identified }\end{array}$ \\
\hline
\end{tabular}

Indicates criterion is satisfied

$\square$ Indicates criterion/evidence is not yet satisfied

"N/A" Indicates criterion is not applicable or satisfied by other means; justification provided in evidence table

Date:

TFA Technology Delivery Manager: 


\section{Evidence Demonstrating Entrance Requirements are Met}

\section{Title: 99001 Radionuclide Separations for INEEL}

Technical Need/Site Need ID(s):

ID-2.1.06 TRU, Cs and Sr Removal from High Activity Wastes

ID-2.1.53 Cs Removal from High Activity Wastes

ID-2.1.54 TRU Removal from High Activity Wastes

ID-2.1.55 Sr Removal from High Activity Wastes

ID-2.1.63 Universal Solvent Process for TRU, Cs and Sr Removal

\section{End User Involvement:}

$\checkmark$ User approved MYTR 99001

$\checkmark$ User cofunding per TFA IPL; document reference below:

Letter TPP/99-STP-440 DOE-RL Robert M. Rosselli, Assistance Manager for Science and Technology to J.T. Case, Program Director Idaho Operations Office "Fiscal Year (FY) 2000 Tanks Focus Area (TFA) Support to the Idaho Operations Office (ID) High-Level Waste Program" dated October 5, 1999

\section{Technical Merit:}

$\checkmark$ ASME Peer Review on TRUEX/SREX conducted in FY98; see report Institute for Regulatory Science CRTD Vol. 50

$\checkmark$ TFA plans to conduct a technical review in FY01 to status progress towards meeting user data needs; INEEL is performing evaluations to select a preferred technology in FY00; TFA scope will be updated as required to align with INEEL selection of a preferred technology

$\checkmark$ The National Research Council conducted a review of the alternatives for treating HLW at INEEL and results are published in Alternative High-Level Waste Treatments at the Idaho National Engineering and Environmental Laboratory (National Academy Press)

$\checkmark$ Information on TRUEX/SREX and CST are available in ITSRs DOE/EM-0419 and DOE/EM-0415 
Cost:

$\checkmark$ See ITSR references above.

$\checkmark$ Technologies are enabling and preferred solution will be selected and cost data will be documented by site as part of the EIS process

$\checkmark$ Costs associated with all HLW treatment options, including radionuclide separations, for INEEL waste is being analyzed as part of the EIS process. This is documented in DOE/ID 10702 "Cost Analysis for the Idaho High-Level Waste Facilities Disposition

Environmental Impact Statement” dated January 2000.

\section{ES\&H Risk:}

$\checkmark$ See ITSR references above.

$\checkmark$ Technology is likely to favorably meet ES\&H requirements for deployment, as it enables segregation and handling of higher dose waste into a smaller waste stream

$\checkmark$ User is evaluating this as part of developing alternative evaluations supporting the site EIS for HLW and related information is presented in the the EIS document; DOE/EIS-0287D Idaho High-Level Waste \& Facilities Disposition Draft Environmental Impact Statement December 1999

$\checkmark$ Issues of secondary waste handling will be evaluated as part of the development work leading to a down-select of a preferred technology(s)

Stakeholder, Regulatory, Tribal Issues:

$\checkmark$ See ITSR references above.

$\checkmark$ User is addressing these issues as part of the overall HLW EIS process and related information is presented in the EIS document; DOE/EIS-0287D Idaho High-Level Waste \& Facilities Disposition Draft Environmental Impact Statement December 1999

\section{Commercial Viability:}

$\checkmark$ See ITSR references above.

$\checkmark$ There are known sources for the materials used to remove the radionuclides; primary issues with production scale-up and modifications to meet specific site requirements would need to be addressed after a preferred technology is selected.

$\checkmark$ The UNEX process that is one of.the alternatives being evaluated was developed by the Russians; there may be potential questions/issues regarding obtaining the material in production quantities to be addressed should this alternative be selected 


\section{Status Questions for Progress Reviews:}

\section{Title: 99001 Radionuclide Separations for INEEL}

\section{Stage:__Development}

1) Has the project been reviewed for advancement through a gate during the past year? No.

2) Has an end user made at least a conditional commitment to implement the technology? Yes. INEEL is using data from this project to support HLW EIS process and down select of preferred option for ROD.

3) Has a technical peer review been completed and is the work highly rated? Yes. An ASME Peer Review on TRUEX, SREX was conducted in FY98. Project was favorably rated.

4) Has a cost-benefit analysis been performed for this technology and does it show potential savings compared to the baseline? Are user requirements for cost data identified and satisfied? INEEL is evaluating cost-benefit as part of the overall EIS process; baseline cost information is available in EIS for use in evaluating effectiveness of options.

5) Will this technology meet or exceed current environmental, safety, health, (ES\&H) protection levels and/or reduce the risk to the public, workers, and the environment compared to the baseline? Technology will likely meet or exceed. User will address this as part of the down select of the preferred alternative for the ROD. Are user requirements for ES\&H and technological risk identified and satisfied? See EIS document referenced above.

6) Briefly discuss any activities and/or interactions with stakeholders, regulators, and tribal organizations relative to the continued research and utilization of this technology. Are user requirements for stakeholder, regulator, and tribal concerns identified and satisfied? INEEL is working this as part of the overall EIS process, including conducting public/stakeholder hearings and comment process.

7) Have invention disclosure and intellectual property issues been addressed? This will be addressed after the down select. There are no know issues at this time. Briefly discuss the measures taken to include private industry in development and application of the technology. Commercially available resins/sorbents are being used in the testing. 
8) Has an appropriate vendor (or other provider) for this technology been identified? Yes. Except for issue with Russian material, which remains to be addressed if selected. 


\section{Project Maturity Status Determination}

Title: 99054A Waste Preparation and Transfer Chemistry

Tech ID:2367 Pipe Unplugging ${ }^{1}$

Stage: Development Last Gate: 2

\begin{tabular}{|c|c|c|c|c|c|c|c|}
\hline $\begin{array}{l}\text { MATURITY } \\
\text { STAGE }\end{array}$ & $\begin{array}{c}\text { TECHNICAL } \\
\text { NEED }\end{array}$ & $\begin{array}{c}\text { END-USER } \\
\text { INVOLVEMENT }\end{array}$ & $\begin{array}{l}\text { TECHNICAL } \\
\text { MERIT }\end{array}$ & COST & ES\&H RISK & $\begin{array}{l}\text { STAKEHOLDER } \\
\text {, REGULATORY, } \\
\text { TRIBAL ISSUES }\end{array}$ & $\begin{array}{l}\text { COMMERCIAL } \\
\text { VIABILITY }\end{array}$ \\
\hline Development & $\begin{array}{l}\text { Need still } \\
\text { exists }\end{array}$ & $\begin{array}{l}\text { Addresses } \\
\text { performance } \\
\text { requirements } \\
\text { Available when } \\
\text { needed }\end{array}$ & $\begin{array}{l}\text { Improved } \\
\text { solution (enabling or } \\
\text { significantly more } \\
\text { effective) } \\
\text { Favorable peer } \\
\text { review rating }\end{array}$ & $\begin{array}{l}\text { Improved } \\
\text { solution (enabling or } \\
\text { significantly less costly) } \\
\text { Demonstration } \\
\text { and operating costs } \\
\text { estimated }\end{array}$ & $\begin{array}{l}\text { Improved } \\
\text { solution (enabling } \\
\text { or significantly lower } \\
\text { risk) } \\
\text { Favorable } \\
\text { peer review } \\
\text { rating }\end{array}$ & $\begin{array}{l}\text { N/A Peer review } \\
\text { finds data valid for } \\
\text { use with regulators } \\
\text { and stakeholders }\end{array}$ & $\begin{array}{l}\text { N/A Potential } \\
\text { vendor identified }\end{array}$ \\
\hline
\end{tabular}

Indicates criterion is satisfied

$\square$ Indicates criterion/evidence is not yet satisfied

"N/A" Indicates criterion is not applicable or satisfied by other means; justification provided in evidence table

Date:

TFA Technology Delivery Manager:

${ }^{1} 2367$ is related but focused on demonstrating equipment to unplug pipelines: TFA will consider adding a new TMS ID to cover this work 


\section{Evidence Demonstrating Entrance Requirements are Met}

\section{Title: Hanford Waste Transfer/Solids Formation}

Stage: _Development

\section{Technical Need/Site Need ID(s):}

RL-WT023 Prediction of Solid Phase Formation in Static and Dynamic

\section{End User Involvement:}

$\checkmark$ User approved MYTR 99054A

$\checkmark$ User participating in defining experimental requirements

$\checkmark$ User cofunding per TFA IPL; document reference below:

Letter TPP/99-STP-440 DOE-RL Robert M. Rosselli, Assistance Manager for Science and Technology to Richard T. French, Manager Office of River Protection "Fiscal Year (FY) 2000 Tanks Focus Area (TFA) Support to the Office of River Protection (ORP) dated October 5,1999

$\checkmark$ User successfully applied recommendations based on this work in assessing and addressing crust growth issue for tank SY-101.

\section{Technical Merit:}

$\checkmark$ ASME Peer Review performed in 1998; recommendations have been implemented

$\checkmark$ TFA will evaluate need for additional review in FY01

$\checkmark$ Work reviewed by TFA TAG in FY1999.

$\checkmark$ FIU test plan HCET-1999-T006-001-02-Rev.4 "Solids formation and Feed Stability During Waste Slurry Transfer - Test Plan for FY2000" establishes requirements for pipeline loop testing activities.

$\checkmark$ Test plans for MSU and ORNL test plans were reviewed by site users and issued [document reference numbers not on file] 
Cost:

$\checkmark$ This work is providing data and technical recommendations to assist Hanford site in planning for and developing recommendations to guide waste preparation and pipeline transfers. No specific technology is being developed therefore a cost evaluation is not required as relates to hardware type development.

$\checkmark$ A recent pipeline blockage in a Hanford saltwell pumping transfer line from tank U-103 caused a six-week delay in operations. Costs associated with such events vary greatly due to the specific circumstances, however a rough estimate for this case is an approximate cost impact of $\$ 800 \mathrm{~K}$ for increased operations and maintenance costs (opening valve pits, checking and removing jumpers, etc.) and loss of productivity. As these type of risks exist for many transfers, the potential cost savings from developing sound technical recommendations on waste preparation and operating envelopes for pipeline transfer could result in significant cost avoidance. [data provided by RPP staff via email].

$\checkmark$ The potential cost impact of a pipeline blockage during retrieval operations is potentially more serious. The TWRS Privatization Contract No. DE-AC06-96RL133308, Part 1, Section H, subsections H30 and H40 (See http://www.hanford.gov/doe/contracts/de-ac0696rl13308/sectionh-1 html) includes an idle facility penalty to DOE for delayed feed delivery to the contractor. These charges have not been established, but have been estimated at $\$ 2 \mathrm{M} /$ day or more. The investment in this project to provide technical basis data for improving pipeline waste transfers has a significant potential for cost avoidance related to feed delivery in the future vitrification operations.

$\checkmark$ Recommend TFA document cost avoidance potential in a letter report prepared by TFA TIM based on above information and other data provided and reviewed by site user.

$\checkmark$ The cost of constructing a new pipeline would be in the range of \$50M. This is based on the costs for the recent pipeline constructed at Hanford as documented in the "Construction Completion and Cost Closing Statement" DOE-HQ Project No. 93-D-182 that places final capital costs at $\$ 42.4 \mathrm{M}$ and associated expense costs at $\$ 7 \mathrm{M}$.

$\checkmark$ Cost estimate for a cross site transfer at Hanford is approximately $\$ 300 \mathrm{~K}$, based on recent Hanford data in RPP's “Cost Estimate Information Sheet” (CEIS) and Technical Baseline Results (TBR) 230.655.

\section{ES\&H Risk:}

$\checkmark$ Process operating limits for tank farms are described in HNF-SD-WM-TSR-006, "Tank Waste Remediation System Technical Safety Requirements". Sections 2 and 3 of this document specify limits relating to temperature, confinement, and flammable gas control. Section 4 specifies surveillance requirements. Section 5 covers administrative controls.

$\checkmark$ Plugging prevention precautions are described in HNF-SD-WM-OCD-015).

$\checkmark$ Risks are addressed in the "Tank Waste Remediation System Final Safety Analysis Report" HNF-SD-WM-SAR-067.

$\checkmark$ Reducing the possibility of pipes plugging and increasing understanding of waste solubility reduces programmatic risk and to the extent that such information permits the program to proceed at a greater pace, it reduces risk to the environment. 
$\checkmark$ Preventing pipeline plugs reduces exposure to workers who would be required in response actions. [data provided by RPP staff via email]

\section{Stakeholder, Regulatory, Tribal Issues:}

$\checkmark$ There are no specific issues related to this project. This work is providing data to improve Hanford tank waste operations. The site user is responsible for any issues in this area.

\section{Commercial Viability:}

$\checkmark$ This work is providing data to improve operations and is not related to any specific technology or hardware.

$\checkmark$ A commercial software product from OLI is being used in work related to the ESP code. The code database is proprietary and its use is provided under a use license (MSU and Hanford). 


\section{Status Questions for Progress Reviews:}

\section{Title: Hanford Waste Transfer/Solids Formation}

1) Has the project been reviewed for advancement through a gate during the past year? No.

2) Has an end user made at least a conditional commitment to implement the technology? End user plans to use data to provide additional technical basis for decisions on waste transfer operations. User has already used data to support evaluation of issues related to SY-101 crust growth. User is participating actively in the project.

3) Has a technical peer review been completed and is the work highly rated? Yes. Work was reviewed in 1998.

4) Has a cost-benefit analysis been performed for this technology and does it show potential savings compared to the baseline? Are user requirements for cost data identified and satisfied? Data on cost provided above.

5) Will this technology meet or exceed current environmental, safety, health, (ES\&H) protection levels and/or reduce the risk to the public, workers, and the environment compared to the baseline? Yes. See above. Are user requirements for ES\&H and technological risk identified and satisfied? Yes. See above.

6) Briefly discuss any activities and/or interactions with stakeholders, regulators, and tribal organizations relative to the continued research and utilization of this technology. Are user requirements for stakeholder, regulator, and tribal concerns identified and satisfied? $N / A$. This is the responsibility of ORP/RPP. There are no issues specifically related to this project.

7) Have invention disclosure and intellectual property issues been addressed? Briefly discuss the measures taken to include private industry in development and application of the technology. None anticipated. See statement above regarding software license.

8) Has an appropriate vendor (or other provider) for this technology been identified? N/A. See above. 


\section{Project Maturity Status Determination}

Title: 99084 Solid Liquid Separations

Tech ID: 350 Crossflow Filtration

Stage: Deployment

Last Gate:

6

\begin{tabular}{|c|c|c|c|c|c|c|c|}
\hline $\begin{array}{l}\text { MATURITY } \\
\text { STAGE }\end{array}$ & $\begin{array}{l}\text { TECHNICAL } \\
\text { NEED }\end{array}$ & $\begin{array}{c}\text { END-USER } \\
\text { INVOLVEMENT }\end{array}$ & $\begin{array}{l}\text { TECHNICAL } \\
\text { MERIT }\end{array}$ & COST & ES\&H RISK & $\begin{array}{l}\text { STAKEHOLDER, } \\
\text { REGULATORY, } \\
\text { TRIBAL ISSUES }\end{array}$ & $\begin{array}{l}\text { COMMERCIAL } \\
\text { VIABILITY }\end{array}$ \\
\hline Demonstration & $\begin{array}{l}\text { Need still } \\
\text { exists }\end{array}$ & $\begin{array}{l}\text { Demonstration } \\
\text { cost-sharing }\end{array}$ & $\begin{array}{l}\text { Demonstration } \\
\text { plan } \\
\text { N/A Favorable } \\
\text { peer review }\end{array}$ & $\begin{array}{l}\text { Demonstration } \\
\text { plan } \\
\text { N/A Favorable } \\
\text { peer review }\end{array}$ & $\begin{array}{l}\text { Demonstration } \\
\text { plan } \\
\text { N/A Favorable } \\
\text { peer review }\end{array}$ & $\begin{array}{l}\text { Demonstration } \\
\text { permits completed }\end{array}$ & $\begin{array}{l}\text { Vendor } \\
\text { participates in } \\
\text { demonstration }\end{array}$ \\
\hline
\end{tabular}

Indicates criterion is satisfied

$\square$ Indicates criterion/evidence is not yet satisfied

"N/A" Indicates criterion is not applicable or satisfied by other means; justification provided in evidence table

Date:

TFA Technology Delivery Manager: 


\section{Evidence Demonstrating Entrance Requirements are Met}

\section{Title: 99084 Solid Liquid Separations}

\section{Stage: Deployment}

Technical Need/Site Need ID(s):

OR-TK-04 Sludge Mixing and Slurry Transport

OR-TK-05 Tank Sludge and Supernatant Separations

End User Involvement:

$\checkmark$ User has deployed technology at ORNL

$\checkmark$ User approve MYTR 99084

$\checkmark$ User cofunding per TFA IPL; reference document below

Letter TPP/99-STP-440 DOE-RL Robert M. Rosselli, Assistance Manager for Science and Technology to R.R. Nelson, Assistant Manager for Environmental Management, OR "Fiscal Year (FY) 2000 Tanks Focus Area (TFA) Support to the Oak Ridge Reservation (ORR)" dated October 5, 1999

\section{Technical Merit:}

$\checkmark$ User selected and deployed technology as baseline for solid liquid separations

$\checkmark$ No ASME Peer Review was conducted; not needed as user has deployed technology

$\checkmark$ TFA Gate Review conducted in June 1998 at midyear review

$\checkmark$ See ITSR DOE/EM-0370

Cost:

$\checkmark$ User selected technology as cost-effective and is now in operation as baseline technology

$\checkmark$ This is an enabling technology to meet requirements to complete retrieval and transfer of waste from the GAAT tanks and to provide waste feed to the privatization contractor for MVST

$\checkmark$ See ITSR DOE/EM-0370 


\section{ES\&H Risk:}

$\checkmark$ Technology deployed by site user; these issues were addressed as part of the operational readiness review process

$\checkmark$ See ITSR DOE/EM-0370

\section{Stakeholder, Regulatory, Tribal Issues:}

$\checkmark$ Technology deployed by site user; these issues were addressed as part of the operational readiness review process

$\checkmark$ See ITSR DOE/EM-0370

\section{Commercial Viability:}

$\checkmark$ A commercial vendor was contracted to design and build the field deployed system to a specification developed by ORNL; Numet Ltd (Ontario, Canada) 


\section{Status Questions for Progress Reviews:}

\section{Title: 99084 Solid Liquid Separations}

Stage: Deployment

1) Has the project been reviewed for advancement through a gate during the past year? No. If yes, what was the result?

2) Has an end user made at least a conditional commitment to implement the technology? Yes, user has deployed technology.

3) Has a technical peer review been completed and is the work highly rated? N/A technology selected and deployed by user.

4) Has a cost-benefit analysis been performed for this technology and does it show potential savings compared to the baseline? Cost of system determined acceptable by end user to establish this technology as baseline. See ITSR reference. Are user requirements for cost data identified and satisfied? Yes.

5) Will this technology meet or exceed current environmental, safety, health, (ES\&H) protection levels and/or reduce the risk to the public, workers, and the environment compared to the baseline? Are user requirements for ES\&H and technological risk identified and satisfied? These requirements were evaluated and determined acceptable as part of ORR process. See ITSR.

6) Briefly discuss any activities and/or interactions with stakeholders, regulators, and tribal organizations relative to the continued research and utilization of this technology. Are user requirements for stakeholder, regulator, and tribal concerns identified and satisfied? Addressed as part of the ORR process. See ITSR.

7) Have invention disclosure and intellectual property issues been addressed? Yes. Briefly discuss the measures taken to include private industry in development and application of the technology. A commercial vendor was contracted to design and build the field deployment unit.

8) Has an appropriate vendor (or other provider) for this technology been identified? Yes. Numet Ltd. 


\section{Project Maturity Status Determination}

Title: 99086 SRS CIF Evaporator Tech ID:20 Out of Tank Evaporator Stage: Demonstration

Last Gate: 5

\begin{tabular}{|c|c|c|c|c|c|c|c|}
\hline $\begin{array}{l}\text { MATURITY } \\
\text { STAGE }\end{array}$ & $\begin{array}{l}\text { TECHNICAL } \\
\text { NEED }\end{array}$ & $\begin{array}{c}\text { END-USER } \\
\text { INVOLVEMENT }\end{array}$ & $\begin{array}{l}\text { TECHNICAL } \\
\text { MERIT }\end{array}$ & Cost & ES\&H RISK & $\begin{array}{l}\text { STAKEHOLDER, } \\
\text { REGULATORY, } \\
\text { TRIBAL ISSUES }\end{array}$ & $\begin{array}{l}\text { COMMERCIAL } \\
\text { VIABILITY }\end{array}$ \\
\hline Demonstration & $\begin{array}{l}\text { Need still } \\
\text { exists }\end{array}$ & $\begin{array}{l}\text { Demonstration } \\
\text { cost-sharing }\end{array}$ & $\begin{array}{l}\text { Demonstration } \\
\text { plan } \\
\text { N/A Favorable } \\
\text { peer review }\end{array}$ & $\begin{array}{l}\text { DDemonstration } \\
\text { plan } \\
\text { N/A Favorable } \\
\text { peer review }\end{array}$ & $\begin{array}{l}\text { 口 } \\
\begin{array}{l}\text { Demonstration } \\
\text { plan }\end{array} \\
\text { N/A Favorable } \\
\text { peer review }\end{array}$ & $\begin{array}{l}\text { Demonstration } \\
\text { permits completed }\end{array}$ & $\begin{array}{l}\text { Vendor } \\
\text { participates in } \\
\text { demonstration }\end{array}$ \\
\hline
\end{tabular}

Indicates criterion is satisfied

$\square$ Indicates criterion/evidence is not yet satisfied

"N/A" Indicates criterion is not applicable or satisfied by other means; justification provided in evidence table

Date:

TFA Technology Delivery Manager: 


\section{Evidence Demonstrating Entrance Requirements are Met}

\section{Title: 99086 SRS CIF Evaporator}

Technical Need/Site Need ID(s):

SR99-1011 Demonstrate Evaporation Technologies to Reduce Generation of Waste

\section{End User Involvement:}

$\checkmark$ User approved MYTR 99086

$\checkmark$ User will deploy technology in FY00/01

$\checkmark$ User cofunding per TFA IPL; see document reference below

Letter TPP/99-STP-440 DOE-RL Robert M. Rosselli, Assistance Manager for Science and Technology to R. J. Schepens, Assistant Manager for High-Level Waste DOE-SR "Fiscal Year (FY) 2000 Tanks Focus Area (TFA) Support to the Savannah River Operations Office (SR) High-Level Waste Program" dated October 5, 1999

\section{Technical Merit:}

$\checkmark$ Technology deployed at ORNL at MVST facility; adapted for SRS based on successful results of ORNL demonstration

$\checkmark$ No ASME Peer Review or TFA Gate Review were performed

$\checkmark$ Technology will be deployed by SRS end user in FY00/01, therefore an ASME Peer Review is not required.

$\checkmark$ Need to evaluate whether SRS has produced a demonstration plan for this work

$\checkmark$ Need reference to SRS acceptance criteria/test plans for the evaporator

\section{Cost:}

$\checkmark$ Cost data is available in ITSR DOE/EM-0373 based on ORNL deployment experience

\section{ES\&H Risk:}

$\checkmark$ See ITSR referenced above.

$\checkmark$ Technology provides enhancement to safety as it reduces potential for HEPA filter plugging and reduces the amount of downstream waste volume significantly 
Stakeholder, Regulatory, Tribal Issues:

$\checkmark$ This is an enhancement to an operating facilities and there are no known issues

\section{Commercial Viability:}

$\checkmark$ Equipment is being manufactured to specification by a commercial vendor (Ionics) under contract to DOE 


\section{Status Questions for Progress Reviews:}

\section{Title:99086 SRS CIF Evaporator Stage:_Demonstration}

1) Has the project been reviewed for advancement through a gate during the past year? No.

2) Has an end user made at least a conditional commitment to implement the technology? Yes. SRS plans to deploy in FY01, however currently the site is evaluating a potential shutdown of CIF that could impact deployment plans.

3) Has a technical peer review been completed and is the work highly rated? None performed. Technology has already been deployed at ORNL. SRS user determined technology acceptability based on performance in ORNL hot demonstration.

4) Has a cost-benefit analysis been performed for this technology and does it show potential savings compared to the baseline? Are user requirements for cost data identified and satisfied? (See ITSR)

5) Will this technology meet or exceed current environmental, safety, health, (ES\&H) protection levels and/or reduce the risk to the public, workers, and the environment compared to the baseline? Are user requirements for ES\&H and technological risk identified and satisfied? (See ITSR)

6) Briefly discuss any activities and/or interactions with stakeholders, regulators, and tribal organizations relative to the continued research and utilization of this technology. Are user requirements for stakeholder, regulator, and tribal concerns identified and satisfied? CIF is an operational facility at SRS. There are no known issues with operating the evaporator upgrade to this facility.

7) Have invention disclosure and intellectual property issues been addressed? Yes as part of contracting process. Briefly discuss the measures taken to include private industry in development and application of the technology. Contract placed with commercial vendor to fabricate the system.

8) Has an appropriate vendor (or other provider) for this technology been identified? Yes. Ionics (located in Pennsylvania) is fabricating the evaporator per specifications issued by DOE. 


\section{Project Maturity Status Determination}

Title: 99070 SRS Salt Processing Project - CST Alternative

Tech ID: 21 Cs Removal with CST

Stage: Development $\quad$ Last Gate: $\quad 3^{1}$

\begin{tabular}{|c|c|c|c|c|c|c|c|}
\hline $\begin{array}{l}\text { MATURITY } \\
\text { STAGE }\end{array}$ & $\begin{array}{l}\text { TECHNICAL } \\
\text { NEED }\end{array}$ & $\begin{array}{c}\text { END-USER } \\
\text { INVOLVEMENT }\end{array}$ & $\begin{array}{l}\text { TECHNICAL } \\
\text { MERIT }\end{array}$ & Cost & ES\&H RISK & $\begin{array}{l}\text { STAKEHOLDER, } \\
\text { REGULATORY, } \\
\text { TRIBAL ISSUES }\end{array}$ & $\begin{array}{l}\text { COMMERCIAL } \\
\text { VIABILITY }\end{array}$ \\
\hline Development & $\begin{array}{l}\text { Need still } \\
\text { exists }\end{array}$ & $\begin{array}{l}\text { Addresses } \\
\text { performance } \\
\text { requirements } \\
\text { Available when } \\
\text { needed }\end{array}$ & $\begin{array}{l}\text { Improved } \\
\text { solution (enabling or } \\
\text { significantly more } \\
\text { effective) } \\
\text { Favorable peer } \\
\text { review rating }\end{array}$ & $\begin{array}{l}\text { Improved } \\
\text { solution (enabling or } \\
\text { significantly less } \\
\text { costly) } \\
\text { Demonstration } \\
\text { and operating } \\
\text { costs estimated }\end{array}$ & $\begin{array}{l}\text { Improved } \\
\text { solution (enabling } \\
\text { or significantly lower } \\
\text { risk) } \\
\text { Favorable } \\
\text { peer review } \\
\text { rating }\end{array}$ & $\begin{array}{l}\text { Peer review finds } \\
\text { data valid for use } \\
\text { with regulators and } \\
\text { stakeholders }\end{array}$ & $\begin{array}{l}\text { Potential } \\
\text { vendor identified }\end{array}$ \\
\hline
\end{tabular}

Indicates criterion is satisfied

$\square$ Indicates criterion/evidence is not yet satisfied

"N/A" Indicates criterion is not applicable or satisfied by other means; justification provided in evidence table

Date: $\quad$ TFA Technology Delivery Manager:

${ }^{1}$ Technology was previously deployed at ORNL, however modifications and scale up issues require project to go back to development stage E.70 


\section{Evidence Demonstrating Entrance Requirements are Met}

Title: 99070 SRS Salt Processing Project - CST Alternative

\section{Stage: _ Development}

\section{Technical Need/Site Need ID(s):}

SR99-2034 Second Generation Salt Feed Preparation

\section{End User Involvement:}

$\checkmark$ User approved MYTR 99070

$\checkmark$ User cofunding per TFA IPL; reference document below:

Letter TPP/99-STP-440 DOE-RL Robert M. Rosselli, Assistance Manager for Science and Technology to R. J. Schepens, Assistant Manager for High-Level Waste DOE-SR "Fiscal Year (FY) 2000 Tanks Focus Area (TFA) Support to the Savannah River Operations Office (SR) High-Level Waste Program" dated October 5, 1999

\section{Technical Merit:}

$\checkmark$ Project reviewed by National Academy of Sciences Board on Radioactive Waste Management and results published in letter report; ref.: Letter Milt Levenson and Greg Choppin to Ernest Moniz dated October 14, 1999

$\checkmark$ Alternative evaluation and recommendations presented in WSRC-RP-98-00165 HLW Salt Disposition Alternatives Identification Preconceptual Phase II Summary Report (6 vols)

$\checkmark$ Scope of work defined in SRS document HLW-SDT-2000-00051; approved by site end user

$\checkmark$ Technology roadmap developed; HLW-SDT-980165

\section{Cost:}

$\checkmark$ The SRS Alternative Salt Project Office is performing detailed cost analysis for implementing TPB alternative

$\checkmark$ Cost analyses developed as part of the alternatives evaluation are documented in WSRC-RP-98-00167, WSRC-RP-98-000166 rv 1, and WSRC-RP-99-0007

$\checkmark$ This is an enabling technology; cost will be evaluated in comparison to other alternatives (TPB and Solvent Extraction) and documented as part of the alternative selection process 
$\checkmark$ Cost data on prior development on CST technology is provided in ITSR DOE/EM-0415

\section{ES\&H Risk:}

$\checkmark$ This is an enabling technology that will likely be assessed as superior to unacceptable baseline process (ITP); ES\&H risk will be evaluated as part of the alternative selection process

\section{Stakeholder, Regulatory, Tribal Issues:}

$\checkmark$ SRS has engaged the Citizens Advisory Board in the alternative review process

$\checkmark$ Public hearings were conducted in 1999

$\checkmark$ SRS is conducting an EIS process that will address these issues prior to ROD; this may not be finalized until after the preferred alternative is selected

$\checkmark \quad$ The Federal Facility Agreement with DOE, State, and EPA requires all non-compliant tanks (Type III) to be out of service by 2022 and all backlogged waste to be processed by 2028

$\checkmark$ See ITSR DOE/EM-0415

\section{Commercial Viability:}

$\checkmark$ UOP is commercial supplier of CST resin under an exclusive licensing agreement through a CRADA

$\checkmark$ DOE is considering privatizing the cesium removal operations at SRS

$\checkmark$ DOE/SRS will develop specifications for the process in-house with TFA support in developing and testing options

$\checkmark$ Equipment for the processing plant is likely to be competitively procured

$\checkmark$ See ITSR DOE/EM-0415 


\section{Status Questions for Progress Reviews:}

\section{Title: 99070 SRS Salt Processing Project - CST Alternative Stage:_Development}

1) Has the project been reviewed for advancement through a gate during the past year? No.

2) Has an end user made at least a conditional commitment to implement the technology? User will down-select the preferred alternative and implement it as the new site baseline process for Cs removal in accordance with the Salt Processing Project schedule.

3) Has a technical peer review been completed and is the work highly rated? National Academy of Sciences review conducted in FY99.

4) Has a cost-benefit analysis been performed for this technology and does it show potential savings compared to the baseline? Are user requirements for cost data identified and satisfied? Yes. (See above)

5) Will this technology meet or exceed current environmental, safety, health, (ES\&H) protection levels and/or reduce the risk to the public, workers, and the environment compared to the baseline? Process must meet all environmental, safety and health requirements. This will be established through testing and demonstration of process options. Are user requirements for ES\&H and technological risk identified and satisfied? Yes.

6) Briefly discuss any activities and/or interactions with stakeholders, regulators, and tribal organizations relative to the continued research and utilization of this technology. DOE-SR and WSRC have conducted public hearings on the Salt Processing Project. Are user requirements for stakeholder, regulator, and tribal concerns identified and satisfied? This has not yet be through an EIS process, these questions will be answered at that time.

7) Have invention disclosure and intellectual property issues been addressed? Partially. There may be outstanding issues related to modification and manufacturing the CST resin for this application. Briefly discuss the measures taken to include private industry in development and application of the technology. Industrial partnership established with UOP through a CRADA with SNL.

8) Has an appropriate vendor (or other provider) for this technology been identified? Yes. UOP is commercial vendor. 


\section{Project Maturity Status Determination}

Title: 99070 SRS Salt Processing Project - MST Alternative

Tech ID: TBD $^{1}$

Stage: Development

Last Gate:

4

\begin{tabular}{|c|c|c|c|c|c|c|c|}
\hline $\begin{array}{l}\text { MATURITY } \\
\text { STAGE }\end{array}$ & $\begin{array}{l}\text { TECHNICAL } \\
\text { NEED }\end{array}$ & $\begin{array}{c}\text { END-USER } \\
\text { INVOLVEMENT }\end{array}$ & $\begin{array}{l}\text { TECHNICAL } \\
\text { MERIT }\end{array}$ & COST & ES\&H RISK & $\begin{array}{l}\text { STAKEHOLDER, } \\
\text { REGULATORY, } \\
\text { TRIBAL ISSUES }\end{array}$ & $\begin{array}{l}\text { COMMERCIAL } \\
\text { VIABILITY }\end{array}$ \\
\hline Development & $\begin{array}{l}\text { Need still } \\
\text { exists }\end{array}$ & $\begin{array}{l}\text { Addresses } \\
\text { performance } \\
\text { requirements } \\
\text { Available when } \\
\text { needed }\end{array}$ & $\begin{array}{l}\text { Improved } \\
\text { solution (enabling or } \\
\text { significantly more } \\
\text { effective) } \\
\text { Favorable peer } \\
\text { review rating }\end{array}$ & $\begin{array}{l}\text { Improved } \\
\text { solution (enabling or } \\
\text { significantly less } \\
\text { costly) } \\
\text { Demonstration } \\
\text { and operating } \\
\text { costs estimated }\end{array}$ & $\begin{array}{l}\text { Improved } \\
\text { solution (enabling } \\
\text { or significantly lower } \\
\text { risk) } \\
\text { Favorable } \\
\text { peer review } \\
\text { rating }\end{array}$ & $\begin{array}{l}\text { Peer review finds } \\
\text { data valid for use } \\
\text { with regulators and } \\
\text { stakeholders }\end{array}$ & $\begin{array}{l}\text { Potential } \\
\text { vendor identified }\end{array}$ \\
\hline
\end{tabular}

Indicates criterion is satisfied

$\square$ Indicates criterion/evidence is not yet satisfied

"N/A" Indicates criterion is not applicable or satisfied by other means; justification provided in evidence table

Date: $\quad$ TFA Technology Delivery Manager:

${ }^{1}$ Need to determine if TMS ID for TBP should be added 


\section{Evidence Demonstrating Entrance Requirements are Met}

\section{Title: 99070 SRS Salt Processing Project - MST Alternative}

\section{Stage: Development}

\section{Technical Need/Site Need ID(s):}

SR99-2034 Second Generation Salt Feed Preparation

\section{End User Involvement:}

$\checkmark$ User approved MYTR 99070

$\checkmark$ User cofunding per TFA IPL; reference document below:

Letter TPP/99-STP-440 DOE-RL Robert M. Rosselli, Assistance Manager for Science and Technology to R. J. Schepens, Assistant Manager for High-Level Waste DOE-SR "Fiscal Year (FY) 2000 Tanks Focus Area (TFA) Support to the Savannah River Operations Office (SR) High-Level Waste Program" dated October 5, 1999

\section{Technical Merit:}

$\checkmark$ Project reviewed by National Academy of Sciences Board on Radioactive Waste Management and results published in letter report; ref.: Letter Milt Levenson and Greg Choppin to Ernest Moniz dated October 14, 1999

$\checkmark$ Alternative evaluation and recommendations presented in WSRC-RP-98-00165 HLW Salt Disposition Alternatives Identification Preconceptual Phase II Summary Report (6 vols)

$\checkmark$ Scope of work defined in SRS document HLW-SDT-2000-00051; approved by site end user

$\checkmark$ Technology roadmap developed; HLW-SDT-980164

\section{Cost:}

$\checkmark$ The SRS Alternative Salt Project Office is performing detailed cost analysis for implementing TPB alternative

$\checkmark$ Cost analyses developed as part of the alternatives evaluation are documented in WSRC-RP-98-00167, WSRC-RP-98-000166 rv 1, and WSRC-RP-99-0007

$\checkmark$ This is an enabling technology; cost will be evaluated in comparison to other alternatives (CST and Solvent Extraction) and documented as part of the alternative selection process 


\section{ES\&H Risk:}

$\checkmark$ This is an enabling technology that will likely be assessed as superior to unacceptable baseline process (ITP); ES\&H risk will be evaluated as part of the alternative selection process

\section{Stakeholder, Regulatory, Tribal Issues:}

$\checkmark$ SRS has engaged the Citizens Advisory Board in the alternative review process

$\checkmark$ Public hearings were conducted in 1999

$\checkmark$ SRS is conducting an EIS process that will address these issues prior to ROD; this may not be finalized until after the preferred alternative is selected

$\checkmark \quad$ The Federal Facility Agreement with DOE, State, and EPA requires all non-compliant tanks (Type III) to be out of service by 2022 and all backlogged waste to be processed by 2028

\section{Commercial Viability:}

$\checkmark$ DOE is considering privatizing the cesium removal operations at SRS

$\checkmark$ DOE/SRS will develop specifications for the process in-house with TFA support in developing and testing options

$\checkmark$ MST process uses standard chemical engineering technologies that can be procured through commercial suppliers; there are several known vendors for this equipment and the required sorbents

$\checkmark$ Equipment is likely to be competitively procured 


\section{Status Questions for Progress Reviews:}

\section{Title: 99070 SRS Salt Processing Project-MST Alternative Stage: Development}

1) Has the project been reviewed for advancement through a gate during the past year? No.

2) Has an end user made at least a conditional commitment to implement the technology? User will down-select the preferred alternative and implement it as the new site baseline process for Cs removal.

3) Has a technical peer review been completed and is the work highly rated? National Academy of Sciences review conducted in FY99.

4) Has a cost-benefit analysis been performed for this technology and does it show potential savings compared to the baseline? Are user requirements for cost data identified and satisfied? Yes. See references above.

5) Will this technology meet or exceed current environmental, safety, health, (ES\&H) protection levels and/or reduce the risk to the public, workers, and the environment compared to the baseline? Process must meet all environmental, safety and health requirements. This will be established through testing and demonstration of process options. Are user requirements for ES\&H and technological risk - identified and satisfied? Yes.

6) Briefly discuss any activities and/or interactions with stakeholders, regulators, and tribal organizations relative to the continued research and utilization of this technology. DOE-SR and WSRC have conducted public hearings on the Salt Processing Project. Are user requirements for stakeholder, regulator, and tribal concerns identified and satisfied? This has not yet be through an EIS process, these questions will be answered at that time.

7) Have invention disclosure and intellectual property issues been addressed? Not at this time. These issues will be evaluated as work progresses further and if selected as the preferred alternative. No issues known at this time. Briefly discuss the measures taken to include private industry in development and application of the technology. Industry is not currently involved. If this alternative is selected for full-scale deployment, industry may provide some components and materials.

8) Has an appropriate vendor (or other provider) for this technology been identified? Not at this time. 


\section{Project Maturity Status Determination}

Title: 99070 SRS Salt Processing Project - Solvent Extraction Alternative. Tech ID: 204 - Advanced Integrated Solvent Extraction Systems ${ }^{1}$

Stage: Development

Last Gate: 2

\begin{tabular}{|c|c|c|c|c|c|c|c|}
\hline $\begin{array}{l}\text { MATURITY } \\
\text { STAGE }\end{array}$ & $\begin{array}{c}\text { TECHNICAL } \\
\text { NEED }\end{array}$ & $\begin{array}{c}\text { END-USER } \\
\text { INVOLVEMENT }\end{array}$ & $\begin{array}{l}\text { TECHNICAL } \\
\text { MERIT }\end{array}$ & COST & ES\&H RISK & $\begin{array}{c}\text { STAKEHOLDER, } \\
\text { REGULATORY, } \\
\text { TRIBAL ISSUES }\end{array}$ & $\begin{array}{l}\text { COMMERCIAL } \\
\text { VIABILITY }\end{array}$ \\
\hline Development & $\begin{array}{l}\text { Need still } \\
\text { exists }\end{array}$ & $\begin{array}{l}\text { Addresses } \\
\text { performance } \\
\text { requirements } \\
\text { Available when } \\
\text { needed }\end{array}$ & $\begin{array}{l}\text { Improved } \\
\text { solution (enabling or } \\
\text { significantly more } \\
\text { effective) } \\
\text { Favorable peer } \\
\text { review rating }\end{array}$ & $\begin{array}{l}\text { Improved } \\
\text { solution (enabling or } \\
\text { significantly less } \\
\text { costly) } \\
\text { Demonstration } \\
\text { and operating } \\
\text { costs estimated }\end{array}$ & $\begin{array}{l}\text { Improved } \\
\text { solution (enabling } \\
\text { or significantly lower } \\
\text { risk) } \\
\text { Favorable } \\
\text { peer review. } \\
\text { rating }\end{array}$ & $\begin{array}{l}\text { Peer review finds } \\
\text { data valid for use } \\
\text { with regulators and } \\
\text { stakeholders }\end{array}$ & $\begin{array}{l}\text { Potential } \\
\text { vendor identified }\end{array}$ \\
\hline
\end{tabular}

Indicates criterion is satisfied

$\square$ Indicates criterion/evidence is not yet satisfied

"N/A" Indicates criterion is not applicable or satisfied by other means; justification provided in evidence table

Date:

TFA Technology Delivery Manager:

${ }^{1}$ Not sure if this TMS ID applies to this application of solvent extraction technology 


\section{Evidence Demonstrating Entrance Requirements are Met}

\section{Title: 99070 SRS Salt Processing Project - Solvent Extraction Alternative Stage: _Development}

\section{Technical Need/Site Need ID(s):}

SR99-2034 Second Generation Salt Feed Preparation

\section{End User Involvement:}

$\checkmark$ User approved MYTR 99070

$\checkmark$ User cofunding per TFA IPL; reference document below:

Letter TPP/99-STP-440 DOE-RL Robert M. Rosselli, Assistance Manager for Science and Technology to R. J. Schepens, Assistant Manager for High-Level Waste DOE-SR "Fiscal Year (FY) 2000 Tanks Focus Area (TFA) Support to the Savannah River Operations Office (SR) High-Level Waste Program" dated October 5, 1999

\section{Technical Merit:}

$\checkmark$ Project reviewed by National Academy of Sciences Board on Radioactive Waste Management and results published in letter report; ref.: Letter Milt Levenson and Greg Choppin to Ernest Moniz dated October 14, 1999

$\checkmark$ Alternative evaluation and recommendations presented in WSRC-RP-98-00165 HLW Salt Disposition Alternatives Identification Preconceptual Phase II Summary Report (6 vols)

$\checkmark$ Scope of work defined in SRS document HLW-SDT-2000-00051; approved by site end user

\section{Cost:}

$\checkmark$ The SRS Alternative Salt Project Office is performing detailed cost analysis for implementing TPB alternative

$\checkmark$ Cost analyses developed as part of the alternatives evaluation are documented in WSRC-RP-98-00167, WSRC-RP-98-000166 rv 1, and WSRC-RP-99-0007

$\checkmark$ This is an enabling technology; cost will be evaluated in comparison to other alternatives (TPB and Solvent Extraction) and documented as part of the alternative selection process 


\section{ES\&H Risk:}

$\checkmark \quad$ This is an enabling technology that will likely be assessed as superior to unacceptable baseline process (ITP); ES\&H risk will be evaluated as part of the alternative selection process

\section{Stakeholder, Regulatory, Tribal Issues:}

$\checkmark$ SRS has engaged the Citizens Advisory Board in the alternative review process

$\checkmark$ Public hearings were conducted in 1999

$\checkmark$ SRS is conducting an EIS process that will address these issues prior to ROD; this may not be finalized until after the preferred alternative is selected

$\checkmark$ The Federal Facility Agreement with DOE, State, and EPA requires all non-compliant tanks (Type III) to be out of service by 2022 and all backlogged waste to be processed by 2028

\section{Commercial Viability:}

$\checkmark$ If alternative is selected, industry involvement will likely be sought to provide centrifugal contactors required for the process

$\checkmark$ DOE is considering privatizing the cesium removal operations at SRS

$\checkmark$ DOE/SRS will develop specifications for the process in-house with TFA support in developing and testing options

$\checkmark$ Project plans to contract with IBC to build system for conducting development testing, but the full-scale system will likely be competitively procured

$\checkmark$ There are several sources for the chemicals required to run this process and equipment is generally standard commercial equipment that can be customized for the specific needs of this process operation 


\section{Status Questions for Progress Reviews:}

\section{Title: 99070 SRS Salt Processing Project - Solvent Extraction Alternative Stage: _Development}

1) Has the project been reviewed for advancement through a gate during the past year No.

2) Has an end user made at least a conditional commitment to implement the technology? User will down-select the preferred alternative and implement it as the new site baseline process for Cs removal. Process will be deployed according to the Salt Processing Project schedule.

3) Has a technical peer review been completed and is the work highly rated? National Academy of Sciences review conducted in FY99 (see letter reference above)

4) Has a cost-benefit analysis been performed for this technology and does it show potential savings compared to the baseline? Are user requirements for cost data identified and satisfied? Yes. See references above.

5) Will this technology meet or exceed current environmental, safety, health, (ES\&H) protection levels and/or reduce the risk to the public, workers, and the environment compared to the baseline? Process must meet all environmental, safety and health requirements. This will be established through testing and demonstration of process options. Are user requirements for ES\&H and technological risk identified and satisfied? Yes.

6) Briefly discuss any activities and/or interactions with stakeholders, regulators, and tribal organizations relative to the continued research and utilization of this technology. DOE-SR and WSRC have conducted public hearings on the Salt Processing Project. Are user requirements for stakeholder, regulator, and tribal concerns identified and satisfied? This has not yet be through an EIS process, these questions will be answered at that time.

7) Have invention disclosure and intellectual property issues been addressed? Not at this time. These issues will be evaluated as work progresses further and if selected as the preferred alternative. No issues known at this time. Briefly discuss the measures taken to include private industry in development and application of the technology. Industry is not currently involved, but a vendor to provide 
the equipment for development testing has been identified.. If this alternative is selected for full-scale deployment an industry solicitation for centrifugal contactors is likely.

8) Has an appropriate vendor (or other provider) for this technology been identified? Only for lab scale development equipment. A vendor or procurement strategy for a full-scale system has not been identified at this time. This will be pursued if this option is selected for full scale testing. 


\section{Project Maturity Status Determination}

Title: 99070 SRS Salt Processing Project - TPB Alternative

Tech ID:TBD

Stage: Development

Last Gate: 3

\begin{tabular}{|c|c|c|c|c|c|c|c|}
\hline $\begin{array}{l}\text { MATURITY } \\
\text { STAGE }\end{array}$ & $\begin{array}{l}\text { TECHNICAL } \\
\text { NEED }\end{array}$ & $\begin{array}{c}\text { END-USER } \\
\text { INVOLVEMENT }\end{array}$ & $\begin{array}{l}\text { TECHNICAL } \\
\text { MERIT }\end{array}$ & COST & ES\&H RISK & $\begin{array}{l}\text { STAKEHOLDER, } \\
\text { REGULATORY, } \\
\text { TRIBAL ISSUES }\end{array}$ & $\begin{array}{l}\text { COMMERCIAL } \\
\text { VIABILITY }\end{array}$ \\
\hline Development & $\begin{array}{l}\text { Need still } \\
\text { exists }\end{array}$ & $\begin{array}{l}\text { Addresses } \\
\text { performance } \\
\text { requirements } \\
\text { Available when } \\
\text { needed }\end{array}$ & $\begin{array}{l}\text { Improved } \\
\text { solution (enabling or } \\
\text { significantly more } \\
\text { effective) } \\
\text { Favorable peer } \\
\text { review rating }\end{array}$ & $\begin{array}{l}\text { Improved } \\
\text { solution (enabling or } \\
\text { significantly less } \\
\text { costly) } \\
\text { Demonstration } \\
\text { and operating } \\
\text { costs estimated }\end{array}$ & $\begin{array}{l}\text { Improved } \\
\text { solution (enabling } \\
\text { or significantly lower } \\
\text { risk) } \\
\text { Favorable } \\
\text { peer review } \\
\text { rating }\end{array}$ & $\begin{array}{l}\text { Peer review finds } \\
\text { data valid for use } \\
\text { with regulators and } \\
\text { stakeholders }\end{array}$ & $\begin{array}{l}\text { Potential } \\
\text { vendor identified }\end{array}$ \\
\hline
\end{tabular}

Indicates criterion is satisfied

$\square$ Indicates criterion/evidence is not yet satisfied

"N/A" Indicates criterion is not applicable or satisfied by other means; justification provided in evidence table

Date:

TFA Technology Delivery Manager: 


\section{Evidence Demonstrating Entrance Requirements are Met}

Title: 99070 SRS Salt Processing Project - TPB Alternative

\section{Stage: Development}

\section{Technical Need/Site Need ID(s):}

SR99-2034 Second Generation Salt Feed Preparation

\section{End User Involvement:}

$\checkmark$ User approved MYTR 99070

$\checkmark$ User cofunding per TFA IPL; reference document below:

Letter TPP/99-STP-440 DOE-RL Robert M. Rosselli, Assistance Manager for Science and Technology to R. J. Schepens, Assistant Manager for High-Level Waste DOE-SR "Fiscal Year (FY) 2000 Tanks Focus Area (TFA) Support to the Savannah River Operations Office (SR) High-Level Waste Program" dated October 5, 1999

\section{Technical Merit:}

$\checkmark$ Project reviewed by National Academy of Sciences Board on Radioactive Waste Management and results published in letter report; ref.: Letter Milt Levenson and Greg Choppin to Ernest Moniz dated October 14, 1999

$\checkmark$ Alternative evaluation and recommendations presented in WSRC-RP-98-00165 HLW Salt Disposition Alternatives Identification Preconceptual Phase II Summary Report (6 vols)

$\checkmark$ Scope of work defined in SRS document HLW-SDT-2000-00051; approved by site end user

$\checkmark$ Technology roadmap developed; HLW-SDT-980164

Cost:

$\checkmark$ The SRS Alternative Salt Project Office is performing detailed cost analysis for implementing TPB alternative

$\checkmark$ Cost analyses developed as part of the alternatives evaluation are documented in WSRC-RP-98-00167, WSRC-RP-98-000166 rv 1, and WSRC-RP-99-0007

$\checkmark \quad$ This is an enabling technology; cost will be evaluated in comparison to other alternatives (CST and Solvent Extraction) and documented as part of the alternative selection process 


\section{ES\&H Risk:}

$\checkmark$ This is an enabling technology that will likely be assessed as superior to unacceptable baseline process (ITP); ES\&H risk will be evaluated as part of the alternative selection process

\section{Stakeholder, Regulatory, Tribal Issues:}

$\checkmark$ SRS has engaged the Citizens Advisory Board in the alternative review process

$\checkmark$ Public hearings were conducted in 1999

$\checkmark$ SRS is conducting an EIS process that will address these issues prior to ROD; this may not be finalized until after the preferred alternative is selected

$\checkmark \quad$ The Federal Facility Agreement with DOE, State, and EPA requires all non-compliant tanks (Type III) to be out of service by 2022 and all backlogged waste to be processed by 2028

\section{Commercial Viability:}

$\checkmark$ DOE is considering privatizing the cesium removal operations at SRS

$\checkmark$ DOE/SRS will develop specifications for the process in-house with TFA support in developing and testing options

$\checkmark$ TBP process uses standard chemical engineering technologies that can be procured through commercial suppliers; there are several known vendors for this equipment

$\checkmark$ Equipment is likely to be competitively procured 


\section{Status Questions for Progress Reviews:}

\section{Title: 99070 SRS Salt Processing Project - TPB Alternative Stage: _ Development}

1) Has the project been reviewed for advancement through a gate during the past year No.

2) Has an end user made at least a conditional commitment to implement the technology? User will down-select the preferred alternative and implement it as the new site baseline process for Cs removal. Process will be deployed according to the Salt Processing Project schedule.

3) Has a technical peer review been completed and is the work highly rated? National Academy of Sciences review conducted in FY99 (see letter reference above)

4) Has a cost-benefit analysis been performed for this technology and does it show potential savings compared to the baseline? Are user requirements for cost data identified and satisfied? Yes. See references above.

5) Will this technology meet or exceed current environmental, safety, health, $(\mathrm{ES} \& \mathrm{H})$ protection levels and/or reduce the risk to the public, workers, and the environment compared to the baseline? Process must meet all environmental, safety and health requirements. This will be established through testing and demonstration of process options. Are user requirements for ES\&H and technological risk identified and satisfied? Yes.

6) Briefly discuss any activities and/or interactions with stakeholders, regulators, and tribal organizations relative to the continued research and utilization of this technology. DOE-SR and WSRC have conducted public hearings on the Salt Processing Project. Are user requirements for stakeholder, regulator, and tribal concerns identified and satisfied? This has not yet be through an EIS process, these questions will be answered at that time.

7) Have invention disclosure and intellectual property issues been addressed? Not at this time, however as the systems required for TPB are standard chemical engineering technology it is not believed there are any IP issues. This question will be evaluated further as work progresses further and if selected as the preferred alternative. No issues known at this time. Briefly discuss the measures taken to include private industry in development and application of the technology. Industry is not currently involved. If this alternative is selected for full-scale deployment, industry may provide some components and materials. 
8) Has an appropriate vendor (or other provider) for this technology been identified? Not at this time. DOE will likely privatize the project to build and operate the plant for the selected alternative. 


\section{Project Maturity Status Determination}

Title: 99019 INEEL LLW Immobilization

Tech ID: 82 LAW Forms

Stage: Demonstration

Last Gate: 5

\begin{tabular}{|c|c|c|c|c|c|c|c|}
\hline $\begin{array}{l}\text { MATURITY } \\
\text { STAGE }\end{array}$ & $\begin{array}{c}\text { TECHNICAL } \\
\text { NEED }\end{array}$ & $\begin{array}{c}\text { END-USER } \\
\text { INVOLVEMENT }\end{array}$ & $\begin{array}{l}\text { TECHNICAL } \\
\text { MERIT }\end{array}$ & COST & ES\&H RISK & $\begin{array}{c}\text { STAKEHOLDER, } \\
\text { REGULATORY, } \\
\text { TRIBAL ISSUES }\end{array}$ & $\begin{array}{l}\text { COMMERCIAL } \\
\text { VIABILITY }\end{array}$ \\
\hline Demonstration & $\begin{array}{l}\text { Need still } \\
\text { exists }\end{array}$ & $\begin{array}{l}\text { Demonstration } \\
\text { cost-sharing }\end{array}$ & $\begin{array}{l}\text { Demonstration } \\
\text { plan } \\
\square \text { Favorable peer } \\
\text { review }\end{array}$ & $\begin{array}{l}\text { Demonstration } \\
\text { plan } \\
\square \text { Favorable peer } \\
\text { review }\end{array}$ & $\begin{array}{l}\square \\
\text { Demonstration } \\
\text { plan } \\
\square \text { Favorable } \\
\text { peer review }\end{array}$ & $\begin{array}{l}\text { Demonstration } \\
\text { permits completed }\end{array}$ & $\begin{array}{l}\text { Vendor } \\
\text { participates in } \\
\text { demonstration }\end{array}$ \\
\hline
\end{tabular}

Indicates criterion is satisfied

$\square$ Indicates criterion/evidence is not yet satisfied

"N/A" Indicates criterion is not applicable or satisfied by other means; justification provided in evidence table

Date:

TFA Technology Delivery Manager: 


\section{Evidence Demonstrating Entrance Requirements are Met}

\section{Title: 99019 INEEL LLW Immobilization}

\section{Stage: _Demonstration}

\section{Technical Need/Site Need ID(s):}

ID-2.1.23 Low-Activity Wasteform Qualification

ID-2.1.28 Cs Removal from Newly Generated Liquid Waste

ID-2.1.35 Direct Immobilization of INTEC Sodium-Bearing Waste

ID-2.1.38 Conditioning of Low Activity Waster for Treatment

\section{End User Involvement:}

$\checkmark$ User approved MYTR 99019

$\checkmark$ User planning to deploy grout process in FY01

Reference: Idaho Nuclear Technology and Engineering Center Newly Generated Liquid Waste Demonstration Project Feasibility Study; INEEL document - draft for review (planned to be issued in March 2000)

$\checkmark$ User cofunding per TFA IPL; see document reference below

Letter TPP/99-STP-440 DOE-RL Robert M. Rosselli, Assistance Manager for Science and Technology to J.T. Case, Program Director Idaho Operations Office "Fiscal Year (FY) 2000 Tanks Focus Area (TFA) Support to the Idaho Operations Office (ID) High-Level Waste Program" dated October 5, 1999

\section{Technical Merit:}

$\checkmark$ TFA conducted Gate 5 Review in May 1999 resulting in recommendation that project proceed to Stage 6; report reference below Letter TFA99-182 Thomas M. Brouns to Theodore P. Pietrok "Idaho Type 2 Waste Cementation Gate Review Results" dated July 19, 1999.

$\checkmark$ Technical progress review conducted February 2000 to review results of feasibility study; INEEL/EXT-2000-00141 Idaho Nuclear Technology and Engineering Center Newly Generated Liquid Waste Demonstration Project Feasibility Study February 2000

$\checkmark$ DOE-ID and BBWI have approved project to begin Title design activities based on recommendations of feasibility study above.

$\checkmark$ ASME Peer Review planned for August 2000 
Cost:

$\checkmark$ Documented in feasibility study report (see reference above)

\section{ES\&H Risk:}

$\checkmark$ Documented in feasibility study report (see reference above)

$\checkmark$ Site is preparing paperwork to apply for RD\&D permit in FY00.

Stakeholder, Regulatory, Tribal Issues:

$\checkmark$ Documented in feasibility study report (see reference above)

$\checkmark$ INEEL is in process of applying for an RD\&D Permit from the State to conduct the pilot plant demonstration.

\section{Commercial Viability:}

$\checkmark$ Documented in feasibility study report (see reference above)

$\checkmark$ AEA Technology is providing support to grout formulation and equipment specification through DOE contract 


\section{Status Questions for Progress Reviews:}

\section{Title: 99019 INEEL LLW Immobilization}

Stage: _Demonstration

1) Has the project been reviewed for advancement through a gate during the past year? Yes. If yes, what was the result? Project was determined to have met criteria to proceed to Stage 6-Demonstration. DOE-ID and BBWI has approved project to move into Title design and preparation for an FYOI hot demonstration of the grout pilot plant.

2) Has an end user made at least a conditional commitment to implement the technology? Yes. INEEL plans to deploy grout process for NGLW in FYOI.

3) Has a technical peer review been completed and is the work highly rated? ASME Peer review planned for August 2000.

4) Has a cost-benefit analysis been performed for this technology and does it show potential savings compared to the baseline? Are user requirements for cost data identified and satisfied? Yes, in feasibility study.

5) Will this technology meet or exceed current environmental, safety, health, (ES\&H) protection levels and/or reduce the risk to the public, workers, and the environment compared to the baseline? Yes. See feasibility study. Are user requirements for ES\&H and technological risk identified and satisfied? Yes, in feasibility study.

6) Briefly discuss any activities and/or interactions with stakeholders, regulators, and tribal organizations relative to the continued research and utilization of this technology. Are user requirements for stakeholder, regulator, and tribal concerns identified and satisfied? Yes, in feasibility study.

7) Have invention disclosure and intellectual property issues been addressed? Yes, see Gate Review Report. Briefly discuss the measures taken to include private industry in development and application of the technology. AEA Technology is developing grout formulations and providing technical assistance in design of grout pilot plant.

8) Has an appropriate vendor (or other provider) for this technology been identified? Yes. Additional commercial suppliers will be identified when grout plant design is completed. Project will determine procurement strategy as part of title design. 


\section{Project Maturity Status Determination}

Title: 99068 SRS DWPF Melter Performance Improvements

Tech ID: 2092

Stage: Demonstration

Last Gate:

5

\begin{tabular}{|c|c|c|c|c|c|c|c|}
\hline $\begin{array}{l}\text { MATURITY } \\
\text { STAGE }\end{array}$ & $\begin{array}{l}\text { TECHNICAL } \\
\text { NEED }\end{array}$ & $\begin{array}{l}\text { END-USER } \\
\text { INVOLVEMENT }\end{array}$ & $\begin{array}{l}\text { TECHNICAL } \\
\text { MERIT }\end{array}$ & COST & ES\&H RISK & $\begin{array}{l}\text { STAKEHOLDER } \\
\text {, REGULATORY, } \\
\text { TRIBAL ISSUES }\end{array}$ & $\begin{array}{l}\text { COMMERCIAL } \\
\text { VIABILITY }\end{array}$ \\
\hline Demonstration & $\begin{array}{l}\text { Need still } \\
\text { exists }\end{array}$ & $\begin{array}{l}\text { Demonstration } \\
\text { cost-sharing }\end{array}$ & $\begin{array}{l}\text { Demonstration } \\
\text { plan } \\
\text { N/A Favorable } \\
\text { peer review }\end{array}$ & $\begin{array}{l}\text { पDemonstration } \\
\text { plan } \\
\text { N/A Favorable } \\
\text { peer review }\end{array}$ & $\begin{array}{l}\text { Demonstration } \\
\text { plan } \\
\text { N/A Favorable } \\
\text { peer review }\end{array}$ & $\begin{array}{l}\text { Demonstration } \\
\text { permits completed }\end{array}$ & $\begin{array}{l}\text { Vendor } \\
\text { participates in } \\
\text { demonstration }\end{array}$ \\
\hline
\end{tabular}

Indicates criterion is satisfied

$\square$ Indicates criterion/evidence is not yet satisfied

"N/A" Indicates criterion is not applicable or satisfied by other means; justification provided in evidence table

Date:

TFA Technology Delivery Manager: 


\section{Evidence Demonstrating Entrance Requirements are Met}

\section{Title: 99068 SRS DWPF Melter Performance Improvements}

\section{Technical Need/Site Need ID(s):}

SR99-2036 - Develop Second Generation DWPF Melter

\section{End User Involvement:}

$\checkmark$ User Approved MYTR 99068

$\checkmark$ Functional requirements established by site user

$\checkmark$ User co-funding per TFA IPL; document references below:

Letter TPP/99-STP-440 DOE-RL Robert M. Rosselli, Assistance Manager for Science and Technology to R. J. Schepens, Assistant Manager for High-Level Waste DOE-SR "Fiscal Year (FY) 2000 Tanks Focus Area (TFA) Support to the Savannah River Operations Office (SR) High-Level Waste Program" dated October 5, 1999

\section{Technical Merit:}

$\checkmark$ ASME Peer Review not performed on this project

$\checkmark$ Peer Review Exemption Justification: User will make decision on proceeding to full-scale design and installation of improvements at DWPF. TFA will conduct a Gate 5 review in FY00 (August), therefore an ASME peer review is not recommended for this project.

$\checkmark$ Work conducted per requirements established in test plan, WSRC-MS-99-00510 by Dennis Bickford and Johnetta George, SRTC

"Experimental Test Plan for Improved Performance of HLW Melter Tests" Rev. 0 dated 6/16/00

Cost:

$\checkmark$ Cost estimate will be included in design recommendations; noted as action for this project.

$\checkmark$ Baseline costs for DWPF facility are known and available at the site; cost impacts of operational issues related to pour spout, knife-edge and riser heaters needs to be evaluated.

\section{ES\&H Risk:}

$\checkmark$ ES\&H issues have already been addressed for the DWPF plant as part of the readiness and startup process. 
$\checkmark$ Design process hazards review will be performed on design change recommendations by SRS DWPF organization.

$\checkmark$ SRTC has performed an Experimental Process Hazards Review and documented the results as a procedure to guide laboratory work both at SRTC and at contracted laboratory facilities (e.g. Clemson Environmental Test Laboratory). [Need document reference from TIM]

SRTC has issued guidelines addressing safety for offsite testing funded by SRTC; SRT-GFM-99-013 "ITS Offsite Work Safety Guidelines" 5/25/99 M.E. Smith et al

\section{Stakeholder, Regulatory, Tribal Issues:}

$\checkmark$ Issues have already been addressed for the DWPF plant as part of the readiness and startup process.

\section{Commercial Viability:}

$\checkmark$ SRS does not intend to contract this work externally. DWPF melter modifications recommended by TFA will be done by SRS fabrication services, which is already QA qualified to perform work on DWPF facility equipment. They have provided all the hardware for the experimental test program.

$\checkmark$ TFA task is focused on recommendations to improve existing melter design and there is no anticipated intellectual property to be generated as part of this project. 


\section{Status Questions for Progress Reviews:}

\section{Title: 99068 SRS DWPF Melter Performance Improvements}

\section{Stage:__Demonstration}

1) Has the project been reviewed for advancement through a gate during the past year? No. TFA Gate Review is planned for August 2000. If yes, what was the result? Results will be issued in a report to TFA Program Manager.

2) Has an end user made at least a conditional commitment to implement the technology? Yes. User is cofunding, participating in development work, and planning to implement design recommendations once testing and design verification is completed.

3) Has a technical peer review been completed and is the work highly rated? None performed. TFA believes an ASME Peer Review is not necessary, as SRS will be making decision in FY 2000 on implementing design recommendations directly into DWPF plant.

4) Has a cost-benefit analysis been performed for this technology and does it show potential savings compared to the baseline? Are user requirements for cost data identified and satisfied? A cost analysis will be performed in development of the design recommendation evaluation and results provided in the documentation package.

5) Will this technology meet or exceed current environmental, safety, health, (ES\&H) protection levels and/or reduce the risk to the public, workers, and the environment compared to the baseline? DWPF is an operating facility that has met all ES\&H requirements to receive authorization to operate. Design modifications to improve operational performance will undergo standard site reviews and be reviewed to ensure compliance with current safety authorization basis. Are user requirements for ES\&H and technological risk identified and satisfied? There are no specific ES\&H and technological risk issues related to the project providing design improvements to DWPF. ES\&H issues have been addressed as part of the plant startup process.

6) Briefly discuss any activities and/or interactions with stakeholders, regulators, and tribal organizations relative to the continued research and utilization of this technology. Are user requirements for stakeholder, regulator, and tribal concerns identified and satisfied? Not applicable, as DWPF is an operating facility that has already addressed any issues.

7) Have invention disclosure and intellectual property issues been addressed? Briefly discuss the measures taken to include private industry in development and application of the technology. There is no anticipated intellectual property resulting from this work. Design recommendations will be provided to SRS DWPF organization and they intend to fabricate modified melter inserts onsite at a 
QA qualified fabrication services shop. This shop has provided all the experimental hardware used in testing the melter modification options.

8) Has an appropriate vendor (or other provider) for this technology been identified? TFA will recommend design modifications for DWPF melter to SRS and modified melter hardware will be fabricated onsite by a $Q A$ qualified fabrication facility. No external procurements are anticipated. 


\section{Project Maturity Status Determination}

\section{Title: 99068 - Improve Performance of HLW Melters}

Tech ID:2009 HAW Forms and Processes 1

Stage: Development Last Gate: 3

\begin{tabular}{|c|c|c|c|c|c|c|c|}
\hline $\begin{array}{l}\text { MATURITY } \\
\text { STAGE }\end{array}$ & $\begin{array}{l}\text { TECHNICAL } \\
\text { NEED }\end{array}$ & $\begin{array}{c}\text { END-USER } \\
\text { INVOLVEMENT }\end{array}$ & $\begin{array}{l}\text { TECHNICAL } \\
\text { MERIT }\end{array}$ & COST & ES\&H RISK & $\begin{array}{l}\text { STAKWHOLDER, } \\
\text { REGULATORY, } \\
\text { TRIBAL ISSUES }\end{array}$ & $\begin{array}{l}\text { COMMERCIAL } \\
\text { VIABILITY }\end{array}$ \\
\hline Development & $\begin{array}{l}\text { Need still } \\
\text { exists }\end{array}$ & $\begin{array}{l}\text { Addresses } \\
\text { performance } \\
\text { requirements } \\
\text { Available when } \\
\text { needed }\end{array}$ & $\begin{array}{l}\text { Improved solution } \\
\text { (enabling or significantly } \\
\text { more effective) } \\
\square \text { Favorable peer } \\
\text { review rating }\end{array}$ & $\begin{array}{l}\text { Improved } \\
\text { solution (enabling or } \\
\text { significantly less } \\
\text { costly) } \\
\square \text { Demonstration } \\
\text { and operating } \\
\text { costs estimated }\end{array}$ & $\begin{array}{l}\text { Improved } \\
\text { solution (enabling } \\
\text { or significantly lower } \\
\text { risk) } \\
\square \text { Favorable } \\
\text { peer review } \\
\text { rating }\end{array}$ & $\begin{array}{l}\text { N/A Peer review } \\
\text { finds data valid for } \\
\text { use with regulators } \\
\text { and stakeholders }\end{array}$ & $\begin{array}{l}\square \text { Potential } \\
\text { vendor identified }\end{array}$ \\
\hline
\end{tabular}

Indicates criterion is satisfied

$\square$ Indicates criterion/evidence is not yet satisfied

"N/A" Indicates criterion is not applicable or satisfied by other means; justification provided in evidence table

Date: $\quad$ TFA Technology Delivery Manager:

1 TMS ID 2009 is loosely related to this work but more specific to glass formulation work. TFA will consider adding a new TMS ID to cover Melter Design Alternative Studies and Development to cover work for Idaho and other sites on new or alternative HLW melter technologies. 


\section{Evidence Demonstrating Entrance Requirements are Met}

\section{Title: 99068 -Improve Performance of HLW Melters Stage: __ Development}

Technical Need/Site Need ID(s):

SR99-2036 - Develop Second Generation DWPF Melter

ID-2.1.57 - Conditioning of HAW for Treatment

ID-2.1.58 - HAW Immobilization

RL-WT80 - Melter Improvements for Hanford High \& Low Level Waste

End User Involvement:

$\checkmark$ User Approved MYTR 99068

$\checkmark$ Functional requirements established by site user

$\checkmark$ User cofunding per TFA IPL; document references below:

Letter TPP/99-STP-440 DOE-RL Robert M. Rosselli, Assistance Manager for Science and Technology to R. J. Schepens, Assistant Manager for High-Level Waste DOE-SR "Fiscal Year (FY) 2000 Tanks Focus Area (TFA) Support to the Savannah River Operations Office (SR) High-Level Waste Program” dated October 5, 1999

Letter TPP/99-STP-440 DOE-RL Robert M. Rosselli, Assistance Manager for Science and Technology to J.T. Case, Program Director Idaho Operations Office "Fiscal Year (FY) 2000 Tanks Focus Area (TFA) Support to the Idaho Operations Office (ID) High-Level Waste Program" dated October 5, 1999

\section{Technical Merit:}

$\checkmark$ ASME Peer Review or TFA Gate Review has not been conducted on this project, but the project will be evaluated as FY2001 peer review candidate

$\checkmark$ Work conducted per requirements established in test plan, WSRC-MS-99-00510 by Dennis Bickford and Johnetta George, SRTC "Experimental Test Plan for Improved Performance of HLW Melter Tests" Rev. 0 dated 6/16/00

$\checkmark$ A TFA sponsored technical exchange was conducted in FY99, which included a wide range of participants representing technical performers, universities, industry, and site user organizations. Results of the technical workshop and resulting recommendations are 
documented in PNNL-13030 "Technical Exchange on Improved Design and Performance of High Level Melters - Final Report" dated September 1999.

Cost:

$\checkmark$ Costs associated with all HLW treatment options, including vitrification, for INEEL waste are being analyzed as part of the EIS process. This is documented in DOE/ID 10702 "Cost Analysis for the Idaho High-Level Waste Facilities Disposition Environmental Impact Statement" dated January 2000.

$\checkmark$ A cost comparison of specific melter technologies has not yet been done for this project. Costs requirements and analysis need to be evaluated and results documented prior to Gate 5 progression.

\section{ES\&H Risk:}

$\checkmark$ SRTC has performed an Experimental Process Hazards Review and documented the results as a procedure to guide laboratory work both at SRTC and at contracted laboratory facilities (e.g. Clemson Environmental Test Laboratory). [Need document reference from TIM]

$\checkmark$ SRTC has issued guidelines addressing safety for offsite testing funded by SRTC; SRT-GFM-99-013 "ITS Offsite Work Safety Guidelines" 5/25/99 M.E. Smith et al

\section{Stakeholder, Regulatory, Tribal Issues:}

$\checkmark$ DWPF is in operation; all such issues have been addressed as part of plant startup approval

$\checkmark$ INEEL will address issues as part of EIS/ROD process

\section{Commercial Viability:}

$\checkmark$ TFA scope is data delivery to support flowsheet development and facility/process specifications; INEEL and SRS user responsible for technology acquisition decisions

$\checkmark$ A review of commercially available technologies was conducted and report issued documenting results [need reference from TFA Immobilization TIM]

$\checkmark$ MIT research under EMSP on milliwave sensors for measuring temperature and viscosity is being integrated into this project. There may be the potential for commercialization of this technology. It is believed that a patent has been applied for and will need to be evaluated as part of the commercial viability assessment. 


\section{Status Questions for Progress Reviews:}

\section{Title: 99068 - Improve Performance of HLW Melters Stage: ___ Development}

1) Has the project been reviewed for advancement through a gate during the past year? No

2) Has an end user made at least a conditional commitment to implement the technology? Yes, strong integration with site user, documented commitment to and co-funding of the work. INEEL is using data to support EIS and ROD on HLW treatment and disposal.

3) Has a technical peer review been completed and is the work highly rated? None performed. TFA will evaluate project as a candidate for FY2001 technical peer review.

4) Has a cost-benefit analysis been performed for this technology and does it show potential savings compared to the baseline? Are user requirements for cost data identified and satisfied? INEEL has a documented cost analysis performed in support of the EIS process see reference above.

5) Will this technology meet or exceed current environmental, safety, health, (ES\&H) protection levels and/or reduce the risk to the public, workers, and the environment compared to the baseline? INEEL is addressing this as part of the EIS process. Are user requirements for ES\&H and technological risk identified and satisfied? See DOE/EIS-0287D "Idaho High-Level Waste \& Facility Disposition Draft Environment Impact Statement" December 1999.

6) Briefly discuss any activities and/or interactions with stakeholders, regulators, and tribal organizations relative to the continued research and utilization of this technology. Are user requirements for stakeholder, regulator, and tribal concerns identified and satisfied? Idaho is currently conducting public hearing on EIS for HLW treatment and disposal. These issues will be addressed as part of this process. These issues were previously addressed as part of the DWPF plant ROD and startup.

7) Have invention disclosure and intellectual property issues been addressed? Briefly discuss the measures taken to include private industry in development and application of the technology. At current stage of development, national laboratories and university participants (FIU and Clemson) are performing work to develop technical recommendations. Part of the scope of this project is to review available commercial technologies and assess their capabilities to meet requirements. 
8) Has an appropriate vendor (or other provider) for this technology been identified? Identification of a vendor is not required as part of the TFA scope at this stage, site end user will determine procurement strategy for application of TFA recommendations. 


\section{Project Maturity Status Determination}

Title: 99073 Improved HLW Glass Loading

Tech ID: 2009 HAW Forms \& Processes

Stage: Development

Last Gate:

\begin{tabular}{|c|c|c|c|c|c|c|c|}
\hline $\begin{array}{l}\text { MATURITY } \\
\text { STAGE }\end{array}$ & $\begin{array}{l}\text { TECHNICAL } \\
\text { NEED }\end{array}$ & $\begin{array}{c}\text { END-USER } \\
\text { INVOLVEMENT }\end{array}$ & $\begin{array}{l}\text { TECHNICAL } \\
\text { MERIT }\end{array}$ & COST & ES\&H RISK & $\begin{array}{l}\text { STAKEHOLDER, } \\
\text { REGULATORY, } \\
\text { TRIBAL ISSUES }\end{array}$ & $\begin{array}{l}\text { COMMERCIAL } \\
\text { VIABILITY }\end{array}$ \\
\hline Development & $\begin{array}{l}\text { Need still } \\
\text { exists }\end{array}$ & $\begin{array}{l}\text { Addresses } \\
\text { performance } \\
\text { requirements } \\
\text { Available } \\
\text { when needed }\end{array}$ & $\begin{array}{l}\text { Improved } \\
\text { solution (enabling or } \\
\text { significantly more } \\
\text { effective) } \\
\square \text { Favorable peer } \\
\text { review rating }\end{array}$ & $\begin{array}{l}\text { Improved } \\
\text { solution (enabling or } \\
\text { significantly less } \\
\text { costly) } \\
\square \text { Demonstration } \\
\text { and operating } \\
\text { costs estimated }\end{array}$ & 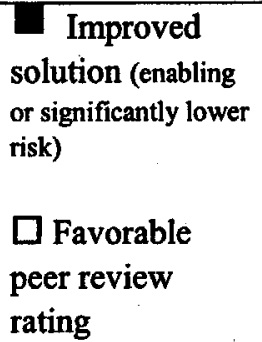 & $\begin{array}{l}\square \text { Peer review finds } \\
\text { data valid for use } \\
\text { with regulators and } \\
\text { stakeholders }\end{array}$ & $\begin{array}{l}\text { N/A Potential } \\
\text { vendor identified }\end{array}$ \\
\hline
\end{tabular}

Indicates criterion is satisfied

$\square$ Indicates criterion/evidence is not yet satisfied

"N/A" Indicates criterion is not applicable or satisfied by other means; justification provided in evidence table

Date:

TFA Technology Delivery Manager: 


\section{Evidence Demonstrating Entrance Requirements are Met}

Title: 99073 Improved HLW Glass Loading

Technical Need/Site Need ID(s):

ID-2.1.58 HAW Immobilization

RL-WT06 Identification and Management of Problem Constituents for Hanford Glass

SR99-2032 Optimize Melter Glass Chemistry

\section{End User Involvement:}

$\checkmark$ User Approved MYTR 99073

$\checkmark$ User cofunding per TFA IPL; document references below:

Letter TPP/99-STP-440 DOE-RL Robert M. Rosselli, Assistance Manager for Science and Technology to R. J. Schepens, Assistant Manager for High-Level Waste DOE-SR "Fiscal Year (FY) 2000 Tanks Focus Area (TFA) Support to the Savannah River Operations Office (SR) High-Level Waste Program" dated October 5, 1999

Letter TPP/99-STP-440 DOE-RL Robert M. Rosselli, Assistance Manager for Science and Technology to J.T. Case, Program Director Idaho Operations Office "Fiscal Year (FY) 2000 Tanks Focus Area (TFA) Support to the Idaho Operations Office (ID) High-Level Waste Program" dated October 5, 1999

Letter TPP/99-STP-440 DOE-RL Robert M. Rosselli, Assistance Manager for Science and Technology to Richard T. French, Manager Office of River Protection "Fiscal Year (FY) 2000 Tanks Focus Area (TFA) Support to the Office of River Protection (ORP) dated October 5,1999 


\section{Technical Merit:}

$\checkmark$ ASME Peer Review scheduled for September 2000

$\checkmark$ Test plans issued and reviewed by TFA; document reference below

Letter WSRC-TR-2000-00026 E. William Holtzscheiter to Roger L. Gilchrist "Test Plan: Effects of Phase Separation on Waste Loading for High Level Waste Glasses (U)"; dated January 27, 2000.

$\checkmark$ Technical progress/scope for FY01 reviewed with TFA Technical Advisory Group 2/00; comments being incorporated into FY01 planning documents

$\checkmark$ Glass product must meet the waste acceptance criteria product specification; DOE/EM-0093 Rv2 Waste Acceptance Product Specification for Vitrified High-level Waste Forms $12 / 96$

Cost:

$\checkmark$ Cost savings estimates are defined in TFA MYTR 98059; significant savings are predicted as a result of even small increased in glass loading at DWPF and other facilities

$\checkmark \quad$ INEEL is performing cost analysis to support the EIS/ROD for HLW disposition; DOE/ID 10702 Cost Analysis of Alternatives for the Idaho High-level Waste and Facilities Disposition Environmental Impact Statement January 2000

\section{ES\&H Risk:}

$\checkmark$ Glass product must meet the waste acceptance criteria product specification; DOE/EM-0093 Rv2 Waste Acceptance Product Specification for Vitrified High-level Waste Forms $12 / 96$

\section{Stakeholder, Regulatory, Tribal Issues:}

$\checkmark$ None known outside of the glass plant issues that have been or are being addressed under site projects

$\checkmark \quad$ Idaho has published a draft EIS for public comment; DOE/EIS-0287D Idaho High-Level Waste \& Facilities Disposition Draft Environmental Impact Statement December 1999

\section{Commercial Viability:}

$\checkmark$ This work is providing technical data on glass formulation and composition regions for use by sites in planning an operational improvements; there is no commercial industry involvement planned at this time 


\section{Status Questions for Progress Reviews:}

\section{Title: 99073 Improved HLW Glass Loading}

\section{Stage:}

1) Has the project been reviewed for advancement through a gate during the past year? No.

2) Has an end user made at least a conditional commitment to implement the technology? SRS is planning to implement waste loading improvement recommendations at DWPF. Hanford and INEEL using data for planning/EIS development.

3) Has a technical peer review been completed and is the work highly rated? ASME Peer Review planned for 9/00.

4) Has a cost-benefit analysis been performed for this technology and does it show potential savings compared to the baseline? Are user requirements for cost data identified and satisfied? Yes. See 98059. Additional data will be provided during ASME peer review.

5) Will this technology meet or exceed current environmental, safety, health, (ES\&H) protection levels and/or reduce the risk to the public, workers, and the environment compared to the baseline? Will be an enhancement to current glass formulations. No issues identified. Are user requirements for ES\&H and technological risk identified and satisfied? Will meet the WAPS (see reference above)

6) Briefly discuss any activities and/or interactions with stakeholders, regulators, and tribal organizations relative to the continued research and utilization of this technology. Are user requirements for stakeholder, regulator, and tribal concerns identified and satisfied? These interactions are the responsibility of the sites as part of their plant operations and EIS processes.

7) Have invention disclosure and intellectual property issues been addressed? None known at this time. Briefly discuss the measures taken to include private industry in development and application of the technology. Development work on glass formulation being done by DOE laboratories. Data will be available to support DOE sites privatization efforts.

8) Has an appropriate vendor (or other provider) for this technology been identified? $N / A$ 


\section{Project Maturity Status Determination}

Title: 99077 ASTD West Valley Vitrification Expended Materials Processing System Tech ID:2383 Vitrification Expended Materials Processing System

Stage: Demonstration Last Gate: 5

\begin{tabular}{|c|c|c|c|c|c|c|c}
\hline $\begin{array}{c}\text { MATURITY } \\
\text { STAGE }\end{array}$ & $\begin{array}{c}\text { TECHNICAL } \\
\text { NEED }\end{array}$ & $\begin{array}{c}\text { END-USER } \\
\text { INVOLVEMENT }\end{array}$ & $\begin{array}{c}\text { TECHNICAL } \\
\text { MERIT }\end{array}$ & \multicolumn{1}{|c|}{ COST } & ES\&H RISK & $\begin{array}{l}\text { STAKEHOLDER } \\
\text {, REGULATORY, } \\
\text { TRIBAL ISSUES }\end{array}$ & $\begin{array}{l}\text { COMMERCIAL } \\
\text { VIABILITY }\end{array}$ \\
\hline $\begin{array}{l}\text { Need still } \\
\text { exists }\end{array}$ & $\begin{array}{l}\text { Demonstration } \\
\text { cost-sharing }\end{array}$ & $\begin{array}{l}\text { Demonstration } \\
\text { plan } \\
\text { Demonstration }\end{array}$ & $\begin{array}{l}\text { Demonstration } \\
\text { plan } \\
\text { N/A Favorable } \\
\text { peer review }\end{array}$ & $\begin{array}{l}\text { Demonstration } \\
\text { plan Favorable } \\
\text { peer review }\end{array}$ & $\begin{array}{l}\text { Demonstration } \\
\text { permits completed } \\
\text { peer review }\end{array}$ & $\begin{array}{l}\text { Vendor } \\
\text { participates in } \\
\text { demonstration }\end{array}$ \\
\hline
\end{tabular}

Indicates criterion is satisfied

$\square$ Indicates criterion/evidence is not yet satisfied

"N/A" Indicates criterion is not applicable or satisfied by other means; justification provided in evidence table

Date:

TFA Technology Delivery Manager: 


\section{Evidence Demonstrating Entrance Requirements are Met}

\section{Title: ASTD WV Vitrification Expended Materials Processing System}

Technical Need/Site Need ID(s):

OH-WV-903 Vitrification Expended Materials Processing

\section{End User Involvement:}

$\checkmark$ User approved MYTR 99077

$\checkmark$ User cofunding ASTD Project 99-ASTD-03

$\checkmark$ User cofunding per TFA IPL; document reference below

Letter TPP/99-STP-440 DOE-RL Robert M. Rosselli, Assistance Manager for Science and Technology to B.A. Mazurowski, Director West Valley Demonstration Project "Fiscal Year (FY) 2000 Tanks Focus Area (TFA) Support to the West Valley Demonstration Program (WVDP) High-Level Waste Program" dated October 5, 1999

\section{Technical Merit:}

$\checkmark \quad$ User deploying technologies per ASTD project deployment plan; additional technologies are being developed and demonstrated under FY00 funding

$\checkmark$ Project at deployment stage; no ASME Peer Review required

Cost:

$\checkmark$ Documented in ASTD proposal for 99-ASTD-03

\section{ES\&H Risk:}

$\checkmark$ Documented in ASTD proposal for 99-ASTD-03

Stakeholder, Regulatory, Tribal Issues:

$\checkmark$ Documented in ASTD proposal for 99-ASTD-03 


\section{Commercial Viability:}

$\checkmark$ Documented in ASTD proposal for 99-ASTD-03 


\section{Status Questions for Progress Reviews:}

\section{Title: ASTD WV Vitrification Expended Materials Processing System}

1) Has the project been reviewed for advancement through a gate during the past year? No.

2) Has an end user made at least a conditional commitment to implement the technology? Yes. WVDP is deploying Phase 1 technologies under ASTD project. As additional capabilities are demonstrated, they will also be deployed.

3) Has a technical peer review been completed and is the work highly rated? None performed. ASTD project.

4) Has a cost-benefit analysis been performed for this technology and does it show potential savings compared to the baseline? Are user requirements for cost data identified and satisfied? Documented in ASTD proposal.

5) Will this technology meet or exceed current environmental, safety, health, (ES\&H) protection levels and/or reduce the risk to the public, workers, and the environment compared to the baseline? Are user requirements for ES\&H and technological risk identified and satisfied? Documented in ASTD proposal.

6) Briefly discuss any activities and/or interactions with stakeholders, regulators, and tribal organizations relative to the continued research and utilization of this technology. Are user requirements for stakeholder, regulator, and tribal concerns identified and satisfied? Documented in ASTD proposal.

7) Have invention disclosure and intellectual property issues been addressed? Yes. Briefly discuss the measures taken to include private industry in development and application of the technology. Documented in ASTD proposal.

8) Has an appropriate vendor (or other provider) for this technology been identified? Documented in ASTD proposal. 


\section{Project Maturity Status Determination}

Title: 99023 Idaho Tank Closure Demonstration

Tech ID:

Stage: Development _ Last Gate:_ 3

\begin{tabular}{|c|c|c|c|c|c|c|c|}
\hline $\begin{array}{l}\text { MATURITY } \\
\text { STAGE }\end{array}$ & $\begin{array}{c}\text { TECHNICAL } \\
\text { NEED }\end{array}$ & $\begin{array}{c}\text { END-USER } \\
\text { INVOLVEMENT }\end{array}$ & $\begin{array}{l}\text { TECHNICAL } \\
\text { MERIT }\end{array}$ & COST & ES\&H RISK & $\begin{array}{l}\text { STAKEHOLDER } \\
\text {, REGULATORY, } \\
\text { TRIBAL ISSUES }\end{array}$ & $\begin{array}{l}\text { COMMERCIAL } \\
\text { VIABILITY }\end{array}$ \\
\hline Development & $\begin{array}{l}\text { Need still } \\
\text { exists }\end{array}$ & $\begin{array}{l}\text { Addresses } \\
\text { performance } \\
\text { requirements } \\
\text { Available when } \\
\text { needed }\end{array}$ & $\begin{array}{l}\text { Improved } \\
\begin{array}{l}\text { solution (enabling or } \\
\text { significantly more } \\
\text { effective) }\end{array} \\
\text { N/A Favorable } \\
\text { peer review rating }\end{array}$ & $\begin{array}{l}\text { Improved } \\
\text { solution (enabling or } \\
\text { significantly less costly) } \\
\text { N/A Demonstration } \\
\text { and operating costs } \\
\text { estimated }\end{array}$ & $\begin{array}{l}\text { Improved } \\
\text { solution (enabling } \\
\text { or significantly } \\
\text { lower risk) } \\
\text { N/A Favorable } \\
\text { peer review } \\
\text { rating }\end{array}$ & $\begin{array}{l}\text { N/A Peer review } \\
\text { finds data valid for } \\
\text { use with regulators } \\
\text { and stakeholders }\end{array}$ & $\begin{array}{l}\text { N/A Potential } \\
\text { vendor identified }\end{array}$ \\
\hline
\end{tabular}

Indicates criterion is satisfied

$\square$ Indicates criterion/evidence is not yet satisfied

"N/A" Indicates criterion is not applicable or satisfied by other means; justification provided in evidence table

Date:

TFA Technology Delivery Manager: 


\section{Evidence Demonstrating Entrance Requirements are Met}

Title: 99023 Idaho Tank Closure Demonstration

\section{Stage: Development}

\section{Technical Need/Site Need ID(s):}

ID-2.1.39 Acceptance Criteria for LAW Disposal in Underground Storage Tanks

ID-2.1.42 Acceptance Criteria for Tank Closure

ID-2.1.45 Acceptance Criteria for Grouting Tank Heels

ID-2.1.46 Management of Tank Heel Liquids

ID-2.1.47 Management of Tank Heel Solids

ID-2.1.48 Wasteform Qualification for Low-Activity Waste

\section{End User Involvement:}

$\checkmark$ User approved MYTR 99023

$\checkmark$ User leading task to prepare Closure Plan submittal to DOE-ID and State of Idaho

$\checkmark$ User cofunding per TFA IPL; see document reference below

Letter TPP/99-STP-440 DOE-RL Robert M. Rosselli, Assistance Manager for Science and Technology to J.T. Case, Program Director Idaho Operations Office "Fiscal Year (FY) 2000 Tanks Focus Area (TFA) Support to the Idaho Operations Office (ID) High-Level Waste Program" dated October 5, 1999

\section{Technical Merit:}

$\checkmark$ This project is supporting technical analyses and mockup testing to confirm proposed closure process prior to submitting the Closure Plan to DOE-ID and the State of Idaho; end user will make determination on technology recommendations that will be included in the plan

$\checkmark$ An ASME Peer Review has not been conducted; end user will make recommendations to DOE and State based on results of Closure Plan formulation; therefore the project is not deemed an appropriate candidate for ASME Peer Review

$\checkmark$ Project primarily funded by end user and was just started in FY00 with INEEL HLW program funds; TFA funds will be released in March or April 2000 
$\checkmark$ DOE Order 435.1 and RCRA requirements provide the technical basis for this work

Cost:

$\checkmark$ End user is evaluating cost data under the EM-30 funded scope; this information will be included in the Closure Plan to be delivered to DOE-ID in September, 2000.

$\checkmark$ Idaho is addressing costs for disposal processes and options under current EIS process; DOE/ID 10702 Cost Analysis of Alternatives for he Idaho High-Level Waste and Facilities Disposition Environmental Impact Statement January 2000

\section{ES\&H Risk:}

$\checkmark$ End user is evaluating ES\&H issues under the EM-30 funded scope; this information will be included in the Closure Plan to be delivered to DOE-ID in September, 2000.

$\checkmark$ Related information is presented in the the EIS document; DOE/EIS-0287D Idaho High-Level Waste \& Facilities Disposition Draft Environmental Impact Statement December 1999

$\checkmark$ Long-term environmental risk of tank closures must satisfy DOE Order 435.1 and RCRA requirements

\section{Stakeholder, Regulatory, Tribal Issues:}

$\checkmark$ End user is evaluating stakeholder, regulatory, tribal issues under the EM-30 funded scope; this information will be included in the Closure Plan to be delivered to DOE-ID in September, 2000.

$\checkmark$ Draft EIS on HLW disposition is out for public comment (see above)

$\checkmark$ DOE Order 435.1 and RCRA requirements provide the technical basis for this work

\section{Commercial Viability:}

$\checkmark$ TFA and site end user are conducting demonstration of grout deployment concepts and have not yet determined the preferred method

$\checkmark$ INEEL is aware of waste retrieval, tank cleaning, and tank grouting work being performed by SRS and ORNL and will evaluate this data in determining the preferred method and requirements for involvement of commercial vendors. 


\section{Status Questions for Progress Reviews:}

\section{Title: 99023 Idaho Tank Closure Demonstration}

\section{Stage: _Development}

1) Has the project been reviewed for advancement through a gate during the past year? No. Work just started in FY00 and will be a one year task.

2) Has an end user made at least a conditional commitment to implement the technology? A specific technology has not yet been selected. Work is currently focused on providing data to support development of the closure plan document. Data will be used by INEEL in preparing the closure plan.

3) Has a technical peer review been completed and is the work highly rated? A review has not been conducted; end user will determine path forward and make selection of preferred closure option. This work is not an appropriate candidate for ASME peer review as it is providing direct technical assistance to end user.

4) Has a cost-benefit analysis been performed for this technology and does it show potential savings compared to the baseline? Are user requirements for cost data identified and satisfied? End user is preparing this data as part of the closure plan development.

5) Will this technology meet or exceed current environmental, safety, health, (ES\&H) protection levels and/or reduce the risk to the public, workers, and the environment compared to the baseline? Proposed closure plan must meet requirements listed above. Are user requirements for ES\&H and technological risk identified and satisfied? This is being evaluated as part of the closure plan development. These issues will be addressed in the plan when issued.

6) Briefly discuss any activities and/or interactions with stakeholders, regulators, and tribal organizations relative to the continued research and utilization of this technology. INEEL is communicating with State of Idaho and stakeholders on tank closure as part of their overall EIS process. This is the responsibility of the end user. Are user requirements for stakeholder, regulator, and tribal concerns identified and satisfied? This is being evaluated as part of the closure plan development. These issues will be addressed in the plan when issued. 
7) Have invention disclosure and intellectual property issues been addressed? $N / A$. Briefly discuss the measures taken to include private industry in development and application of the technology. A specific technology or closure process has not yet been selected. The Closure Plan will establish the preferred alternatives and determine the path forward for industry involvement.

8) Has an appropriate vendor (or other provider) for this technology been identified? Not yet. INEEL is investigating method for grout emplacement and is aware of the potential commercial suppliers of this type of technology. Depending on the method selected, INEEL will make a determination on involving a commercial supplier. 


\section{Project Maturity Status Determination}

Title: 99085 Demonstrate Grout Injection Technologies

Tech ID: 2368 Multi-point Grout Injection

Stage: Demonstration Last Gate: 5

\begin{tabular}{|c|c|c|c|c|c|c|c|}
\hline $\begin{array}{l}\text { MATURITY } \\
\text { STAGE }\end{array}$ & $\begin{array}{c}\text { TECHNICAL } \\
\text { NEED }\end{array}$ & $\begin{array}{c}\text { END-USER } \\
\text { INVOLVEMENT }\end{array}$ & $\begin{array}{l}\text { TECHNICAL } \\
\text { MERIT }\end{array}$ & COST & ES\&H RISK & $\begin{array}{l}\text { STAKEHOLDER } \\
\text {, REGULATORY, } \\
\text { TRIBAL ISSUES }\end{array}$ & $\begin{array}{l}\text { COMMERCIA } \\
\text { L VIABILITY }\end{array}$ \\
\hline Demonstration & $\begin{array}{l}\text { Need still } \\
\text { exists }\end{array}$ & $\begin{array}{l}\text { Demonstration } \\
\text { cost-sharing }\end{array}$ & $\begin{array}{l}\text { Demonstration } \\
\text { plan } \\
\text { N/A Favorable } \\
\text { peer review }\end{array}$ & $\begin{array}{l}\text { Demonstration } \\
\text { plan } \\
\text { N/A Favorable } \\
\text { peer review }\end{array}$ & $\begin{array}{l}\text { Demonstration } \\
\text { plan } \\
\text { N/A Favorable } \\
\text { peer review }\end{array}$ & $\begin{array}{l}\text { Demonstration } \\
\text { permits completed }\end{array}$ & $\begin{array}{l}\text { Vendor } \\
\text { participates in } \\
\text { demonstration }\end{array}$ \\
\hline
\end{tabular}

Indicates criterion is satisfied

$\square$ Indicates criterion/evidence is not yet satisfied

"N/A" Indicates criterion is not applicable or satisfied by other means; justification provided in evidence table

Date:

TFA Technology Delivery Manager: 


\section{Evidence Demonstrating Entrance Requirements are Met}

\section{Title: 99085 Demonstrate Grout Injection Technologies Stage: _Demonstration}

Technical Need/Site Need ID(s):

OH-WV-904 High Level Waste Tank Closure

OR-TK-09 Tank Closure

SR99-3022 In-situ Grouting and/or Retrieval of Waste from Underground Storage Tanks

\section{End User Involvement:}

$\checkmark$ Users approved MYTR 99085

$\checkmark$ ORNL will deploy technology in FY00

$\checkmark$ User cofunding per TFA IPL; reference document below

Letter TPP/99-STP-440 DOE-RL Robert M. Rosselli, Assistance Manager for Science and Technology to R.R. Nelson, Assistant Manager for Environmental Management, OR "Fiscal Year (FY) 2000 Tanks Focus Area (TFA) Support to the Oak Ridge Reservation (ORR)" dated October 5, 1999

\section{Technical Merit:}

$\checkmark$ ASME Peer Review not performed; user will deploy in FY00 therefore an ASME review is not required

$\checkmark$ The selected vendor will prepare a work plan/demonstration plan for approval by ORNL and DOE-ORO

$\checkmark$ TFA Gate Reviews conducted in August 1999 recommended proceeding to Stage 6; reference document below

Letter TFA99-285 Thomas M. Brouns (PNNL) to Theodore Pietrok (DOE-RL) “Oak Ridge Multi-Point (MPI@) Gate Review Results” dated October 25, 1999.

Cost:

$\checkmark$ Documented in Gate Review Report - reference above

$\checkmark$ ORNL is establishing a contract with vendor; cost meets sites requirements for deployment 
$\checkmark$ Work will be more costly than baseline (no grouting), but is being performed to provide an additional level of environmental protections and assurance that waste is stabilized

\section{ES\&H Risk:}

$\checkmark$ Documented in Gate Review Report - reference above

$\checkmark$ Work is being performed as an enhancement to the baseline to provide additional performance assurance above the minimum regulatory requirements to enhance long-term protection of the environment

$\checkmark$ Specific ES\&H requirements for the demonstration will be established in the contract with the performing vendor; vendor must demonstrate that they can meet these requirements as part of their Health and Safety and QA plans.

\section{Stakeholder, Regulatory, Tribal Issues:}

$\checkmark$ Documented in Gate Review Report - reference above

$\checkmark$ Work is being performed as an enhancement to the baseline to provide additional performance assurance above the minimum regulatory requirements to enhance long-term protection of the environment

$\checkmark$ Site readiness review activities will determine compliance with all ARARs prior to the hot demonstration

\section{Commercial Viability:}

$\checkmark$ A commercial vendor (Ground Environmental Services) is under contract to provide the technology and conduct the site deployment 


\section{Status Questions for Progress Reviews:}

\section{Title: 99085 Demonstrate Grout Injection Technologies_ Stage:__Demonstration}

1) Has the project been reviewed for advancement through a gate during the past year? Yes. If yes, what was the result? Recommended proceeding to Stage 6.

2) Has an end user made at least a conditional commitment to implement the technology? Yes, ORNL will deploy in FY00.

3) Has a technical peer review been completed and is the work highly rated? Not reviewed by ASME. Will be deployed in FY00 therefore this project is not a candidate for an ASME peer review

4) Has a cost-benefit analysis been performed for this technology and does it show potential savings compared to the baseline? See above under cost. Are user requirements for cost data identified and satisfied? Cost is not driver for this work. Site is negotiating an acceptable contract cost with vendor.

5) Will this technology meet or exceed current environmental, safety, health, (ES\&H) protection levels and/or reduce the risk to the public, workers, and the environment compared to the baseline? Yes. Work is being pursued to provide additional environmental assurance that residual waste in OHF tanks is properly stabilized. Are user requirements for ES\&H and technological risk identified and satisfied? Yes. Any remaining issues will be addressed as part of the ORR process.

6) Briefly discuss any activities and/or interactions with stakeholders, regulators, and tribal organizations relative to the continued research and utilization of this technology. State of Tennessee has agreed to deployment demonstration in OHF tanks. Are user requirements for stakeholder, regulator, and tribal concerns identified and satisfied? Yes.

7) Have invention disclosure and intellectual property issues been addressed? Yes, as part of contract with GES. Briefly discuss the measures taken to include private industry in development and application of the technology. GES is under contract to provide technology and conduct field demonstration.

8) Has an appropriate vendor (or other provider) for this technology been identified? Yes. Ground Environmental Services will supply the technology and conduct the demonstration at ORNL. 


\section{Project Maturity Status Determination}

Title: 99071 Alternative Filtration Technologies

Tech ID: 2091 Alternative Filtration Technologies

Stage: Development Last Gate:

\begin{tabular}{|c|c|c|c|c|c|c|c|}
\hline $\begin{array}{l}\text { MATURITY } \\
\text { STAGE }\end{array}$ & $\begin{array}{l}\text { TECHNICAL } \\
\text { NEED }\end{array}$ & $\begin{array}{c}\text { END-USER } \\
\text { INVOLVEMENT }\end{array}$ & $\begin{array}{l}\text { TECHNICAL } \\
\text { MERIT }\end{array}$ & COST & ES\&H RISK & $\begin{array}{l}\text { STAKEHOLDER, } \\
\text { REGULATORY, } \\
\text { TRIBAL ISSUES }\end{array}$ & $\begin{array}{l}\text { COMMERCIAL } \\
\text { VIABILITY }\end{array}$ \\
\hline Development & $\begin{array}{l}\text { Need still } \\
\text { exists }\end{array}$ & $\begin{array}{l}\text { Addresses } \\
\text { performance } \\
\text { requirements } \\
\text { Available when } \\
\text { needed }\end{array}$ & $\begin{array}{l}\text { Improved } \\
\text { solution (enabling or } \\
\text { significantly more } \\
\text { effective) } \\
\text { Favorable peer } \\
\text { review rating }\end{array}$ & $\begin{array}{l}\text { Improved } \\
\text { solution (enabling or } \\
\text { significantly less } \\
\text { costly) } \\
\square \text { Demonstration } \\
\text { and operating } \\
\text { costs estimated }\end{array}$ & 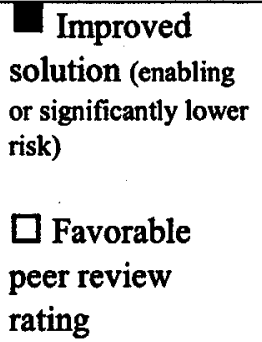 & $\begin{array}{l}\square \text { Peer review finds } \\
\text { data valid for use } \\
\text { with regulators and } \\
\text { stakeholders }\end{array}$ & $\begin{array}{l}\text { Potential } \\
\text { vendor identified }\end{array}$ \\
\hline
\end{tabular}

Indicates criterion is satisfied

$\square$ Indicates criterion/evidence is not yet satisfied

"N/A" Indicates criterion is not applicable or satisfied by other means; justification provided in evidence table

Date:

TFA Technology Delivery Manager: 


\section{Evidence Demonstrating Entrance Requirements are Met}

\section{Title: 99071 Alternative Filtration Technologies}

\section{Technical Need/Site Need ID(s):}

ID-2.1.27 Blowback Metal Filters for Solids (Calcine) Retrieval

SR99-2027 Demonstrate Alternative Filtration Technologies to Replace

\section{End User Involvement:}

$\checkmark$ Users approved MYTR 99071

$\checkmark$ User has selected deployment tank for technology

$\checkmark$ User cofunding per TFA IPL; reference documents below

Letter TPP/99-STP-440 DOE-RL Robert M. Rosselli, Assistance Manager for Science and Technology to R. J. Schepens, Assistant Manager for High-Level Waste DOE-SR "Fiscal Year (FY) 2000 Tanks Focus Area (TFA) Support to the Savannah River Operations Office (SR) High-Level Waste Program" dated October 5, 1999

Letter TPP/99-STP-440 DOE-RL Robert M. Rosselli, Assistance Manager for Science and Technology to J.T. Case, Program Director Idaho Operations Office "Fiscal Year (FY) 2000 Tanks Focus Area (TFA) Support to the Idaho Operations Office (ID) High-Level Waste Program" dated October 5, 1999

\section{Technical Merit:}

$\checkmark$ ASME Peer Review scheduled for September 12, 2000

$\checkmark$ NETL/FETC Procurement Specification RFP DE-RP26-99FT40316 Alternative High Efficiency Particulate Air (HEPA) Filtration System defines technical requirements vendors must meet in testing/demonstration of filter elements for SRS

$\checkmark$ DOE Standard DOE-STD-3020-97 (1/97) Specification for HEPA Filters Used by DOE Contractors establishes technical performance requirements that apply to this project

$\checkmark$ Technical report DNFSB/Tech-23 HEPA Filters Used in Department of Energy's Hazardous Facilities discusses requirements and performance of filtration systems that are relevant to this project. 
Cost:

$\checkmark$ "Survey of Life Cycle Cost of Glass Paper HEPA Filters" presented at $22^{\text {nd }}$ Nuclear Air Cleaning Conference (incomplete document reference) provide related information, but is not specific to this project

$\checkmark$ Filters were selected through a competitive procurement process; cost was reviewed as part of the procurement contract action

$\checkmark$ Additional detail on specific cost advantages is required to support ASME review

\section{ES\&H Risk:}

$\checkmark$ User of HEPA filtration is covered under site facility ES\&H requirements; specifications for levels of filtration required to be met by vendors filter media is included in above referenced procurement specification.

$\checkmark$ TFA/SRS are conducting testing and design reviews to ensure selected filters meet requirements

$\checkmark$ DOE standard reference above provides relevant information on ES\&H requirements

\section{Stakeholder, Regulatory, Tribal Issues:}

$\checkmark$ ASME Code AG-1 Code on Nuclear Air and Gas Treatment establishes code requirements for HEPA filtration; currently only covers glass fiber filter media; ASME AG-1 committee is currently considering standards for sintered metal filtration that would cover one of the two alternatives being considered; as the final glass fiber filter in the tank system will be maintained this is not an issue

$\checkmark$ No known stakeholder or tribal issues identified

\section{Commercial Viability:}

$\checkmark$ Two commercial suppliers are demonstrating their technologies (Ceramem Corp. and Mott Corp.); SRS will downselect one technology for in-tank demonstration 


\section{Status Questions for Progress Reviews:}

\section{Title: 99071 Alternative Filtration Technologies}

\section{Stage: _Development}

1) Has the project been reviewed for advancement through a gate during the past year? No.

2) Has an end user made at least a conditional commitment to implement the technology? Yes. SRS Tank 7 has been selected as the deployment site for the demonstration..

3) Has a technical peer review been completed and is the work highly rated? Peer review scheduled for 9/00.

4) Has a cost-benefit analysis been performed for this technology and does it show potential savings compared to the baseline? No. Are user requirements for cost data identified and satisfied? No. Additional documentation needs to be developed to support ASME review.

5) Will this technology meet or exceed current environmental, safety, health, $(E S \& H)$ protection levels and/or reduce the risk to the public, workers, and the environment compared to the baseline? Yes. This filtration will not replace the final glass-fiber HEPA filter that meets requirements. It will be used to improve performance and extend life of current filter systems. Are user requirements for ES\&H and technological risk identified and satisfied? Yes. See above.

6) Briefly discuss any activities and/or interactions with stakeholders, regulators, and tribal organizations relative to the continued research and utilization of this technology. Are user requirements for stakeholder, regulator, and tribal concerns identified and satisfied? No specific interaction is expected as this is an enhancement to an existing system that has been in operation. No issues have been identified or are expected.

7) Have invention disclosure and intellectual property issues been addressed? Issues were addressed as part of NETL contract with vendors demonstrating technologies. SRS has separate invention disclosure and a COI mitigation plan was developed. Briefly discuss the measures taken to include private industry in development and application of the technology. Two commercial vendors are providing prototypes for testing, one will be selected for full-scale development. 
8) Has an appropriate vendor (or other provider) for this technology been identified? Two potential vendors have been placed under contract to demonstrate and develop designs for alternative filtration systems. SRS will down select one vendor following completion of testing and demonstration activities. 


\section{Project Maturity Status Determination}

Title: 99078 Dual Coriolis Slurry Monitoring

\section{Tech ID:}

\section{Stage: Development Last Gate:}

4

\begin{tabular}{|c|c|c|c|c|c|c|c|}
\hline $\begin{array}{l}\text { MATURITY } \\
\text { STAGE }\end{array}$ & $\begin{array}{l}\text { TECHNICAL } \\
\text { NEED }\end{array}$ & $\begin{array}{c}\text { END-USER } \\
\text { INVOLVEMENT }\end{array}$ & $\begin{array}{l}\text { TECHNICAL } \\
\text { MERIT }\end{array}$ & $\cos T$ & ES\&H RISK & $\begin{array}{l}\text { STAKEHOLDER, } \\
\text { REGULATORY, } \\
\text { TRIBAL ISSUES }\end{array}$ & $\begin{array}{l}\text { COMMERCIAL } \\
\text { VIABILITY }\end{array}$ \\
\hline Development & $\begin{array}{l}\text { Need still } \\
\text { exists }\end{array}$ & $\begin{array}{l}\text { Addresses } \\
\text { performance } \\
\text { requirements } \\
\text { Available when } \\
\text { needed }\end{array}$ & $\begin{array}{l}\text { Improved } \\
\text { solution (enabling or } \\
\text { significantly more } \\
\text { effective) } \\
\text { Favorable peer } \\
\text { review rating }\end{array}$ & $\begin{array}{l}\text { Improved } \\
\text { solution (enabling or } \\
\text { significantly less } \\
\text { costly) } \\
\text { Demonstration } \\
\text { and operating } \\
\text { costs estimated }\end{array}$ & $\begin{array}{l}\text { Improved } \\
\text { solution (enabling } \\
\text { or significantly lower } \\
\text { risk) } \\
\text { Favorable peer } \\
\text { review rating }\end{array}$ & $\begin{array}{l}\text { Peer review finds } \\
\text { data valid for use } \\
\text { with regulators and } \\
\text { stakeholders }\end{array}$ & $\begin{array}{l}\text { Potential } \\
\text { vendor identified }\end{array}$ \\
\hline
\end{tabular}

Indicates criterion is satisfied

$\square$ Indicates criterion/evidence is not yet satisfied

"N/A" Indicates criterion is not applicable or satisfied by other means; justification provided in evidence table

Date:

TFA Technology Delivery Manager: 


\section{Evidence Demonstrating Entrance Requirements are Met}

\section{Title: 99078 Dual Coriolis Slurry Monitoring}

\author{
Stage: Development
}

\section{Technical Need/Site Need ID(s):}

OR-TK-04 Sludge Mixing and Slurry Transport

SR99-2037 Tank Heel Removal/Closure Technology

SR99-2044 Demonstrate In-Situ Characterization Weight Percent Probe

\section{End User Involvement:}

$\checkmark$ Users approved MYTR 99078

$\checkmark$ User has selected deployment tank for technology

$\checkmark$ User cofunding per TFA IPL; reference documents below

Letter TPP/99-STP-440 DOE-RL Robert M. Rosselli, Assistance Manager for Science and Technology to R. J. Schepens, Assistant Manager for High-Level Waste DOE-SR "Fiscal Year (FY) 2000 Tanks Focus Area (TFA) Support to the Savannah River Operations Office (SR) High-Level Waste Program" dated October 5, 1999

Letter TPP/99-STP-440 DOE-RL Robert M. Rosselli, Assistance Manager for Science and Technology to R.R. Nelson, Assistant Manager for Environmental Management, OR "Fiscal Year (FY) 2000 Tanks Focus Area (TFA) Support to the Oak Ridge Reservation (ORR)" dated October 5, 1999

\section{Technical Merit:}

$\checkmark$ SRS requirements are documented in SRS Plant Modification Traveler U-PMT-H-04861 Slurry Monitoring Prototype System by Gary Johnson 2/00

$\checkmark$ Conceptual design is documented in FIU-HCET report entitled Conceptual Design - Slurry Monitoring System for SRS Implementation by Richard Musgrove $3 / 00$

$\checkmark$ Test program planning is documented in Experimental Test Plan for the Dual Coriolis System at FIU-HCET by Dave Roelant and Richard Musgrove 3/00 
$\checkmark$ Additional technical requirements specific to the tank deployment requirements will be developed, however criteria from 99043 EIC probe will be provided to FIU for reference on general requirements for tank deployment criteria; Reference: U-PMT-H-044484 "Task Requirements \& Criteria - Install Corrosion Probe on Tank 43 Riser H" by Terry Phillips (SRS) dated 7/27/99

Cost:

$\checkmark$ No specific cost analysis data is available; if project continues beyond FY00 data will be required to support deployment decision

\section{ES\&H Risk:}

$\checkmark$ SRS requirements are included in above referenced document by Gary Johnson

$\checkmark$ Additional information is provided in FIU-HCET design documents

$\checkmark$ ORNL has deployed the technology to support transfer of waste from the GAAT tanks; ES\&H requirements were satisfied

$\checkmark$ Technology reduces risk of worker exposure as compared to baseline grab sampling method

\section{Stakeholder, Regulatory, Tribal Issues:}

$\checkmark$ No specific issues identified at this time.

\section{Commercial Viability:}

$\checkmark$ Endress + Hauser is the commercial supplier of the Coriolis Monitor instruments used to develop this system

$\checkmark$ ORNL developed their system using these commercial monitors; SRS plans to have FIU-HCET design and build their system using this commercially available monitor 


\section{Status Questions for Progress Reviews:}

\section{Title: 99078 Dual Coriolis Slurry Monitoring}

\section{Stage: _Development}

1) Has the project been reviewed for advancement through a gate during the past year? No.

2) Has an end user made at least a conditional commitment to implement the technology? Yes. ORNL has deployed the technology and SRS is evaluating a future deployment.

3) Has a technical peer review been completed and is the work highly rated? Project has not been peer reviewed.

4) Has a cost-benefit analysis been performed for this technology and does it show potential savings compared to the baseline? No. Are user requirements for cost data identified and satisfied? ORNL user has deployed the technology, so it can be assumed cost requirements were met. SRS will evaluate cost as part of the design review process.

5) Will this technology meet or exceed current environmental, safety, health, (ES\&H) protection levels and/or reduce the risk to the public, workers, and the environment compared to the baseline? Yes. Are user requirements for ES\&H and technological risk identified and satisfied? Yes, see above.

6) Briefly discuss any activities and/or interactions with stakeholders, regulators, and tribal organizations relative to the continued research and utilization of this technology. Are user requirements for stakeholder, regulator, and tribal concerns identified and satisfied? No specific requirements or issues have been identified at this time.

7) Have invention disclosure and intellectual property issues been addressed? The technology is commercially available and is being modified for this application. Briefly discuss the measures taken to include private industry in development and application of the technology. Commercial slurry monitor technology is being used.

8) Has an appropriate vendor (or other provider) for this technology been identified? Yes. 


\section{Project Maturity Status Determination}

Title: 99048 Testing/Prediction of Long-term Glass Performance

Tech ID: 82 LAW Forms; 2094 Product Acceptance Testing

Stage: Development Last Gate: 2

\begin{tabular}{|c|c|c|c|c|c|c|c|}
\hline $\begin{array}{l}\text { MATURITY } \\
\text { STAGE }\end{array}$ & $\begin{array}{c}\text { TECHNICAL } \\
\text { NEED }\end{array}$ & $\begin{array}{c}\text { END-USER } \\
\text { INVOLVEMENT }\end{array}$ & $\begin{array}{l}\text { TECHNICAL } \\
\text { MERIT }\end{array}$ & Cost & ES\&H RISK & $\begin{array}{l}\text { STAKEHOLDER, } \\
\text { REGULATORY, } \\
\text { TRIBAL ISSUES }\end{array}$ & $\begin{array}{l}\text { COMMERCIAL } \\
\text { VIABILITY }\end{array}$ \\
\hline Development & $\begin{array}{l}\text { Need still } \\
\text { exists }\end{array}$ & $\begin{array}{l}\text { Addresses } \\
\text { performance } \\
\text { requirements } \\
\text { Available when } \\
\text { needed }\end{array}$ & $\begin{array}{l}\text { Improved } \\
\text { solution (enabling or } \\
\text { significantly more } \\
\text { effective) } \\
\square \text { Favorable peer } \\
\text { review rating }\end{array}$ & $\begin{array}{l}\text { Improved } \\
\text { solution (enabling or } \\
\text { significantly less } \\
\text { costly) } \\
\square \text { Demonstration } \\
\text { and operating } \\
\text { costs estimated }\end{array}$ & $\begin{array}{l}\text { Improved } \\
\text { solution (enabling } \\
\text { or significantly lower } \\
\text { risk) } \\
\square \text { Favorable } \\
\text { peer review } \\
\text { rating }\end{array}$ & $\begin{array}{l}\square \text { Peer review finds } \\
\text { data valid for use } \\
\text { with regulators and } \\
\text { stakeholders }\end{array}$ & $\begin{array}{l}\text { N/A Potential } \\
\text { vendor identified }\end{array}$ \\
\hline
\end{tabular}

Indicates criterion is satisfied

$\square$ Indicates criterion/evidence is not yet satisfied

"N/A" Indicates criterion is not applicable or satisfied by other means; justification provided in evidence table

Date:

TFA Technology Delivery Manager: 


\section{Evidence Demonstrating Entrance Requirements are Met}

Title: 99048 Testing/Prediction of Long-term Glass Performance Stage:___Development

\section{Technical Need/Site Need ID(s):}

RL-WT015 Standard Method for Determining Waste Form Release Rate

RL-WT066 Compositional Dependence of the Long Term Performance of Glass as a Low-Activity Waste Form

End User Involvement:

$\checkmark$ User approved MYTR 99048

$\checkmark$ User cofunding per TFA IPL; document references below:

Letter TPP/99-STP-440 DOE-RL Robert M. Rosselli, Assistance Manager for Science and Technology to Richard T. French, Manager Office of River Protection "Fiscal Year (FY) 2000 Tanks Focus Area (TFA) Support to the Office of River Protection (ORP) dated October 5,1999

Technical Merit:

$\checkmark$ TFA conducted a technical peer review of the project including a panel of subject matter experts; results are documented in an SRTC report SRT-PCC-2000-00011

$\checkmark$ Project Test Plan WSRC-RP-99-00288 Hanford Immobilized Low-Activity Waste Product Acceptance Test Plan (U) Rv. 0

$\checkmark$ Project development strategy PNNL-11384 A Strategy to Conduct an Analysis of the Long-Term Performance of Low-Activity Waste Glass in a Shallow Subsurface Disposal System at Hanford

$\checkmark$ Applicable test standards defined in ASTM Standard C1285-97 Standard Test Methods for Determining Chemical Durability of Nuclear, Hazardous, and Mixed Waste Glasses: The Product Consistency Test (PCT)

$\checkmark$ PNNL GDL-VHT Rv. 1 Vapor-phase Hydration Test Procedure 1999

$\checkmark$ Product acceptance requirements defined in PNNL-13101 Hanford Immobilized LAW Product Acceptance: Initial Tanks Focus Area Testing Data Package 2000

$\checkmark$ Technical publication on test method "The Pressurized Unsaturated Flow (PUF) Test: A New Method for Engineered-Barrier Materials Evaluation" Ceramic Transactions vol. 72 pp 317-329 
Cost:

$\checkmark$ Cost is included in the development of the Hanford Immobilized Low-Activity Waste (ILAW) Performance Assessment (PA) being conducted by the Hanford site user

$\checkmark$ This task provides data to support the technical analyses for the ILAW PA; there are no specific cost requirements related to this work

\section{ES\&H Risk:}

$\checkmark$ ES\&H risk and requirements are evaluated as part of the Hanford ILAW PA

$\checkmark$ See references above which relate to test methods used to ensure ES\&H requirements are met

\section{Stakeholder, Regulatory, Tribal Issues:}

$\checkmark$ This area will be addressed as part of the ILAW PA and EIS process; site responsibility

\section{Commercial Viability:}

$\checkmark$ This project is providing technical data to support Hanford ILAW PA and EIS; there is no specific technology or commercial product involved. 


\section{Status Questions for Progress Reviews:}

\section{Title: 99048 Testing/Prediction of Long-term Glass Performance Stage:_Development}

1) Has the project been reviewed for advancement through a gate during the past year? No.

2) Has an end user made at least a conditional commitment to implement the technology? Hanford is using data in development of ILAW $P A$ and to support the EIS process.

3) Has a technical peer review been completed and is the work highly rated? A technical peer review was performed by a panel of subject matter experts selected by TFA (see report reference above). No ASME review has been performed.

4) Has a cost-benefit analysis been performed for this technology and does it show potential savings compared to the baseline? $N / A$ Cost being evaluated as part of site PA and EIS process and is not part of this scope. Are user requirements for cost data identified and satisfied? N/A

5) Will this technology meet or exceed current environmental, safety, health, $(\mathrm{ES} \& \mathrm{H})$ protection levels and/or reduce the risk to the public, workers, and the environment compared to the baseline? ILAWPA will determine this. Are user requirements for ES\&H and technological risk identified and satisfied? ILAW PA will determine this

6) Briefly discuss any activities and/or interactions with stakeholders, regulators, and tribal organizations relative to the continued research and utilization of this technology. Are user requirements for stakeholder, regulator, and tribal concerns identified and satisfied? This will be handled as part of the ILAW EIS process.

7) Have invention disclosure and intellectual property issues been addressed? $N / A$ Briefly discuss the measures taken to include private industry in development and application of the technology. N/A See above.

8) Has an appropriate vendor (or other provider) for this technology been identified? N/A See above. 
Appendix F

Other FY00 Reviews 


\section{Appendix F}

\section{Other FY00 Reviews}

\begin{tabular}{|l|l|c|c|}
\hline $\begin{array}{l}\text { FY00 } \\
\text { Technical } \\
\text { Response }\end{array}$ & Project & $\begin{array}{c}\text { ASME } \\
\text { Review }\end{array}$ & $\begin{array}{c}\text { Gate } \\
\text { Review }\end{array}$ \\
\hline 99019 & $\begin{array}{l}\text { Low-Activity Waste Forms/Newly Generated Liquid Waste } \\
\text { Cementation }\end{array}$ & $\mathrm{X}$ & \\
\hline 99043 & Corrosion Species Probe for Savannah River Site & & $\mathrm{X}$ \\
\hline $99052^{*}$ & Remote System for Pit Operations and Maintenance & $\mathrm{X}$ \\
\hline 99067 & Chemical Cleaning of Tanks & $\mathrm{X}$ \\
\hline 99067 & Heel Retrieval from Unobstructed Tanks (Tank 19) & $\mathrm{X}$ \\
\hline 99068 & Defense Waste Processing Facility Melter Improvements & $\mathrm{X}$ \\
\hline 99071 & Alternative Filtration Technology & $\mathrm{X}$ & $\mathrm{X}$ \\
\hline 99073 & Improve Waste Loading in High-Level Waste Glass & $\mathrm{X}$ & \\
\hline 99076 & Pipeline Unplugging Methods & & $\mathrm{X}$ \\
\hline 99085 & Demonstration of Grout Injection Technology for Tank Closure & & \\
\hline
\end{tabular}

* Not reviewed at Midyear 
Appendix G

Environmental Management Science Program Tasks 


\section{Appendix G}

\section{Environmental Management Science Program Tasks}

\begin{tabular}{|c|c|c|c|c|c|c|}
\hline . & $\begin{array}{c}\text { EMSP } \\
\text { Project \# }\end{array}$ & EMSP Project Title & PI & Affiliation & $\begin{array}{c}\text { 3-year EMSP } \\
\text { Budget }\end{array}$ & $\begin{array}{l}\text { Year of } \\
\text { Award }\end{array}$ \\
\hline$A R-W T-01-01$ & \multicolumn{6}{|c|}{ In-Situ Waste Analysis } \\
\hline & 65435 & $\begin{array}{l}\text { Millimeter-Wave Measurements of High-Level and Low- } \\
\text { Activity Glass Melts }\end{array}$ & Woskov & MIT & $\$ 1,429,400$ & 1998 \\
\hline \multirow[t]{3}{*}{$S-W T-04-01$} & \multicolumn{6}{|c|}{ Tank Corrosion } \\
\hline & 60219 & $\begin{array}{l}\text { Development of Advanced Electrochemical Emission } \\
\text { Spectroscopy for Monitoring Corrosion in Simulated DOE } \\
\text { Liquid Waste }\end{array}$ & Macdonald & $\begin{array}{l}\text { Penn State } \\
\text { University }\end{array}$ & $\$ 350,000$ & 1997 \\
\hline & 60401 & $\begin{array}{l}\text { Mechanism of Pitting Corrosion Prevention by Nitrite in } \\
\text { Carbon Steel Exposed to Dilute Salt Solutions }\end{array}$ & Zapp & SRTC & $\$ 650,000$ & 1997 \\
\hline \multirow[t]{4}{*}{$S-W T-05-01$} & \multicolumn{6}{|c|}{ Technetium Chemistry } \\
\hline & 59990 & $\begin{array}{l}\text { Fundamental Chemistry, Characterization, and Separation of } \\
\text { Technetium Complexes in Hanford Waste }\end{array}$ & Schroeder & LANL & $\$ 730,000$ & 1997 \\
\hline & 60017 & $\begin{array}{l}\text { Removal of Technetium, Carbon Tetrachloride, and Metals } \\
\text { from DOE Properties }\end{array}$ & Mallouk & $\begin{array}{l}\text { Penn State } \\
\text { University }\end{array}$ & $\$ 390,000$ & 1997 \\
\hline & 60296 & $\begin{array}{l}\text { Research Program to Investigate the Fundamental Chemistry of } \\
\text { Technetium }\end{array}$ & Edelstein & LBLL & $\$ 900,000$ & 1997 \\
\hline \multirow[t]{2}{*}{$S-W T-06-01$} & \multicolumn{6}{|c|}{ Improved Waste Loading in HLW Glasses } \\
\hline & 59827 & $\begin{array}{l}\text { The Influence of Radiation and Multivalent Cation Additions } \\
\text { on Phase Separation and Crystallization of Glass }\end{array}$ & Weinberg & $\begin{array}{l}\text { University of } \\
\text { Arizona }\end{array}$ & $\$ 723,000$ & 1997 \\
\hline
\end{tabular}




\begin{tabular}{|c|c|c|c|c|c|c|}
\hline & $\begin{array}{c}\text { EMSP } \\
\text { Project \# }\end{array}$ & EMSP Project Title & PI & Affiliation & $\begin{array}{l}\text { 3-year EMSP } \\
\text { Budget }\end{array}$ & $\begin{array}{l}\text { Year of } \\
\text { Award }\end{array}$ \\
\hline \multirow[t]{4}{*}{$S-W T-07-01$} & \multicolumn{6}{|c|}{ Long-Term Waste Glass Performance } \\
\hline & 54982 & $\begin{array}{l}\text { Analysis of Surface Leaching Processes in-Vitrified High- } \\
\text { Level Nuclear Waste Using In-Situ Raman Imaging and } \\
\text { Atomistic Modeling }\end{array}$ & Simmons & $\begin{array}{l}\text { University of } \\
\text { Florida }\end{array}$ & $\$ 559,000$ & 1996 \\
\hline & 60020 & Stability of High-Level Waste Forms & Besmann & ORNL & $\$ 762,000$ & 1997 \\
\hline & 60362 & Ion-Exchange Processes and Mechanisms in Glasses & McGrail & PNNL & $\$ 901,000$ & 1997 \\
\hline \multirow[t]{7}{*}{$S-W T-08-0 I$} & \multicolumn{6}{|c|}{ Waste and Radionuclide Chemistry } \\
\hline & 54621 & $\begin{array}{l}\text { Chemical Speciation of Strontium, Americium, and Curium in } \\
\text { High-Level: Predictive Modeling of Phase Partitioning During } \\
\text { Tank Processing }\end{array}$ & Felmy & PNNL & $\$ 1,050,778$ & 1996 \\
\hline & 54646 & Interfacial Radiolysis Effects in Tank Waste Speciation & Orlando & PNNL & $\$ 871,389$ & 1996 \\
\hline & 55229 & The NOx System in Nuclear Waste & Meisel & ANL & $\$ 1,200,833$ & 1996 \\
\hline & 65368 & $\begin{array}{l}\text { Speciation, Dissolution, and Redox Reactions of Chromium } \\
\text { Relevant to Pretreatment and Separation of High-Level Tank } \\
\text { Wastes }\end{array}$ & Rai & PNNL & $\$ 899,375$ & 1998 \\
\hline & 65398 & $\begin{array}{l}\text { Characterization of Actinides in Simulated Alkaline Tank } \\
\text { Waste Sludges and Leach Solutions }\end{array}$ & Nash & ANL & $\$ 930,000$ & 1998 \\
\hline & 65408 & $\begin{array}{l}\text { Mechanisms and Kinetics of Organic Aging in High-Level } \\
\text { Nuclear Wastes }\end{array}$ & Camaioni & PNNL & $\$ 900,000$ & 1998 \\
\hline \multirow[t]{4}{*}{$A R-W T-08-0 I$} & \multicolumn{6}{|c|}{ Waste Chemistry and Physical Properties for Processing } \\
\hline & 55179 & Acoustic Probe for Solid-Gas Suspensions & Tavlarides & $\begin{array}{l}\text { Syracuse } \\
\text { University }\end{array}$ & $\$ 750,841$ & 1996 \\
\hline & 54890 & $\begin{array}{l}\text { On-Line Slurry Viscosity and Concentration Measurements as } \\
\text { a Real-time Waste Stream Characterization Tool }\end{array}$ & Powell & $\begin{array}{l}\text { University of } \\
\text { California at } \\
\text { Davis }\end{array}$ & $\$ 691,154$ & 1996 \\
\hline & 54628 & $\begin{array}{l}\text { Colloidal Agglomerates in Tank Sludge: Impact on Waste } \\
\text { Processing }\end{array}$ & Tingey & PNNL & $\$ 1,788,000$ & 1996 \\
\hline
\end{tabular}




\begin{tabular}{|c|c|c|c|c|c|c|}
\hline & $\begin{array}{c}\text { EMSP } \\
\text { Project \# }\end{array}$ & EMSP Project Title & PI & Affiliation & $\begin{array}{c}\text { 3-year EMSP } \\
\text { Budget }\end{array}$ & $\begin{array}{l}\text { Year of } \\
\text { Award }\end{array}$ \\
\hline & 54773 & $\begin{array}{l}\text { Microstructural Properties of High-Level Waste Concentrates } \\
\text { and Gels with Raman and Infrared Spectroscopies }\end{array}$ & Agnew & LANL & $\$ 465,000$ & 1996 \\
\hline & 59982 & $\begin{array}{l}\text { Reactivity of Peroxynitrite: Implications for Hanford Waste } \\
\text { Management and Remediation }\end{array}$ & Lymar & $\mathrm{BNL}$ & $\$ 699,999$ & 1997 \\
\hline & 59993 & $\begin{array}{l}\text { Dynamic Effects of Tank Waste Aging on Radionuclide- } \\
\text { Complexant Interactions }\end{array}$ & Chamberlin & LANL & $\$ 549,000$ & 1997 \\
\hline & 60143 & $\begin{array}{l}\text { Foaming in Radioactive Waste Treatment and Immobilization } \\
\text { Processes }\end{array}$ & Wasan & $\begin{array}{c}\text { Illinois } \\
\text { Institute of } \\
\text { Technology }\end{array}$ & 360,360 & 1997 \\
\hline & 60403 & Phase Chemistry of Tank Sludge Residual Components & Krumhansl & SNL & $\$ 1,157,000$ & 1997 \\
\hline \multirow[t]{5}{*}{$A R-W T-09-01$} & \multicolumn{6}{|c|}{ Radionuclide Separations } \\
\hline & 54735 & $\begin{array}{l}\text { Development of Inorganic Ion Exchangers for Nuclear Waste } \\
\text { Remediation }\end{array}$ & Clearfield & $\begin{array}{c}\text { Texas A\&M } \\
\text { University }\end{array}$ & $\$ 599,999$ & 1996 \\
\hline & 54791 & $\begin{array}{l}\text { Managing Tight-Binding Receptors for New Separations } \\
\text { Technologies }\end{array}$ & Busch & $\begin{array}{l}\text { University of } \\
\text { Kansas }\end{array}$ & $\$ 350,000$ & 1996 \\
\hline & 55087 & $\begin{array}{l}\text { Design and Systhesis of the Next Generation of Crown Ethers } \\
\text { for Waste Separations: An Inter-Laboratory Comprehensive } \\
\text { Proposal }\end{array}$ & Moyer & ORNL & $\$ 1,920,000$ & 1996 \\
\hline & 60345 & $\begin{array}{l}\text { New Silicotitanate Waste Forms: Development and } \\
\text { Characterization }\end{array}$ & Balmer & PNNL & $\$ 1,200,000$ & 1997 \\
\hline \multirow[t]{3}{*}{$A R-W T-11-01$} & \multicolumn{6}{|c|}{ Chemical Analysis Methods Validation } \\
\hline & 55205 & $\begin{array}{l}\text { A Fundamental Study of Laser-Induced Breakdown } \\
\text { Spectroscopy Using Fiber Optics for Remote Measurements of } \\
\text { Trace Metals }\end{array}$ & Goode & $\begin{array}{l}\text { University of } \\
\text { South } \\
\text { Carolina }\end{array}$ & $\$ 630,000$ & 1996 \\
\hline & 55318 & $\begin{array}{l}\text { Improved Analytical Characterization of Solid Waste Forms by } \\
\text { Fundamental Development of Laser Ablation Technology }\end{array}$ & Russo & LBLL & $\$ 1,229,167$ & 1996 \\
\hline
\end{tabular}




\begin{tabular}{|c|c|c|c|c|c|c|}
\hline & $\begin{array}{c}\text { EMSP } \\
\text { Project \# }\end{array}$ & EMSP Project Title & PI & Affiliation & $\begin{array}{c}\text { 3-year EMSP } \\
\text { Budget }\end{array}$ & $\begin{array}{l}\text { Year of } \\
\text { Award }\end{array}$ \\
\hline & 60075 & $\begin{array}{l}\text { Particle Generation by Laser Ablation in Support of Chemical } \\
\text { Anallysis of High-Level Mixed Waste from Plutonium } \\
\text { Production Operations }\end{array}$ & Dickinson & $\begin{array}{l}\text { Washington } \\
\text { State } \\
\text { University }\end{array}$ & $\$ 544,500$ & 1997 \\
\hline & 65425 & $\begin{array}{l}\text { Mass Spectometric Fingerprinting of Tank Waste Using } \\
\text { Tunable Ultrafast Infrared Lasers }\end{array}$ & Haglund & $\begin{array}{l}\text { Vanderbilt } \\
\text { University }\end{array}$ & $\$ 760,000$ & 1998 \\
\hline$A R-W T-12-01$ & \multicolumn{6}{|c|}{ Vadose Zone Characterization } \\
\hline & 55332 & $\begin{array}{l}\text { A Hybrid Hydrologic-Geophysical Inverse Technique for the } \\
\text { Assessment and Monitoring of Leachates in the Vadose Zone }\end{array}$ & Alumbaugh & SNL & $\$ 2,024,074$ & 1996 \\
\hline$S-W T-12-01$ & \multicolumn{6}{|c|}{ Moisture and Contaminant Transport } \\
\hline & 65410 & $\begin{array}{l}\text { Rapid Migration of Radionuclides Leaked from High-Level } \\
\text { Waste Tanks: A Study of Salinity Gradients, Wetted Path } \\
\text { Geometry and Water Vapor Transport }\end{array}$ & Ward & PNNL & $\$ 905,000$ & 1998 \\
\hline
\end{tabular}




\section{Distribution}

No. of

Copies

\section{OFFSITE}

2 Office of Scientific and

Technical Information

Akgunduz, Nina

U.S. Department of Energy

Fernald Environmental Management Project

7400 Willey Rd.

Cincinnati, $\mathrm{OH} 45030$

G. J. Bastiaans

Ames Laboratory, Iowa State University

125 Spedding Hall

Ames, IA 50011-3020

M. Baker

Los Alamos National Laboratory

Environmental Science and Waste

Technology Division PO Box 1663,

MS: J591

Las Alamos, NM 87545

J. Bell

Bell Consultants, Inc.

137 Bowsprit Lane

Kingston, TN 37763

R. Bromm

Fluor Fernald

P.O. Box 538704, MSTP: 52-4

Cincinnati, OH 45253-8704

B. L. Burks

The Providence Group, Inc.

P.O. Box 23408

Knoxville, TN 37933-1408

L. D. Bustard

Sandia National Laboratories

P.O. Box 5800, MS: 0734

Albuquerque, NM 87185-5800
No. of

Copies

J. Carberry

DuPont

Experimental Station

Building 249/119

P.O. Box 80249

Wilmington, DE 19880-0249

G. A. Choppin

Chemistry Department

Florida State University

$600 \mathrm{~W}$. College Ave

Tallahassee, FL 32306-3006

F. Damerow

West Valley Nuclear Services

10282 Rock Springs Rd.

West Valley, NY 14171-9799

J. Drake

U.S. Department of Energy

10282 Rock Springs Rd.

West Valley, NY 14171

P. G. Eller

Los Alamos National Laboratory

NMT-6 Advanced Technology Group

MS: E5-10

Nuclear Material Technology Division

Los Alamos, NM 87544

R: C. Erdmann

P.O. Box 922

Grass Valley, CA 95945

J. A. Gentilucci

JAG Technical Services, Inc.

127 Savannah Drive

Aiken, SC 29803

Distr.1 
No. of

Copies

12 K. D. Gerdes

U.S. Department of Energy

Office of Science and Technology

19901 Germantown Rd.

1154 Cloverleaf Bldg.

Germantown, MD 20874-1290

J. Ginanni

U.S. Department of Energy

Nevada Operations Office

232 Energy Way

Las Vegas, NV 89030

T. S. Gutmann

U.S. Department of Energy

Savannah River Operations Office

P.O. Box A

Aiken, SC 29802

\section{J. Harness}

U.S. Department of Energy

P.O. Box 2001, MS EM-93

Oak Ridge, TN 37831-8620

W. Haslebacher

U.S. Department of Energy

National Energy Technology

Laboratory (NETL)

3610 Collins Ferry Rd.

Morgantown, WV 26507-0880

E. W. Holtzscheiter

Westinghouse Savannah River

Company

Savannah River Technology Center

Aiken, SC 29802

J. Jones

U.S. Department of Energy

Nevada Operations Office

232 Energy Way

North Las Vegas, NV 89030-4199
No. of

Copies

D. S. Kaback

Concurrent Technologies Corp.

99918 th St, Ste 1615

Denver, CO 80202

B. R. Kowalski

5720 CR 116

Hesperus, CO 81326

B. Lewis

Westinghouse Savannah River Company

Building 703-8C, Room 7

P.O. Box 616

Aiken, SC 29802

K. Lockie

U.S. Department of Energy

Idaho Operations Office

750 DOE Place

Idaho Falls, ID 83402

C. P. McGinnis

Oak Ridge National Laboratory

P.O. Box 2008

Oak Ridge, TN 37821-6273

C. S. Mims

U.S. Department of Energy

Oak Ridge Operations Office

P.O. Box 2001

Oak Ridge, TN $37830-8620$

J. P. Morin

Westinghouse Savannah River Company

P.O. Box 616

Aiken, SC 29802

J. R. Noble-Dial

U.S. Department of Energy

Oak Ridge Operations Office

P.O. Box 2001

Oak Ridge, TN 37830-8620 
No. of

Copies

K. G. Picha

U.S. Department of Energy EM-32

Office of Eastern Operations

19901 Germantown Road

343/TREV

Germantown, MD 20874-1290

S. Pickering

Sandia National Laboratories

PO Box 5800, MSIN: 0771

Albuquerque, NM 87185-0771

R.K. Quinn

Battelle Albuquerque Office

801 University Blvd., SE Suite 102

Albuquerque, NM 87106

S. M. Robinson

Oak Ridge National Laboratory

P.O. Box 2088, MS: 6044

Oak Ridge, TN 37831-6044

W. W. Schulz

W2S Company, Inc.

12704 Sandia Ridge Place NE

Albuquerque, NM 87111

J. L. Swanson

1318 Cottonwood

Richland, WA 99352

L. L. Talvarides

Syracuse University

334 Hinds Hall

Syracuse, NY 13244

T. R. Thomas

Lockheed Martin Idaho Technologies

Company

P.O. Box 1625 MSIN 3458

Idaho Falls, ID 83415-3423

M. C. Thompson

Westinghouse Savannah River Company

Building 773-A, C140

P.O. Box 616

Aiken, SC 29802
No. of

Copies

J. Unterzuber

SAIC

555 Quince Orchard Rd., Suite 500

Gaithersburg; MD 20878

P. Valenti

West Valley Nuclear Services

MS-53

10282 Rock Springs Rd.

West Valley, NY 14171

J. H. Valentine

Lockheed Martin Idaho

Technologies Company

P.O. Box 1625

Idaho Falls, ID 83415-3100

G. Vandegrift

Argonne National Laboratory

Building 205

9700 South Cass Avenue

Argonne, IL 60439

J. S. Watson

Oak Ridge National Laboratory

P.O. Box 2008, MS: 6178

Oak Ridge, TN 37831-6178

T. E. Weber

6622. West Victoria

Kennewick, WA 99336

T. D. Welch

Oak Ridge National Laboratory

P.O. Box 2008, MS: 6273

Oak Ridge, TN 37831-6273

F. Woolley

1 Walker Court, Apt. \#1

Cambridge, MA 02138 
No. of

Copies

ONSITE

6 DOE-RL

R. F. Brich

M. J. Glasper

L. S. Mamiya

B. M. Mauss

E. J. Cruz

T. P. Pietrok
No. of

Copies

28 Pacific Northwest National Laboratory

R. W. Allen

K9-69

T. M. Brouns

K9-08

J. L. Buelt

P7-41

B. A. Carteret

K9-91

K8-50

K8-50

S. H. Chin

K1-39

L.R. Roeder-Smith

J. H. Westsik

K8-50

Los Alamos National Laboratory

M. T. Terry

K9-91

CH2M Hill (CHG) Hanford Group, Inc.
J. O. Honeyman
G3-21

Numatec Hanford Corporation

P. W. Gibbons

H5-61

Waste Policy Institute

E. Dysland

H0-50

S. S. Briggs

H0-50 